\title{
Models and solution approaches for integrated student to school assignment and school bus routing problem focusing on special needs students
}

\author{
Azadeh Ansari \\ West Virginia University, aansari@mix.wvu.edu
}

Follow this and additional works at: https://researchrepository.wvu.edu/etd

Part of the Business Administration, Management, and Operations Commons, Industrial Engineering Commons, Operational Research Commons, and the Operations and Supply Chain Management

\section{Commons}

\section{Recommended Citation}

Ansari, Azadeh, "Models and solution approaches for integrated student to school assignment and school bus routing problem focusing on special needs students" (2021). Graduate Theses, Dissertations, and Problem Reports. 8235.

https://researchrepository.wvu.edu/etd/8235

This Dissertation is protected by copyright and/or related rights. It has been brought to you by the The Research Repository @ WVU with permission from the rights-holder(s). You are free to use this Dissertation in any way that is permitted by the copyright and related rights legislation that applies to your use. For other uses you must obtain permission from the rights-holder(s) directly, unless additional rights are indicated by a Creative Commons license in the record and/ or on the work itself. This Dissertation has been accepted for inclusion in WVU Graduate Theses, Dissertations, and Problem Reports collection by an authorized administrator of The Research Repository @ WVU.

For more information, please contact researchrepository@mail.wvu.edu. 
Models and solution approaches for integrated student to school assignment and school bus routing problem focusing on special needs students

\title{
Azadeh Ansari
}

Dissertation submitted to the Benjamin M. Statler College of Engineering and Mineral Resources at West Virginia University

\author{
in partial fulfillment of the requirements for the degree of \\ Doctor of Philosophy in \\ Industrial Engineering
}

Leily Farrokhvar, Ph.D., Chair

Kenneth Currie, Ph.D.

Behrooz Kamali, Ph.D.

Majid Jaridi, Ph.D.

Dimitra Pyrialakou, Ph.D.

Department of Industrial and Management Systems Engineering

Morgantown, West Virginia

2021

Keyword: Special Needs Students, Optimization, Routing, Assignment, Heuristic Copyright 2021 Azadeh Ansari 


\begin{abstract}
Models and solution approaches for integrated student to school assignment and school bus routing problem focusing on special needs students
\end{abstract}

\begin{abstract}
Azadeh Ansari
This dissertation addresses the integrated problem of assigning students to schools and generating school bus routes particularly focusing on the special needs students is addressed. Special needs students generally require supplementary accommodations and must be picked up from and dropped off at their home addresses. This will increase the number of nodes in the network and therefore introduces additional complexities to the problems of assignment and routing for students. An integrated single objective mathematical model is first developed that simultaneously assigns the students to schools based on their needs and generates efficient bus routes to deliver the students to their designated schools, while incorporating multi-loads and heterogeneous bus fleet features as well. This problem is known to be NP-hard, meaning that it is most likely not solvable using exact methods especially when the size of the network increases.

A two-phase heuristic solution approach that can generate high quality solutions is proposed based on the capacitated clustering problem. Several random instances are generated to evaluate the performance of the model and the proposed solution approach. A real-world case study from Fort Smith Public School in Arkansas is also used to evaluate and compare the performance of the integrated model and the proposed solution approach with the literature. The case study results determine that the proposed heuristic approach improves the quality of the solution (total miles driven) by $35 \%$ on average when compared with the previously developed heuristic solution approaches in the literature. Additionally, goal programming is adopted to convert the integrated model to a multi-objective assignment and routing model in which the number of buses and maximum ride distance are minimized along with the total travel distance. The goal programming model improves the ride distances by $21 \%$ on average when compared with the post process analysis on ride distances using the optimum solution from the single objective model.
\end{abstract}


To my dad, whom I promised to dedicate this dissertation before he left this world. 


\section{Acknowledgments}

I would like to thank my advisor, Dr. Leily Farrokhvar, for giving me the opportunity to work with her, and for her endless support throughout my study. It is my great honor to work under her guidance. I am also thankful to Dr. Currie, Dr. Jaridi, Dr. Kamali, and Dr. Pyrialakou for agreeing to serve on my committee. Thank you for being more than generous with your expertise and precious time. 


\section{Table of Contents}

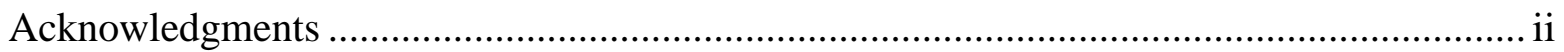

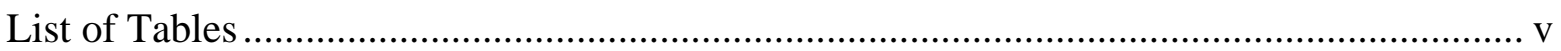

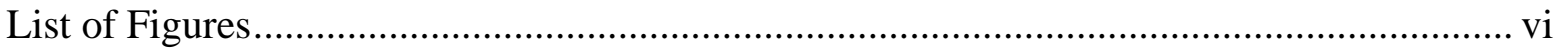

Chapter 1: Introduction and Problem Description ....................................................................... 1

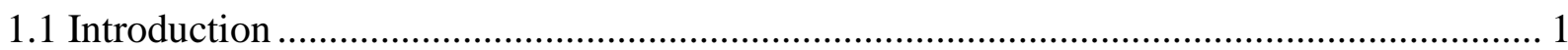

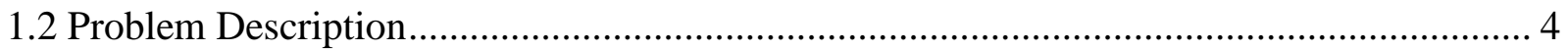

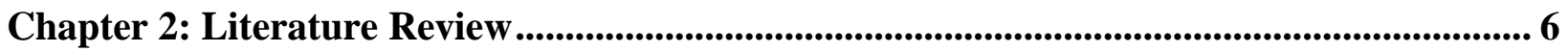

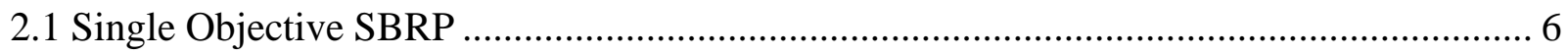

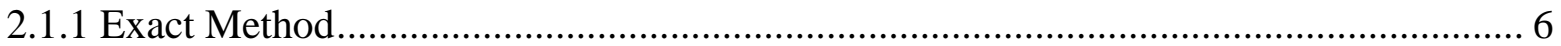

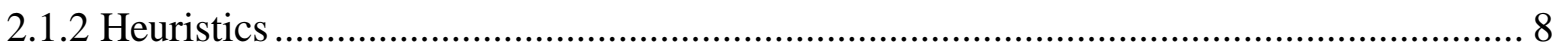

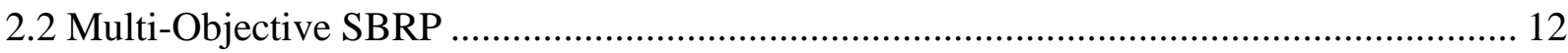

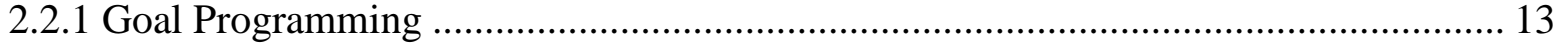

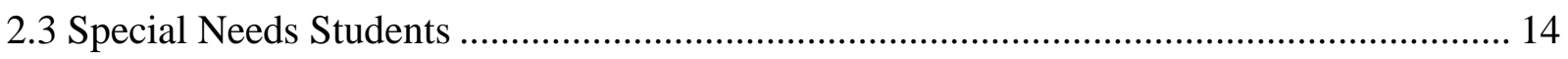

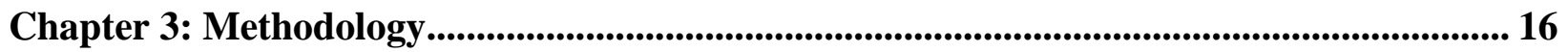

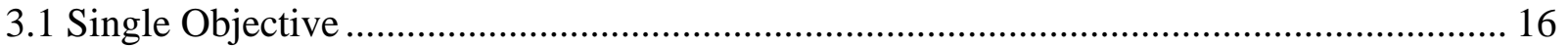

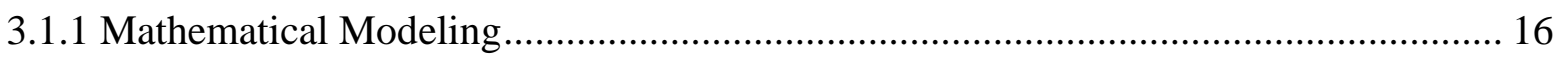

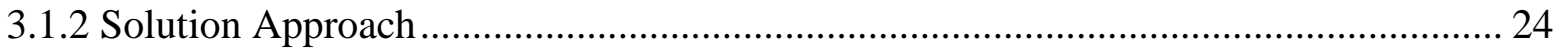

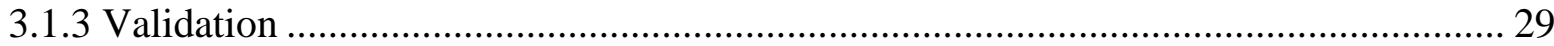

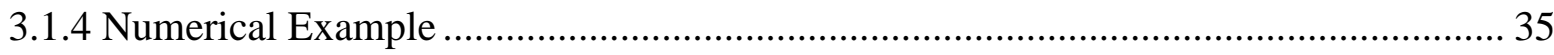

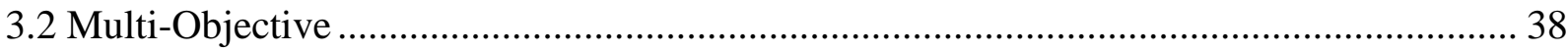

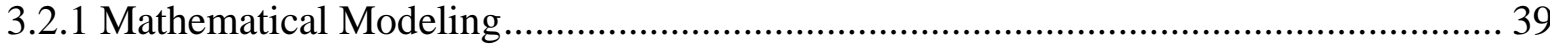

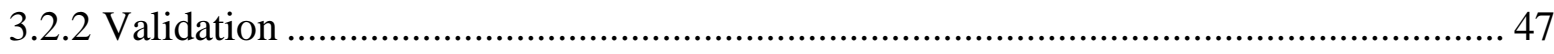

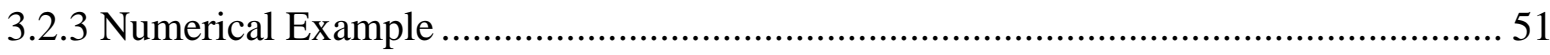

Chapter 4: Case Study ............................................................................................................................. 56

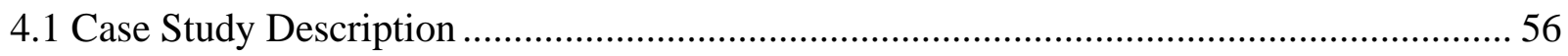

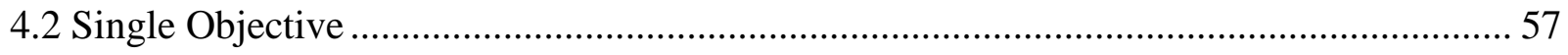

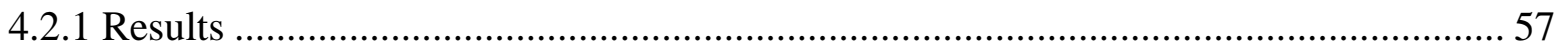

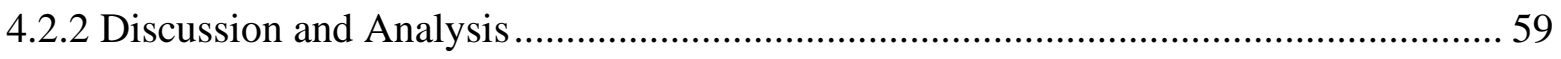

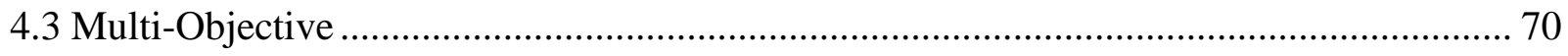


Chapter 5: Potential Applications ........................................................................................................ 72

5.1 Model II with ride time component ……………….................................................... 72

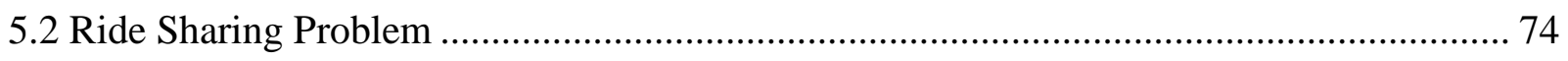

5.2.1 Ride Sharing Problem with Time Window ………………………………............ 81

5.2.2 Flexible Public Transportation Services...................................................................... 83

Chapter 6: Conclusion and Future Work............................................................................................ 85

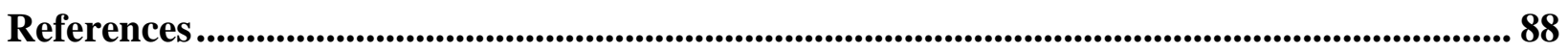

Appendix A: Detailed Result............................................................................................................... 94 


\section{List of Tables}

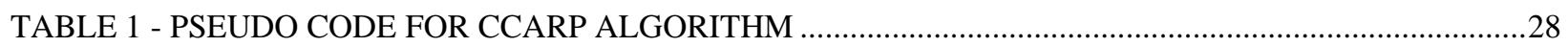

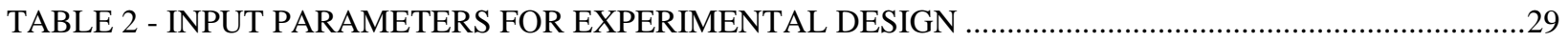

TABLE 3 - COMPARISON OF RESULTS OBTAINED BY GUROBI FROM MODEL II AND THE MODEL

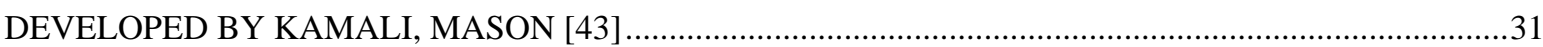

TABLE 4 - DETAILED RESULTS OF MODEL II AND ROUTING DEVELOPED BY KAMALI, MASON [43] BY GUROBI

TABLE 5 - COMPARISON OF PERFORMANCE RATIOS OBTAINED BY CCARP VS. IH2 DEVELOPED BY

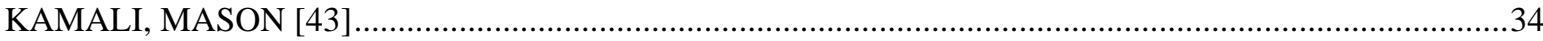

TABLE 6 - CAPACITY OF SCHOOLS PER CLASS TYPE USED FOR THE NUMERICAL EXAMPLE (ajm) 35

TABLE 7 - CLASS TYPE (SERVICE) NEEDED BY THE STUDENTS USED FOR THE NUMERICAL EXAMPLE ( $\mathrm{gim})$.

TABLE 8 - OPTIMUM ASSIGNMENT OF STUDENTS GENERATED BY GUROBI 9.1.0 FOR THE NUMERICAL EXAMPLE

TABLE 9 - ASSIGNMENT OF STUDENTS GENERATED BY THE CCARP ALGORITHM FOR THE NUMERICAL EXAMPLE 38

TABLE 10 - GOAL PROGRAMMING MODEL VALIDATION USING RANDOMLY GENERATED INSTANCES

TABLE 11 - MAXIMUM RIDE DISTANCE SAVINGS WHEN COMPARING MULTI-OBJECTIVE AND SINGLE OBJECTIVE MODELS

TABLE 12 - ASSIGNMENTS OBTAINED FROM MODEL II AND MODEL IV FOR THE NUMERICAL EXAMPLE

TABLE 13 - COMPARISON OF THE RESULTS AND PERFORMANCES OF CCARP AND IH2 DEVELOPED BY KAMALI, MASON [43]

TABLE 14 - RESULT OF THREE HEURISTIC APPROACHES ON FPSP CASE STUDY . .60

TABLE 15 - PSEUDO CODE FOR CCARP II ALGORITHM......................................................................

TABLE 16 - PSEUDO CODE FOR CCARP III ALGORITHM …….....................................................................62

TABLE 17 - RESULT OF THREE HEURISTIC APPROACHES ON FPSP CASE STUDY ..................................63

TABLE 18 - RESULTS OF INTER-CLUSTER STUDENT EXCHANGES ……..................................................65

TABLE 19 - ANALYSIS AND RESULT COMPARISON BETWEEN MODEL II AND MODEL IV ....................70

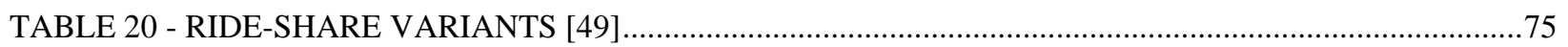

TABLE 21 - COMPARISON OF SSA-SBRP-SNS WITH RIDE-SHARING PROBLEM........................................76

TABLE 22 - DETAILED RESULT OF RANDOMLY GENERATED INSTANCES .................................................95 


\section{List of Figures}

FIGURE 1 - OPTIMUM ROUTES GENERATED FROM MODEL II SOLVED BY GUROBI 9.1.0 FOR NUMERICAL EXAMPLE 36

FIGURE 2 - ROUTES GENERATED BY CCARP ALGORITHM FOR THE NUMERICAL EXAMPLE .37

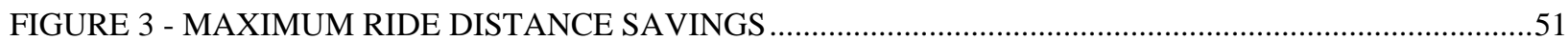

FIGURE 4 - RIDE DISTANCES CALCULATED FOR THE OPTIMUM SOLUTION OBTAINED FROM

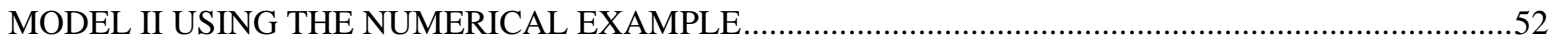

FIGURE 5 - SOLUTION OBTAINED FROM GOAL PROGRAMMING MODEL IN THE 1-HOUR TIME LIMIT USING THE NUMERICAL EXAMPLE

FIGURE 6 - GAPS BETWEEN RESULTS OBTAINED USING HEURISTIC APPROACHES AND OPTIMAL

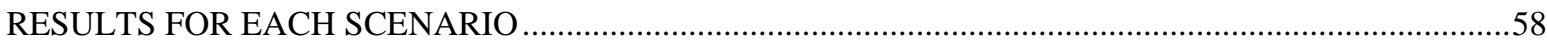

FIGURE 7 - MODEL II SENSITIVITY TO THE NUMBER OF BUSES ………............................................66

FIGURE 8 - CCARP ALGORITHM SENSITIVITY TO SELECTION OF CENTROIDS FOR JUNIOR HIGH SCHOOL CASE .....

FIGURE 9 - CCARP ALGORITHM SENSITIVITY TO SELECTION OF CENTROIDS FOR SENIOR HIGH SCHOOL CASE . .68

FIGURE 10 - CCARP ALGORITHM SENSITIVITY TO SELECTION OF CENTROIDS FOR ELEMENTARY SCHOOL CASE 


\section{Chapter 1: Introduction and Problem Description}

\subsection{Introduction}

It has always been a challenge for school district officials to develop an efficient transportation plan to transfer students between their homes and schools. Efficient transportation policies can improve operational efficiency for both school districts and students. Efficient processes of bus route generation and assignment of students to schools determine the efficiency of transportation. Thus, efficient assignments and route generation can significantly decrease the operational costs and increase the service quality provided to students. In many school districts around the world, the students' home addresses determine their school assignments, and a manual process generates the routes to deliver them to their pre-determined schools. However, this manual route generation process may lead to incompetent transportation policies. Consideration of the assignment and route generation processes apart from each other causes additional inefficiencies and interrupts the integrated process.

There are additional complexities when the students are special needs or special education. The term special needs refers to the special education needs which are mainly used for students with disabilities that result in delayed or altered learning processes when compared to other students. McPherson, Arango [1] define special needs or medically fragile students as "children with special health care needs who have or are at increased risk for a chronic physical, developmental, behavioral, or emotional condition and who also require health and related services of a type or amount beyond that required by children generally." These special needs students typically require special buses, special classrooms, and home pickup and delivery. The 
schools that provide services to these students use a low student to teacher ratio indicating the maximum number of students in the class with one teacher and must provide special bus services. These challenges have to be incorporated into the School Bus Routing Problem (SBRP) when focusing on special needs students, as they may have different needs that must be met both on school buses and at schools. As an example, a student that is visually impaired may need a different service type at school and while on the bus compared to a physically disabled student. The traditional SBRP assumes that the students are already assigned to schools. Therefore, it uses pre-determined assignments to generate efficient routes. The only assignment that might be accomplished in the traditional SBRP is assigning the students to pre-specified bus stops so the buses can pick up all the students in groups from each bus stop. Students are normally assigned to schools by the school district based on their home addresses. In this work, we develop an integrated model that not only assigns the students to schools based on their needs but also generates efficient routes to deliver them to their schools. These schools have limited capacities at each service level which must be taken into consideration when assigning special needs students with different levels of needs. The other challenge in this problem as mentioned before is the home pickup and delivery, which makes the number of nodes more than the traditional SBRP.

Mathematical programming has been used to address the problem of assigning students to schools and bus routing separately. The student to school assignment problem is a form of the generalized assignment problem and the school bus routing problem is a variation of Vehicle Routing Problem (VRP) that belongs to the class of NP-hard problems meaning that they cannot be solved using traditional methods or solvers as the size of the problem increases. 
Mixed Integer Programing (MIP) has been used in the literature to formulate SBRP due to the nature of the problem having assignment variable as well as the variables showing the order of the visited nodes. The outcome of the SBRP is typically an efficient route that gives the school administrators and officials insights on how to best serve the students while controlling the costs. The NP-Hardness of this problem is due to the fact that the complexity increases exponentially as the network size enlarges. This makes it impossible to solve a practical size of this problem to optimality using traditional methods. All the mentioned reasons above highlight the importance of developing a heuristic solution approach that is capable of providing good quality solutions quickly.

An integrated mathematical model is proposed in this dissertation that assigns the special needs student to schools based on their needs and school capacities and generates efficient routes to deliver them to their designated schools while minimizing the total travel distance. Additionally, a clustering based heuristic solution approach is proposed called Capacitated Clustering for Assignment and Routing Problem (CCARP) that is also adopted to solve the randomly generated instances as well as the real-world case study in Fort Smith school district in Arkansas which is proven to generate high quality solutions in a reasonable amount of time.

The main contributions of this study are:

1. An integrated model that addresses an assignment and mixed load SBRP while considering additional requirements for special needs students;

2. A novel heuristic approach that is capable of solving practical sized instances in a reasonable amount of time; 
3. detailed analyses of the results obtained using the proposed approach, and comparisons with a leading approach in the literature;

4. demonstration of the proposed approach using a case study in Fort Smith, Arkansas, which results in savings of over $40 \%$.

\subsection{Problem Description}

The assignment problem analyzes the problem of assigning students to schools in groups such that the total travel distance is minimized. The routing problem mainly aims to manage the school bus fleet such that the students are delivered to schools efficiently. In this work, we formulate an integrated mathematical model addressing student to school assignment and the school bus routing problem for special needs students (SSA-SBRP-SNS). The purpose of the model is to generate an efficient assignment of special needs students to schools based on their needs, while generating efficient routes for a heterogeneous fleet of school buses to pick up the students from their homes and drop them off at their assigned schools. Efficient routes usually lead to shorter ride times for students and lower transportation costs.

The buses are assumed to depart from a single depot, pick up the assigned students, drop them off at their designated schools, and end their trip by returning to the depot. In this context, the entire tour from the depot back to the depot is referred to as a single trip. It is also assumed that each bus visits a school at most once (i.e., all students assigned to a school should be picked up before the bus visits that school). Not all the schools are necessarily visited, as there might be enough resources available in the remaining schools to accommodate all the special needs students. The fleet of buses is assumed to be heterogeneous and the buses can have different capacities and service levels. The number of buses and their capacities are known, and are 
considered input parameters in the model. The model assures that the capacities of the buses are not violated at any time. Also, schools have limited capacities for each service type that should not be violated. Each student must be assigned to only one school and one bus based on his/her needs and available capacities. The objective of the model is to minimize the total distance that all buses travel while delivering the students to their designated schools. We validate the model using small instances and propose a heuristic approach to solve practical sized problems within a reasonable amount of time.

The literature review is presented in the next chapter using the different components of the proposed model. In Chapter 3:, the variations of our proposed models are discussed and formulated along with the steps to linearize them. A heuristic solution approach is developed and proposed in this chapter as well. Subsequently in Chapter 4:, the model and solution approach are both validated using an experimental design and once validated, is applied to a real-world case study. A sensitivity analysis is conducted in this chapter to investigate how different parameters can impact the final result and findings. Next, other applications of the proposed model is discussed along with their similarities and differences in Chapter 5:. Finally, the conclusion and directions for future study is presented in Chapter 6:. 


\section{Chapter 2: Literature Review}

Park and Kim [2] review all the articles published on SBRP with different constraints including time window, capacity, and student travel time limit. Bus stop selection, bus route generation, school bell time adjustment, and route scheduling were four main groups they used to categorize the published works in this area. They present all assumptions, constraints, and solution techniques published in 2010 or before. A few years later, Ellegood, Solomon [3] provide a more comprehensive survey on all the research studies that addressed SBRP before 2020.

\subsection{Single Objective SBRP}

\subsubsection{Exact Method}

The traditional SBRP, first developed by Newton and Thomas [4], selects bus stops that students must be picked up at and schedules the order of the bus stops in the bus routes to deliver the students to a single school. This problem can be solved to optimality using the exact solution approaches or commercial solvers when the network size is reasonably small. Kumar, Jain [5] propose a Branch and Bound routing algorithm to solve SBRP that optimizes the number of buses, routes, and transportation costs for small instances. As they increase the size of the problem, computational time increases while the solutions are not even feasible. Bektas and Elmastas [6] use an exact solution technique to solve a SBRP for the students of an elementary school in Ankara, Turkey. They group the students based on their home addresses and generate 29 sub-regions with the pickup points at the centers. They use commercial solver CPLEX to solve their model leading to a travel plan that can save up to $28.6 \%$ in the total travel distance when compared to the existing strategy. 
Fugenschuh [7] uses branch and cut algorithm to solve a SBRP. He concludes that 10-25\% of the buses are redundant when utilizing the existing strategy. Therefore, he recommends a new strategy of starting the schools at different times that would lead to significant savings in the total costs if implemented. Column Generation (CG) is another exact method that a few researchers (Kinable, Spieksma [8], and Riera-Ledesma and Salazar-Gonzalez [9]) have adopted when solving their proposed SBRP model. Riera-Ledesma and Salazar-Gonzalez [9] present Multiple Vehicle Purchaser Problem with Resource Constraint (MV-TPP-RC) in five different formulations. This problem is a version of SBRP obtaining the best bus stop selections and routes by minimizing the total routing and assignment costs. Their proposed model takes into consideration the maximum allowable distance traveled by students on the bus and maximum number of bus stops on each route and a minimum allowable limit for the number of students picked up by each bus. They use column generation algorithm, Dantzig-Wolfe decomposition method and Branch-and-Cut-and-Price (BCP) algorithm to solve the proposed model and provide computational times on several instances for comparison purposes.

Mixed load or multi load is a strategy in which students that are assigned to different schools are picked up by the same bus at the same time. In this case, the bus stops at a specific school and drops off some of the students and then visit the other school(s) to drop off the other students on the bus. Although mixed load is allowed in most of the real-world cases of SBRP, there are only a few research studies that have addressed this strategy. Park, Tae [10] develop a SBRP that minimizes the number of buses for a mixed load problem in which students are picked up from home. They compare their model with literature using benchmark examples and conclude that their model performs better compared with the literature. Ellegood, Campbell [11] provide an 
analysis on mixed load strategy dealing with SBRP that could have more advantage over the traditional single load strategy specially when the schools are close to each other. Yao, Cao [12] present two modes of mixed load SBRP and develop a two-stage heuristic algorithm including clustering algorithm and ACO to solve their proposed models using several test instances.

Lima, Pereira [13] propose a SBRP that can handle mixed loads, heterogeneous fleet, and school starting times and minimized total cost. They use Clark and Wright algorithm to generate initial solutions and then adopt five different meta-heuristic search algorithms to solve the problem. They apply their approach to four different data sets including a real data from Brazil and conclude that their approach provides better solutions than the single load vehicle problem. Additionally, Lima, Pereira [14] develop four multi-objective local search heuristics all of which outperform the results of their previously developed meta-heuristic approaches when solving the same multi-objective capacitated SBRP that considers mixed loads and heterogeneous vehicles.

\subsubsection{Heuristics}

SBRP is a variation of the Vehicle Routing Problem (VRP) and because VRP is an NP-hard problem, SBRP is also considered an NP-Hard problem. Karp [15] discusses that the computational complexity of the combinatorial problems including VRP and its variations increases exponentially as the network size grows. Kumar, Gopal [16] prove that all variations of VRP are NP-hard problems, which cannot be solved to optimality for large instances in deterministic polynomial time, and SBRP is no exception either. Due to this fact, several researchers have recently focused on developing heuristic and meta-heuristic solution approaches for solving SBRP and its variations. 
Al-Khatib and Nahar [17] propose a hybrid solution approach to solve SBRP known as Smart Real Time using Genetic Algorithm (SRT-GA). They use SBRP standard benchmark data sets to evaluate and compare their results with other methods available in literature and they conclude that their approach outperforms all other previously developed methods. They also develop a smart phone application which updated the locations periodically. Oluwadare, Oguntuyi [18] develop a SBRP that minimizes the total distance traveled, number of buses used and the number of generated routes. They solve the assignment problem and use Genetic Algorithm (GA) to solve the routing phase. They apply their model and solution approach on a real data set from Nigeria and conclude that less buses can be used to reduce the costs comparing to the existing strategy. Díaz-Parra, Ruiz-Vanoye [19] have generated the School Bus Routing Problem Library-SBRPLIB which is a depository of test instances for SBRP that is available for all researchers. They use the instances to evaluate the performance of the proposed model in which students are assigned to pick up points while minimizing the total distance traveled. A year later, Diaz-Parra, Ruiz-Vanoye [20] apply a vertical transfer algorithm which is a variation of GA to solve SBRP that minimizes the number of buses and total distance traveled. They use the same test instances from School Bus Routing Problem Library-SBRPLIB to test the performance of their methodology. Minocha and Tripathi [21] use hybrid genetic algorithm to solve a SBRP that maximizes the utilization of the buses. They provide a new travel plan for the buses to transfer students more efficiently in Blooming Dales School District situated in Ganga Nagar, Rajasthan, India. Phyu, Srijuntongsiri [22] use GA and Multi-Parent Genetic Algorithm (MPGA) using binary encoding to solve SBRP that minimizes the total distance traveled by buses in Thammasat University in Thailand. They find out that the efficiency of their solution approach improves when they increase the number of parents in GA. 
There are other heuristics and meta-heuristic solution methods that are less popular but have been used in the literature in this context. Zhang and Li [23] develop a solution approach based on improved quantum-behaved Particle Swarm Optimization (PSO) to solve the proposed SBRP model that minimizes the transportation cost. They use a real data set from Gansu Normal College for Nationalities in Hezuo City, China. Jaradat [24] uses Intelligent Water Drops (IWD) optimization approach to solve SBRP which determines the tour with minimum length among all possible tours. He finds out that IWD solution approach can obtain near optimal solutions using different instances. Elgarej, Mansouri [25] present a School Bus Dispatching Problem (SBDP) with a single school that minimizes the total transportation cost. They adopt and improve Ant Colony Optimization (ACO) meta-heuristic algorithm to find the shortest path each student can travel to get to the school.

Spada, Bierlaire [26] proposes a SBRP that optimizes the service level for a fixed number of buses. They develop a solution approach that starts with a feasible initial solution and improves through a heuristic method. They suggest that Simulated Annealing performs better comparing to Tabu Search and the Local Search they use on this specific data set. Using average service level results in a better performance for all three methods rather than using the extreme values. They also provide an interface to use as a decision support tool for practitioners. Galdi and Thebpanya [27] apply a Geographical Information System (GIS) based heuristic to locate unnecessary bus stop placement that are initially selected manually based on a set of variables such as efficiency. They use ArcGIS Network Analyst Extension to select stop candidates to be eliminated from the existing list of stops. School officials finally decide to eliminate $15 \%$ of the bus stops as those are determined to be unnecessary according to the proposed approach. Kim, Kim [28] present 
two exact approaches and a heuristic method to solve a SBRP with time window that minimizes the number of buses and total distance traveled. They use benchmark problems to analyze the performance of their solution approach. Chen, Kong [29] compare the results of an aggregated Simulated Annealing and local search meta-heuristic solution approaches with the result of the exact method in solving a bi-objective mixed integer SBRP that minimizes number of buses and total traveled distance. They use two benchmark data sets to prove that their meta-heuristic approach outperforms.

Schittekat, Kinable [30] develop a meta-heuristic solution approach based on Greedy Randomized Adaptive Search Procedure and Variable Neighborhood Descent (GRASP + VND) to solve their proposed SBRP. They apply their solution approach to 112 generated instances and prove that their meta-heuristic solution approach provides optimal or close to optimal solutions when compared to the exact results. Kinable, Spieksma [8] apply Branch and Price solution method via a Column Generation (CG) approach to solve a SBRP that assigns students to bus stops and selects the best routes by minimizing the total cost. They use local search heuristics to improve the quality of the initial solutions. They also apply their solution approach to the same instances from Schittekat, Kinable [30] where many of them are solved to optimality, and lower bounds are provided for the remaining instances.

Faraj et al. (2014) present a mixed integer programming model for SBRP to optimize the daily trips of students and use Greedy Randomized Adaptive Search Procedure (GRASP) to solve this model using real data from Brazil which includes 944 students and 23 schools. The GRASP algorithm is capable of producing good quality solutions for most of the instances in a reasonable amount of time based on their result. Sarubbi, Mesquite [32] then use the same data 
set to evaluate their developed SBRP model that assigns students to bus stops by minimizing the number of selected stops. They utilize Pseudo-random consecutive heuristic algorithm for the assignment purpose and conclude that their approach provides better results for $80 \%$ of the test cases provided by Faraj, Sarubbi [31].

Bogl, Doerner [33] develop SBRP model that allows transfer of students between the buses in the middle of the routes while minimizing the total operating cost. They also develop a heuristic solution approach to solve this model and conclude that the model with allowable transfer has less operating cost compared to the results of the model with no transfer allowed.

Some researchers take further actions by developing an interface or a software that can be used to generate the routes by efficiently solving a variation of SBRP. Unsal and Yigit [34] develop an application using GA to dynamically record bus locations and stops using the GPS system to solve dynamic SBRP also known as DSBRP. They improve the routes by $17.63 \%$ reduction in the total cost when they use their developed software on a real data from Ankara, Turkey. Wang, Huang [35] also develop a web-based software for a SBRP that can find a tradeoff between efficiency of the bus, student safety, total traveled distance and the education policy and evaluate the performance of the software using a real-world case study in Oklahoma.

\subsection{Multi-Objective SBRP}

It is more practical to consider multiple objectives when dealing with school bus routing problems. Several objectives have been addressed in the literature including but not limited to minimizing the total miles driven, or number of buses or maximizing bus utilization, or service quality. Several research studies have combined the objectives in the literature to develop a 
multi-objective SBRP. Lima, Pereira [13] and Lima, Pereira [14] as mentioned above developed a multi-objective SBRP that minimizes the total weighted time, balances the routes between bus drivers, and minimizes the total cost. Hashi, Hasan [36] present a multi-objective SBRP that minimizes the transportation cost and travel time. They use a GIS based solution approach to solve this SBRP with time window by applying it to a data set from a school in Dhaka, Bangladesh for validation of the model and solution approach that result in an improvement of the result by $80 \%$ compared to the previous studies.

Parvasi, Mahmoodjanloo [37] propose a bi-level model that maximizes the profit for the transportation firm by providing the students with transportation choices at the upper level to obtain locations of the stations and efficient routes. At the next level also called lower level, the students are assigned to stations while minimizing the total cost. They obtain the location of the bus stops, assignment of the student to bus stop, and the route of the busses in the first, second, and third steps in their solution approaches; respectively. Their develop meta-heuristic solution approaches are called Genetic Algorithm-Exact Solution-Tabu Search (GA-EX-TS) and Simulated Annealing-Exact Solution-Tabu Search (SA-EX-TS). The results demonstrate well performance of these meta-heuristic approaches when compared to the optimal solution obtained through complete enumeration for smaller examples.

\subsubsection{Goal Programming}

The decision makers are normally concerned with multiple conflicting objectives in practice. There is no guarantee that traditional solution approaches for single objective models provide feasible solutions for multi-objective models. Therefore, multi-objective combinatorial optimization (MOCO) plays a vital role in obtaining feasible solutions called Pareto optimal 
solutions that optimize multiple goals simultaneously. One of the methods to handle the multiobjective models is the $\varepsilon$-constraint method that converts the multi-objective model to a single objective by constraining the additional objectives (i.e. force the objectives to be lower than a pre-defined upper value for minimization problems). Bouzarth, Forrester [38] calculate Utopia and Nadir points to provide an upper bound for minimax objective in a multi-objective student to school assignment model. The other most common methods to handle multi-objective models is goal programming approach first proposed by Charnes, Cooper [39]. The main idea behind the GP approach is to set pre-defined goals for each objective and minimize the total deviation between the goals and the achieved objectives. Minocha and Tripathi [21], Ghoseiri and Ghannadpour [40], and Jolai, Aghdaghi [41] use GP to solve variations of multi-objective VRP models. However, there is only one study [42] that formulate a multi-objective SBRP using GP in the literature. Their model minimizes the total cost and maximum walking distance (from home to bus stops).

\subsection{Special Needs Students}

School bus routing for special needs or special education students significantly differ from the original SBRP as the special need students must be picked up and dropped off at their home. They may also need different types of service and special buses that can accommodate their needs. There are few research studies focusing on assignment and/or routing of special needs students.

Kamali, Mason [43] develop a two phase SBRP for special needs students. Students are assigned to schools in the first phase by minimizing the total distance traveled and the routes are generated in the second phase considering the assignments as input to minimize the total distance 
all buses travel. They adopt greedy heuristic approach to solve this problem which results in feasible and good quality solutions in a reasonable amount of time on both validation instances and a real data from a public school in Arkansas.

Also, Caceres, Batta [44] address a SBRP focusing on special need students which minimizes the total number of buses and distance traveled. They use a real case at a school district in a suburban area in Western New York. They develop a greedy heuristic with a column generation approach to provide a good quality solution which reduced the total cost by $10-20 \%$ for the solved instances. 


\section{Chapter 3: Methodology}

Student to school assignment and bus routing problems have been both addressed in the literature. In this study, these two problems have been integrated into a Non-Linear Programming Model (NLP) to find the assignment and routing at the same time by minimizing the total distance traveled by buses which is addressed in section 2.1. The nonlinear model is then linearized so that Gurobi and CPLEX can be used to solve them.

\subsection{Single Objective}

Initially, an integrated model is presented that exclusively minimizes the total traveled distance. The mathematical model for both nonlinear and linear models are presented in the following sections. We evaluate the performance of the algorithm using the randomly generated instances in section 3.1.3. Then, a detailed example is presented in section 3.1.4 to compare the original optimum routes and assignments with the results generated by the CCARP algorithm. The application of the solution approach to a real-world case study is discussed in Chapter 4:.

\subsubsection{Mathematical Modeling}

The integrated model that combines the student to school assignment problem and school bus routing problem is nonlinear as the parameter that shows the assignment of students to schools is now a decision variable in the integrated model.

\section{Notation}

The notation, parameters, decision variables, and the assumptions we made are all introduced. 


\section{Sets}

S: Set of schools (indexed by $i$ and $j$ )

$\mathrm{T}$ : Set of student homes (indexed by $\mathrm{i}$ and $\mathrm{j}$ )

D: Set of depots (indexed by $i$ and $j$ )

$\mathrm{N}$ : Set of nodes (Union of S, T, and D) (indexed by i and j)

CT: Set of class types (indexed by $\mathrm{m}$ )

B: Set of Busses (indexed by k)

Parameters

$n:$ Total number of nodes

$d_{i j}$ : Distance between nodes $i$ and $j$

$C_{k}:$ Capacity of bus $k$

$g_{\text {im }}=\left\{\begin{array}{rr}1 & \text { if student } \text { i requires class type } m \\ 0 & \text { Otherwise }\end{array}\right.$

$a_{j m}$ : Capacity of class type $m$ in school $j$

\section{Decision Variables}

$x_{i j k}=\left\{\begin{array}{rr}1 & \text { if bus } k \text { goes from node } i \text { to node } j \\ 0 & \text { Otherwise }\end{array}\right.$

$l_{i j}=\left\{\begin{array}{rr}1 & \text { if student } i \text { is assigned to school } j \\ 0 & \text { Otherwise }\end{array}\right.$ 
$y_{i k}=\left\{\begin{array}{rr}1 & \text { if student } i \text { is served by bus } k \\ 0 & \text { Otherwise }\end{array}\right.$

$z_{i k}=\left\{\begin{array}{rr}1 & \text { if school } i \text { is visited by bus } k \\ 0 & \text { Otherwise }\end{array}\right.$

$w_{i k}=$ position of node $i$ on the route of the $k^{\text {th }}$ bus

\section{Assumptions}

- There are specific number of buses all of which must be used for student pickup and delivery.

- A bus picks up all the students first and drops them off at their assigned schools.

- Not all the schools are necessarily used. (There might be enough seats available in other schools so that one or more schools are redundant.)

\section{Model I - Nonlinear SSA-SBRP-SNS}

In this section, an integrated Student to School Assignment and School Bus Routing model that focusses on the Special Needs Students (SSA-SBRP-SNS) is developed. In this work, we refer to the nonlinear SSA-SBRP-SNS model as Model I.

$$
\text { minimize } Z=\sum_{i \in N} \sum_{j \in N} \sum_{k \in B} d_{i j} x_{i j k}+\frac{1}{M} \sum_{i \in N} \sum_{k \in B} w_{i k}
$$

S.T.

$$
\sum_{j \in S \cup T} \sum_{k \in B} x_{i j k}=1 \quad i \in T
$$




$$
\begin{aligned}
& \sum_{i \in D \cup T} \sum_{k \in B} x_{i j k}=1 \quad j \in T \\
& \sum_{j \in N} x_{i j k}=y_{i k} \quad i \epsilon T, k \in B \\
& \sum_{j \in N} x_{j i k}=y_{i k} \quad i \epsilon T, k \epsilon B \\
& \sum_{i \in D} \sum_{j \in T} x_{i j k}=1 \quad k \in B \\
& \sum_{i \in S} \sum_{j \in D} x_{i j k}=1 \quad k \in B \\
& \sum_{j \in D \cup S} x_{i j k}=z_{i k} \quad i \in S, k \in B \\
& \sum_{j \in S \cup T} x_{j i k}=z_{i k} \quad i \epsilon S, k \epsilon B \\
& x_{i i k}=0 \quad i \epsilon N, k \in B \\
& w_{i k}=1 \quad i \epsilon D, k \in B \\
& w_{j k} \geq w_{i k}+1-n *\left(1-x_{i j k}\right) \quad i \epsilon N, j \in S \cup T, j \neq i, k \epsilon B \\
& \sum_{j \in S} l_{i j}=1 \quad i \in T \\
& \sum_{i \in T} l_{i j} g_{i m} \leq a_{j m} \quad j \in S, m \in C \\
& l_{i j} w_{i k}+z_{j k} \leq w_{j k} \quad i \epsilon T, j \epsilon S, k \in B \\
& l_{i j} \cdot y_{i k} \leq z_{j k} \quad i \epsilon T, j \epsilon S, k \in B
\end{aligned}
$$




$$
\sum_{j \in T} y_{j k} \leq C_{k} \quad k \epsilon B
$$

The objective function (1) minimizes the total distance travel that the busses make between any two nodes. A very small term is added to the objective model to penalize variable $w_{i k}$ if gets non-zero values. Constraint (2) forces each bus to visit exactly one node either a student node or a school node immediately after visiting a student node. Constraint (3) makes sure that exactly one node is visited before each student visit.

Constraints sets (4) and (5) update bookkeeping variable $y_{i k}$ by relating it to the main decision variable, $x_{i j k}$. Constraint set (6) forces all buses to start their daily trips from the origin depot node and go to a student node right after the depot.

Constraint set (7) verifies that no bus goes directly from a student node to the depot. Constraint sets (8) and (9) update bookkeeping variable $z_{i k}$ by relating it to the main decision variable $x_{i j k}$. Constraint set (10) ensures that there is no return travel from a node back to itself. Constraint set (11) sets bookkeeping variable $w_{i k}$ for the origin depot node $=1$, thereby forcing the depot to be the first node visited by each bus. Constraint sets (12) update bookkeeping variable $w_{i k}$ and together disallow sub-tours in the routing model.

Constraint set (13) requires that each student be assigned to exactly one school. Constraint set (14) guarantees that the number of students assigned to each class type at any school does not exceed the class's available capacity.

Constraint set (15) guarantees that a bus picks up students before that same bus visits their destination school. Constraint set (16) is another valid inequality that ensures no student is on a 
bus that does not visit his/her destination school. Constraint set (17) makes sure that the students on the bus do not exceed the capacity of the bus after departing each node. The developed integrated is nonlinear due to the change of assignment parameter in the routing model developed by Kamali, Mason [43] to an assignment variable in our proposed model. Therefore, we linearize Model I so we can use the commercial solvers to test and validate our model using random cases.

The constraints containing the variable $w_{i k}((12)$ and (15)) -which capture the position of the nodes in routes- only help us find a lower bound for this variable using the assignments and routes. The nodes that are not visited by bus $\mathrm{k}$ will have a lower bound 0 and those nodes that are supposed to be visited by that bus will have non-zero lower bounds that are determined based on the previous nodes visited in the route. The second term in the objective function forces the model to select the lower bound for each $w_{i k}$ as obtained by the constraints. This way, all the nodes in the route will have consecutive values of $w_{i k}$ and the unvisited nodes will have $w_{i k}=0$. Therefore, without the second term of the objective function, the values are valid based on the constraints, but they are not necessarily consecutive numbers as they should be to show the order of nodes visited. Therefore, we believe the only way to ensure the lower bounds are selected for $w_{i k}$ is minimizing the summation of $w_{i k}$ 's in the objective function. We multiply the summation by a very small value $\left(\frac{1}{M}\right)$ to prevent it from affecting the total travel distance which is our main objective function.

\section{Model II - Linear SSA-SBRP-SNS}

Model I is a nonlinear model because constraints (15) and (16) are nonlinear. To linearize these constraints, additional variables should be introduced to the model as follows: 
$v_{i j k}=l_{i j} \cdot w_{i k}= \begin{cases}w_{i k}, & \text { if } l_{i j}=1 \\ 0, & \text { Otherwise }\end{cases}$

$\mu_{i j k}=l_{i j} \cdot y_{i k}=\left\{\begin{array}{l}1, \quad \text { if } l_{i j}=1 \text { and } y_{i k}=1 \\ 0, \quad \text { otherwise }\end{array}\right.$

The newly introduced variables provide good information about the solution of the problem. In other words, if variable $v_{i j k}$ in not 0 , that means student $\mathrm{i}$ is assigned to school $\mathrm{j}$ and bus $\mathrm{k}$ and the value of variable $v_{i j k}$ actually shows the position of that student on the route of bus $\mathrm{k}$.

Additionally, variable $\mu_{i j k}$ when equal to 1 also shows that student $\mathrm{i}$ is assigned to school $\mathrm{j}$ and bus k. The nonlinear constraint (15) will be replaced by constraints (26) through (21) and constraint (16) will be replaced by constraints (22) through (25).

$$
\begin{aligned}
& v_{i j k}+z_{j k} \leq w_{j k} \quad i \epsilon T, j \in S, k \epsilon B \\
& v_{i j k} \leq M . l_{i j} \quad i \epsilon T, j \in S, k \in B \\
& v_{i j k} \leq w_{i k} \quad i \epsilon T, j \in S, k \in B \\
& v_{i j k} \geq w_{i k}-\left(1-l_{i j}\right) * M \quad i \epsilon T, j \epsilon S, k \in B \\
& \mu_{i j k} \leq z_{j k} \quad i \epsilon T, j \in S, k \in B \\
& \mu_{i j k} \leq l_{i j} \quad i \in T, j \in S, k \in B \\
& \mu_{i j k} \leq y_{i k} \quad i \epsilon T, j \epsilon S, k \epsilon B \\
& \mu_{i j k} \geq l_{i j}+y_{i k}-1 \quad i \epsilon T, j \in S, k \in B
\end{aligned}
$$

Therefore, Model II which is the linear form of SSA-SBRP-SNS will be as follows: 
minimize $Z=\sum_{i \in N} \sum_{j \in N} \sum_{k \in B} d_{i j} x_{i j k}+\frac{1}{M} \sum_{i \in N} \sum_{k \in B} w_{i k}$

S.T.

$\sum_{j \in S \cup T} \sum_{k \in B} x_{i j k}=1 \quad i \in T$

$\sum_{i \in D \cup T} \sum_{k \in B} x_{i j k}=1 \quad j \in T$

$\sum_{j \in N} x_{i j k}=y_{i k} \quad i \epsilon T, k \in B$

$\sum_{j \in N} x_{j i k}=y_{i k} \quad i \in T, k \in B$

$\sum_{i \in D} \sum_{j \in T} x_{i j k}=1 \quad k \in B$

$\sum_{i \in S} \sum_{j \in D} x_{i j k}=1 \quad k \in B$

$\sum_{j \in D \cup S} x_{i j k}=z_{i k} \quad i \in S, k \in B$

$\sum_{j \in S \cup T} x_{j i k}=z_{i k} \quad i \in S, k \in B$

$x_{i i k}=0 \quad i \in N, k \in B$

$w_{i k}=1 \quad i \epsilon D, k \epsilon B$

$w_{j k} \geq w_{i k}+1-n *\left(1-x_{i j k}\right) \quad i \epsilon N, j \epsilon S \cup T, j \neq i, k \epsilon B$

$\sum_{j \in S} l_{i j}=1 \quad i \in T$ 


$$
\begin{array}{lr}
\sum_{i \epsilon T} l_{i j} g_{i m} \leq a_{j m} & j \in S, m \epsilon C \\
v_{i j k}+z_{j k} \leq w_{j k} & i \epsilon T, j \in S, k \epsilon B \\
v_{i j k} \leq M . l_{i j} & i \epsilon T, j \epsilon S, k \epsilon B \\
v_{i j k} \leq w_{i k} & i \epsilon T, j \epsilon S, k \epsilon B \\
v_{i j k} \geq w_{i k}-\left(1-l_{i j}\right) * M & i \epsilon T, j \in S, k \epsilon B \\
\mu_{i j k} \leq z_{j k} & i \epsilon T, j \epsilon S, k \epsilon B \\
\mu_{i j k} \leq l_{i j} & i \epsilon T, j \in S, k \epsilon B \\
\mu_{i j k} \leq y_{i k} & i \epsilon T, j \epsilon S, k \epsilon B \\
\mu_{i j k} \geq l_{i j}+y_{i k}-1 & i \epsilon T, j \in S, k \epsilon B \\
\sum y_{j k} \leq C_{k} & k \epsilon B
\end{array}
$$

\subsubsection{Solution Approach}

The linearized model can be solved using Gurobi commercial solver version 9.1.0 in Python interface. We start from a very small network and gradually increase the number of the nodes to record the computational time. We set a time limit of two hours for every single instance to solve to optimality. The largest network that can be solved to optimality within the two-hour time limit has 42 nodes. However, most of the school districts has a lot more students than that. The reason is that the number of variables and constraints increase significantly when the number of nodes increases and therefore the chance to solve the problem in a reasonable amount of time 
decreases. This highlights the importance of developing a heuristic technique that can generate a good quality solution in a reasonable amount of time. A two-phase solution approach is developed that clusters the students and solved the SSA-SBRP-SNS within each cluster in the second phase. Therefore, the student to school assignment and bus routing problem which is a NP-hard problem is partitioned into a number of smaller solvable problems. Students are clustered along with the Euclidean distances to assure closeness of the students within the cluster. The clustering procedures are described in the following sections of this chapter.

\section{K-means Clustering approach}

K-means clustering algorithm is an unsupervised machine learning method first developed by MacQueen [45] which has been widely used in many applications to categorize unlabeled data. The goal of this algorithm is to find $\mathrm{K}$ number of groups in the data based on a feature such as distance. The logic is to maximize the similarity within the groups and to minimize it between the groups. It is always a challenge to find the optimum number of groups represented by K; however, the number of buses will always define the number of clusters in this work. The number of points in a cluster completely depends on how the data is distributed. This makes most of the generated solutions infeasible if more students than the capacity of the bus is assigned to the cluster that is supposed to be picked up by that bus. Therefore, another solution approach is developed in the next section that considers the capacity of the buses when forming clusters of students.

\section{Capacitated Clustering Problem}

In this research, another algorithm that can form clusters of students by considering the capacity of the buses that are supposed to pick them up is adopted which is called Capacitated 
Clustering Problem (CCP). CCP is also an unsupervised machine learning method for pattern classification, first proposed by Mulvey and Beck [46], which has been widely used in many applications to categorize unlabeled data. CCP can be formulated as a mathematical programming model that can find the assignment of the students to the clusters such that the distances are minimized, and the capacity constraint is not violated at any time for any cluster. The distances can be measured on the actual road however we use the Euclidean distance formulation for the randomly generated points which is the length of the straight line between the two nodes. The Euclidean distance between any two nodes $\left(x_{i}, y_{i}\right)$ and $\left(x_{k}, y_{k}\right)$ can be calculated using equation (49).

$$
\theta_{i k}=\sqrt{\left(x_{i}-x_{k}\right)^{2}+\left(y_{i}-y_{k}\right)^{2}}
$$

The decision variable $\delta_{i k}$ is defined as the binary variable which is 1 if student $i$ is assigned to cluster $k$ and 0 otherwise.

$\delta_{i k}=\left\{\begin{array}{rr}1 & \text { if student } i \text { is assigned to cluster } k \\ 0 & \text { otherwise }\end{array}\right.$

The CCP model formulation is as below:

minimize $\theta_{i k} \delta_{i k}$

S.T.

$$
\sum_{k \in B} \delta_{i k}=1 \quad i \in T
$$




$$
\begin{array}{ll}
\sum_{i \in T} \delta_{i k} \leq C_{k} & k \in B \\
\delta_{i k}=\{0,1\} & i \in T, k \in B
\end{array}
$$

The objective model (50) minimizes the total distances when assigning the students to clusters. Constraint set (51) ensures that each student is assigned to one cluster, no more and no less. Constraint set (52) makes sure that the bus capacity condition is always met when assigning the students to each bus (cluster).

\section{CCARP Heuristic Algorithm}

In this section, the developed two-phase heuristic solution approach is presented. This approach uses the CCP (described in the previous section) to cluster the students based on their home addresses. In this technique, students are grouped in the first phase and then Model II (linearized form of single objective SSA-SBRP-SNS) described in page 21 is solved within each cluster of students. The pseudo code of the algorithm is provided in Table 1. Once Model II is solved for each cluster, the school capacities are updated to reflect the remaining seats available for each service type at each school for the remaining students. This will help ensure that the solutions to Model II for every cluster become a feasible solution to the overall problem. 
Table 1 - Pseudo code for CCARP algorithm

\section{CCARP Algorithm}

I Select number of iterations (IT) and set iter $=1$, and set Best=M (Significantly large

number)

While iter $\leq I T$

\section{Initialization}

II Select $|\mathrm{B}|$ students randomly as initial centroids

III Generate distance matrix $\left(\theta_{i k}\right)$ using the distances from student $\mathrm{i}$ to centroid of cluster $\mathrm{k}$

IV Solve CCP to form clusters

\section{Main Loop}

$\mathrm{V} \quad$ Set $\mathrm{k}=1, Z_{\text {iter }}=0$, and $a^{(k)}=$ updated school capacity for cluster $\mathrm{k}$

VI Set $t^{(k)}=$ number of students assigned to cluster $\mathrm{k}$ from part IV

VII Set $l_{i j}^{(k)}$ binary variable representing the assignment of student $\mathrm{i}$ to school $\mathrm{j}$ at cluster $\mathrm{k}$

VIII Set $a_{j m}^{(k)}=$ remaining capacity of class type $\mathrm{m}$ in school $\mathrm{j}$ at cluster $\mathrm{k}$

While $k \leq|B|$ :

IX - Solve Model II for cluster $\mathrm{k}$ with $t^{(k)}$ students, $|\mathrm{S}|$ schools with capacity $a^{(k)}$, and 1 bus to get $Z(k)$

- Update school capacity: $a_{j m}^{(k)}=a_{j m}^{(k)}-\sum_{i \epsilon T} g_{i m} l_{i j}^{(k)} \quad \forall j \in S, m \in R$

- Update the distance at the end of each loop: $Z_{i t e r}=Z_{i t e r}+Z(k)$

$-k=k+1$

$\mathrm{X} \quad$ If $Z_{\text {iter }} \leq$ Best: Best $=Z_{\text {iter }}$

$\mathrm{XI} \quad$ iter $=$ iter +1

Initially, random students are selected as the center of clusters and other students will be assigned to the clusters with the selected centers. Therefore, this algorithm can be implemented multiple times shown by parameter IT (number of iterations). By randomly selecting different students as the centers at every iteration, the solution will be different, and this creates a pool of 
solutions quickly. The algorithm then selects the best solution among the solutions in the pool as the solution to the overall problem.

In the next chapter, an example is illustrated to show how Model II can be solved using Gurobi (exact solution approach) and CCARP. Several random cases are also generated to evaluate the performance of Model II and CCARP solution approach. The heuristic approach is also applied to a real-world case study in Fort Smith School District in Arkansas and is compared to the previously developed heuristic approaches in the literature.

\subsubsection{Validation}

The models developed in section 3.1.1 need to be validated. To be consistent, we follow the same procedure as Kamali, Mason [43] used for validation of their model. The main parameters in the developed model are number of buses, number of students, number of schools, the area of the school district, and the bus capacities. Several experiments are designed by randomly generated test cases for different values of the parameters in this model. The parameters and their values used to generate the random instances are listed in Table 2.

Table 2 - Input parameters for experimental design

\begin{tabular}{|c|c|c|c|}
\cline { 2 - 4 } \multicolumn{1}{c|}{} & Value 1 & Value 2 & Value 3 \\
\hline Number of Buses & 2 & 3 & 4 \\
\hline Number of Students & 20 & 40 & 60 \\
\hline Number of Schools & 2 & 4 & 6 \\
\hline District Area (miles) & $10 \times 10$ & $20 \times 20$ & \multicolumn{1}{c}{} \\
\hline Bus Capacity & 20 & \multicolumn{2}{c}{} \\
\cline { 1 - 3 } & \multicolumn{2}{c}{} \\
\cline { 1 - 3 } & &
\end{tabular}


In all our random test cases, number of buses vary between 2,3 , or 4 ; the number of students vary between 20,40, or 60; and the number of schools change between 2,4 , or 6 . The area of the school district may be either 10 by 10 square miles or 20 by 20 square miles and the capacity of buses are all 20 seats just to replicate the scenarios in Kamali, Mason [43].

To generate several random instances, we generate the $x$ and $y$ coordinates for schools and students home addresses that are between $(-5,5)$ for the 10 by 10 square miles and between $(-10,10)$ for the 20 by 20 square miles district; respectively. In all of these cases, the depot is located at the origin $(0,0)$. We generate 10 random instances for each combination of parameters, which makes them to be 540 different random cases; however, the cases in which 60 students are supposed to be picked up by two busses with 20 seats is not feasible at all. Therefore, the total number of test cases will be 480 random instances with the parameter values listed in Table 2. For the comparison's sake, the model developed by Kamali, Mason [43] is also solved in Gurobi on the same device to make a fair comparison. They use CPLEX solver to solve all their 480 test cases. By considering the one-hour time limit, among all these 480 test cases, $25.21 \%$ are solved to optimality, a feasible solution is obtained for $50.21 \%$ of these cases, and $24.58 \%$ of the instances are left with no solution in the time limit. However, for consistency and a fair comparison, we code both the assignment and routing models developed by Kamali, Mason [43] in Python and used the same solver Gurobi 9.1.0 in the same computer. The results of our model and the routing model by Kamali, Mason [43] are shown in Table 3. As shown in this table, there are no test cases with no solution in the 1-hour time limit when solved with Gurobi. 
Table 3 - Comparison of results obtained by Gurobi from Model II and the model developed by Kamali, Mason [43]

\begin{tabular}{|c|c|c|c|}
\hline Approach & $\begin{array}{c}\text { Solved to } \\
\text { optimality }\end{array}$ & $\begin{array}{c}\text { A solution in } \\
\text { 1-hour time limit }\end{array}$ & $\begin{array}{c}\text { No solution in } \\
\text { 1-hour time limit }\end{array}$ \\
\hline$[43]$ & $67.91 \%$ & $32.09 \%$ & $0 \%$ \\
\hline Model II & $53.33 \%$ & $46.67 \%$ & $0 \%$ \\
\hline
\end{tabular}

The detailed results of these 480 random test cases are shown in Table 4 . In this table, the percentage of the test cases for each parameter Is calculated to show what proportion of the test cases are solved to optimality in less than an hour, and what proportion just find a feasible solution in the 1-hour time limit, and also what percentage of the test cases find no solution in the time limit which is $0 \%$ for these examples when solved by Gurobi. Each row in this table shows all the cases which have that specific parameter but then different values for other parameters. For example, the first row shows the percentage of the instances that have 2 buses with combinations of 20 and 40 students; 2, 4, and 6 schools; and 100 and 400 square mile district areas. 
Table 4 - Detailed results of Model II and routing developed by Kamali, Mason [43] by Gurobi

\begin{tabular}{|c|c|c|c|c|c|c|}
\cline { 2 - 7 } \multicolumn{1}{c|}{} & \multicolumn{3}{c|}{ [43] } & \multicolumn{3}{c|}{ Model II } \\
\hline Parameter & Optimal & Time Limit & No Solution & Optimal & Time Limit & No Solution \\
\hline 2 Buses & $93 \%$ & $7 \%$ & $0 \%$ & $72 \%$ & $28 \%$ & $0 \%$ \\
\hline 3 Buses & $60 \%$ & $40 \%$ & $0 \%$ & $45 \%$ & $55 \%$ & $0 \%$ \\
\hline 4 Buses & $61 \%$ & $39 \%$ & $0 \%$ & $49 \%$ & $51 \%$ & $0 \%$ \\
\hline 20 Students & $100 \%$ & $0 \%$ & $0 \%$ & $98 \%$ & $2 \%$ & $0 \%$ \\
\hline 40 Students & $82 \%$ & $18 \%$ & $0 \%$ & $44 \%$ & $56 \%$ & $0 \%$ \\
\hline 60 Students & $2 \%$ & $98 \%$ & $0 \%$ & $0 \%$ & $100 \%$ & $0 \%$ \\
\hline 2 Schools & $73 \%$ & $28 \%$ & $0 \%$ & $66 \%$ & $34 \%$ & $0 \%$ \\
\hline 4 Schools & $68 \%$ & $32 \%$ & $0 \%$ & $55 \%$ & $45 \%$ & $0 \%$ \\
\hline 6 Schools & $66 \%$ & $34 \%$ & $0 \%$ & $39 \%$ & $61 \%$ & $0 \%$ \\
\hline 100 sq. miles & $70 \%$ & $30 \%$ & $0 \%$ & $53 \%$ & $47 \%$ & $0 \%$ \\
\hline 400 sq. miles & $68 \%$ & $32 \%$ & $0 \%$ & $54 \%$ & $46 \%$ & $0 \%$ \\
\hline
\end{tabular}

Both Model II and the model developed by Kamali, Mason [43] are not solved to optimality for several instances as shown in Table 4 which highlights the importance of developing a heuristic solution approach that is capable of generating a good quality solution in a reasonable amount of time. The heuristic approach Kamali, Mason [43] use is a greedy based solution approach that generates initial feasible solutions, and then local search techniques are adopted to improve the quality of the initially generated solutions. They use greedy heuristic to assign students to the closest bus that still has available capacity while considering the current location of the bus at the moment. The quality of these generated solutions is not guaranteed even though the solutions are feasible. Therefore, the developed local search-based heuristics called IH1 and IH2 focus on improving the initial solutions. IH1 focuses on assigning the students to the buses until the buses get full one by one before moving on to the next bus while there are unassigned students. IH 2 is 
then proposed to improve the solutions provided by IH1 by ensuring that no bus is underutilized by checking how many students are assigned to each bus. Assuming $n$ is the number of students and $b$ is the number of buses and therefore, they ensure that at least $\left\lceil\frac{n}{b}\right\rceil$ students are assigned to each bus. This value acts as a lower bound for the number of assigned students to each bus. For example, if 25 are to be assigned to 3 buses, then $\left\lceil\frac{25}{3}\right\rceil=\lceil 8.3\rceil=8$ shows that each bus should pick up at least 8 students. Based on their own result, IH2 outperforms the greedy and IH1 so we compare the performance of our developed heuristic approach with IH2. Again, for consistency, we also calculate the performance ratios by dividing the value of objective function obtained from the heuristic approach over the objective function value from Gurobi obtained in the 1-hour time limit. As 10 random cases are generated foreach combination of parameters, average (AVG) values and standard deviations (STD) of the performance ratios for each 10 cases are calculated which is shown in Table 5. For example, all the cases with 2 buses are 120 no matter what the value of other parameters are, cases that have 20 students are 180 instances, or all the cases in which the school district area is 400 square feet are 240 instances out of 480 test cases. The performance ratio can get values less than 1 , equal to 1 , or even greater than 1 depending on the situation. If the model reaches to the optimum solution within the 1-hour time limit, the performance ratio of 1 specifies that CCARP has found the global optimum. The performance ratio greater than 1 indicates that the heuristic solution is worse than the solution provided by Gurobi in the time limit. The values of less than 1 shows that the best value obtained by Gurobi in the time limit is larger (worse) than the CCARP solution. 
Table 5 - Comparison of performance ratios obtained by CCARP vs. IH2 developed by Kamali, Mason [43]

\begin{tabular}{|c|c|c|c|c|c|c|c|c|}
\hline \multirow{3}{*}{$\begin{array}{l}\text { Parameter } \\
\text { Parameter }\end{array}$} & \multicolumn{4}{|c|}{ IH2 (Kamali, Mason [43]) } & \multicolumn{4}{|c|}{ CCARP } \\
\hline & \multicolumn{2}{|c|}{ Optimal } & \multicolumn{2}{|c|}{ Time Limit } & \multicolumn{2}{|c|}{ Optimal } & \multicolumn{2}{|c|}{ Time Limit } \\
\hline & $\mathrm{AVG}$ & STD & AVG & STD & $\mathrm{AVG}$ & STD & $\mathrm{AVG}$ & STD \\
\hline 2 Buses & 1.2 & 0.09 & 1.01 & 0.14 & 1.06 & 0.04 & 1.02 & 0.06 \\
\hline 3 Buses & 1.43 & 0.13 & 1.14 & 0.23 & 1.14 & 0.07 & 0.93 & 0.15 \\
\hline 4 Buses & 1.53 & 0.16 & 1.29 & 0.27 & 1.15 & 0.05 & 0.99 & 0.15 \\
\hline 20 Students & 1.37 & 0.19 & 1.41 & 0.19 & 1.12 & 0.07 & 1.10 & 0.08 \\
\hline 40 Students & - & - & 1.11 & 0.18 & 1.11 & 0.06 & 1.07 & 0.08 \\
\hline 60 Students & - & - & 0.8 & 0.09 & - & - & 0.88 & 0.13 \\
\hline 2 Schools & 1.35 & 0.16 & 1.11 & 0.24 & 1.12 & 0.07 & 1.01 & 0.10 \\
\hline 4 Schools & 1.4 & 0.2 & 1.16 & 0.22 & 1.12 & 0.07 & 0.96 & 0.13 \\
\hline 6 Schools & 1.38 & 0.22 & 1.19 & 0.26 & 1.11 & 0.07 & 0.96 & 0.17 \\
\hline 100 sq. miles & 1.37 & 0.18 & 1.14 & 0.25 & 1.11 & 0.07 & 0.97 & 0.15 \\
\hline 400 sq. miles & 1.38 & 0.19 & 1.16 & 0.25 & 1.12 & 0.07 & 0.98 & 0.14 \\
\hline Overall & 1.37 & 0.19 & 1.15 & 0.25 & 1.12 & 0.07 & 0.97 & 0.15 \\
\hline
\end{tabular}

The overall average and standard deviations in Table 5 show that CCARP outperforms IH2 in all the random cases. The performance ratios cannot be calculated for the test cases with 40 students in the routing model developed by Kamali, Mason [43] as no solution is found in the time limit. To determine the largest problem that CCARP can solve in an hour time limit, we increase the number of nodes in randomly generated examples. It comes to a conclusion that the largest problem for which CCARP can generate a solution has 740 students, 7 schools, and 28 school buses. 


\subsubsection{Numerical Example}

In this section, we use an example to illustrate how Model II solves to optimality for a relatively small instance with 20 students and evaluate how the heuristic solution approach CCARP performs when compared to the optimal solution. In this example, these 20 students are to be assigned to 2 schools with 2 different service levels and to be delivered by 3 buses with capacities 5, 5, and 10; respectively. Students are shown by $T_{1}, T_{2}, \ldots, T_{20}$ and schools are denoted by $S_{1}$ and $S_{2}$. One of the parameters used in Model II is $a_{j m}$ which is the capacity of school $j$ at service level $m$. The values of this parameter used for the numerical example is shown in Table 6.

Table 6 - Capacity of schools per class type used for the numerical example $\left(a_{j m}\right)$

\begin{tabular}{|c|c|c|}
\cline { 2 - 3 } \multicolumn{1}{c|}{} & \multicolumn{2}{c|}{ Class types } \\
\cline { 2 - 3 } \multicolumn{1}{c|}{} & $1: 10$ & $1: 6$ \\
\hline$S_{1}$ & 4 & 4 \\
\hline$S_{2}$ & 7 & 5 \\
\hline
\end{tabular}

The class type or service level each of these 20 students need is shown by the parameter $g_{i m}$ which is used as a binary parameter in Model II. Table 7 shows the value of this parameter for all students in the numerical example.

Table 7 - Class type (service) needed by the students used for the numerical example $\left(g_{i m}\right)$

\begin{tabular}{|c|c|c|c|c|c|c|c|c|c|c|c|c|c|c|c|c|c|c|c|c|}
\hline Students & $T_{1}$ & $T_{2}$ & $T_{3}$ & $T_{4}$ & $T_{5}$ & $T_{6}$ & $T_{7}$ & $T_{8}$ & $T_{9}$ & $T_{10}$ & $T_{11}$ & $T_{12}$ & $T_{13}$ & $T_{14}$ & $T_{15}$ & $T_{16}$ & $T_{17}$ & $T_{18}$ & $T_{19}$ & $T_{20}$ \\
\hline $\begin{array}{l}\text { Service } \\
\text { needed }\end{array}$ & $1: 10$ & $1: 6$ & $1: 6$ & $1: 10$ & $1: 6$ & $1: 6$ & $1: 6$ & $1: 10$ & $1: 6$ & $1: 10$ & $1: 10$ & $1: 6$ & $1: 10$ & $1: 10$ & $1: 6$ & $1: 6$ & $1: 6$ & $1: 6$ & $1: 10$ & $1: 10$ \\
\hline
\end{tabular}

Model II is run using this numerical example and results in the total optimum distance traveled by all 3 busses to be 65.74 miles. The optimum routes that are generated by solving model II using Gurobi optimizer are shown in Figure 1. The buses are used at their full capacity 
and bus number 3 that has 10 seats available visits both of the schools. Therefore, this instance is an example that illustrates the capability of the developed model (Model II) to handle heterogeneous fleet of buses and mixed load (multi-load). The computational time to obtain this optimum solution using Gurobi is 41.13 seconds.

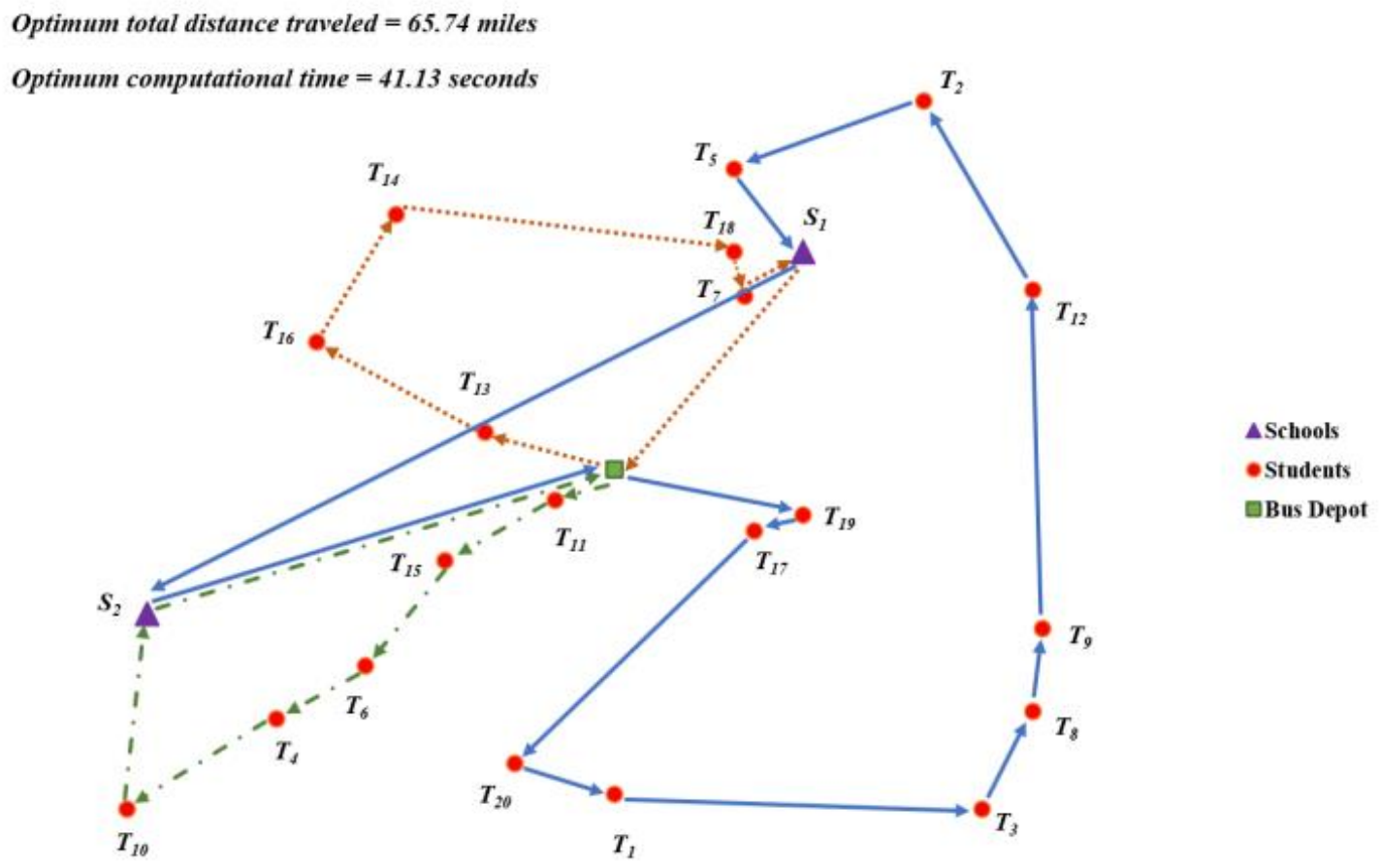

Figure 1 - Optimum routes generated from Model II solved by Gurobi 9.1.0 for numerical example

Now that the optimal solution is obtained through solving Model II, the heuristic solution approach CCARP is applied to the same example to evaluate the performance of the algorithm in terms of both solution quality and computational time. The algorithm is iterated 5 times $(I T=5)$ by selecting different students as the center of clusters every time it is implemented. The total distance obtained by five iterations of CCARP on this example results in $69.97,83.3,74.63$, 71.4, and 68.84 miles. Therefore, the best answer among these five iterations is the result of the last iteration which is 68.84 miles that has an optimality gap of $4.71 \%$. The routes and 
assignments of this solution is illustrated in Figure 2. Most importantly, the computational time for all five iterations is 1.281 seconds so CCARP algorithm is significantly quicker than solving Model II to optimality.

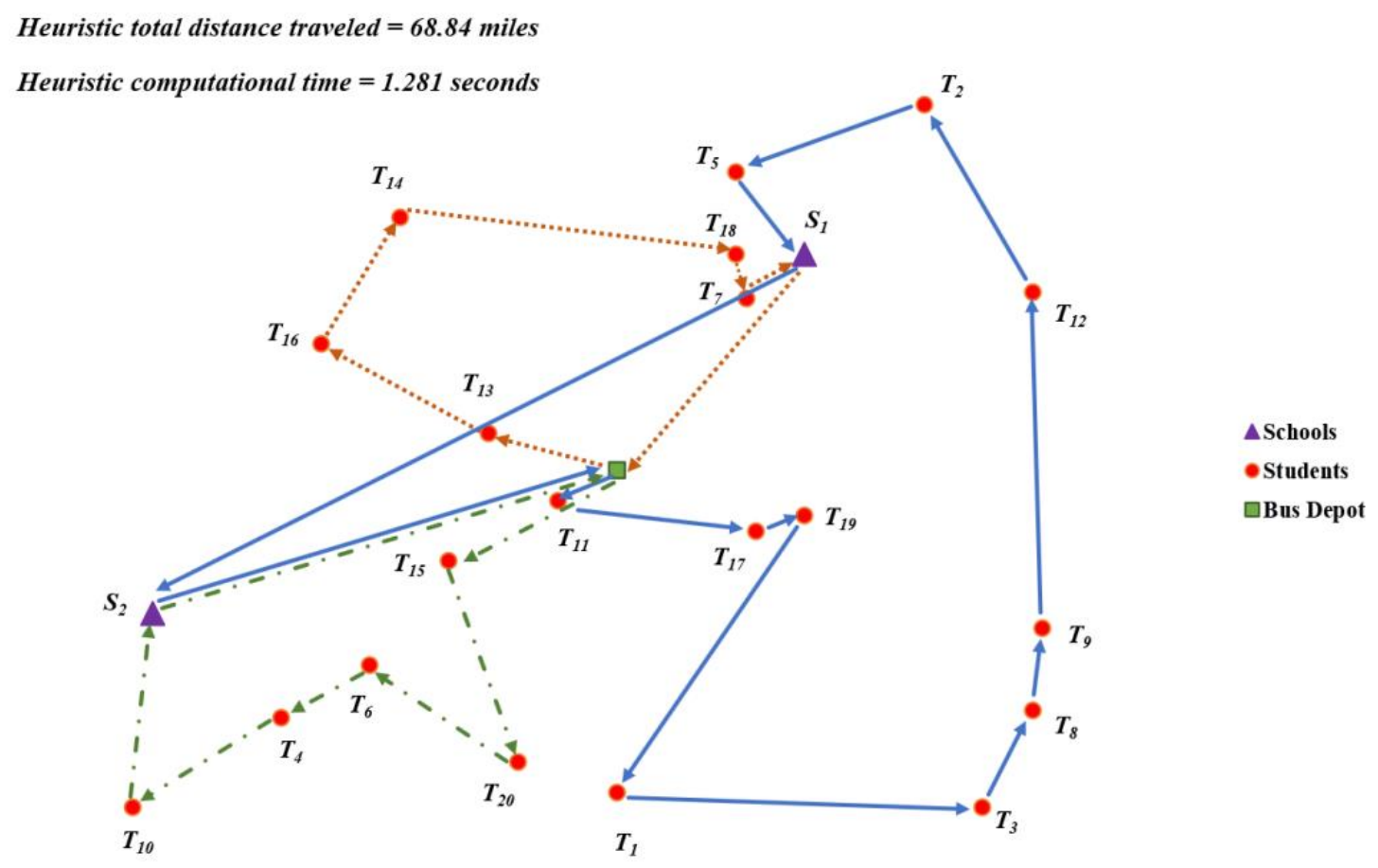

Figure 2 - Routes generated by CCARP algorithm for the numerical example

The routes generate for both optimum and heuristic solutions do not show what schools each student is assigned to, especially the routes of those buses that visit both schools. Therefore, the assignments are shown in Table 8 and Table 9 for the optimum assignment and the assignment generated by the heuristic approach; respectively. In the optimum solution, student $T_{11}$ is picked up by the second bus with students $\left\{T_{11}, T_{4}, T_{6}, T_{10}, T_{15}\right\}$ and student $T_{20}$ is to be picked up by the third bus with students $\left\{T_{1}, T_{2}, T_{3}, T_{5}, T_{8}, T_{9}, T_{12}, T_{17}, T_{19}\right\}$. However, these two students ( $T_{11}$ and $T_{20}$ ) are swapped in the solution generated by the CCARP heuristic. The differences in 
student to school assignments obtained from the two approaches are also underlined in these Tables.

Table 8 - Optimum assignment of students generated by Gurobi 9.1.0 for the numerical example

\begin{tabular}{|c|c|c|c|c|c|c|c|c|c|c|c|c|c|c|c|c|c|c|c|c|}
\hline & $T_{1}$ & $T_{2}$ & $T_{3}$ & $T_{4}$ & $T_{5}$ & $T_{6}$ & $T_{7}$ & $T_{8}$ & $T_{9}$ & $T_{10}$ & $T_{11}$ & $T_{12}$ & $T_{13}$ & $T_{14}$ & $T_{15}$ & $T_{16}$ & $T_{17}$ & $T_{18}$ & $T_{19}$ & $T_{20}$ \\
\hline Bus 1 & & & & & & & $S_{1}$ & & & & & & $S_{1}$ & $S_{1}$ & & $S_{1}$ & & $S_{1}$ & & \\
\hline Bus 2 & & & & $S_{2}$ & & $S_{2}$ & & & & $S_{2}$ & $S_{2}$ & & & & $S_{2}$ & & & & & \\
\hline Bus 3 & $\underline{S_{2}}$ & $\underline{S_{2}}$ & $S_{2}$ & & $S_{2}$ & & & $\underline{S_{1}}$ & $S_{2}$ & & & $\underline{S_{1}}$ & & & & & $S_{2}$ & & $S_{1}$ & $S_{2}$ \\
\hline
\end{tabular}

Table 9 - Assignment of students generated by the CCARP algorithm for the numerical example

\begin{tabular}{|l|l|l|l|l|l|l|l|l|l|l|l|l|l|l|l|l|l|l|l|l|}
\cline { 2 - 14 } \multicolumn{1}{l|}{} & $T_{1}$ & $T_{2}$ & $T_{3}$ & $T_{4}$ & $T_{5}$ & $T_{6}$ & $T_{7}$ & $T_{8}$ & $T_{9}$ & $T_{10}$ & $T_{11}$ & $T_{12}$ & $T_{13}$ & $T_{14}$ & $T_{15}$ & $T_{16}$ & $T_{17}$ & $T_{18}$ & $T_{19}$ & $T_{20}$ \\
\hline Bus 1 & & & & & & & $S_{1}$ & & & & & & $S_{1}$ & $S_{1}$ & & $S_{1}$ & & $S_{1}$ & & \\
\hline Bus 2 & & & & $S_{2}$ & & $S_{2}$ & & & & $S_{2}$ & & & & & $S_{2}$ & & & & & $S_{2}$ \\
\hline Bus 3 & $\underline{S_{1}}$ & $\underline{S_{1}}$ & $S_{2}$ & & $S_{2}$ & & & $\underline{S_{2}}$ & $S_{2}$ & & $S_{2}$ & $\underline{S_{2}}$ & & & & & $S_{2}$ & & $S_{1}$ & \\
\hline
\end{tabular}

The comparison of the computational times to obtain a solution from Gurobi (41.13 seconds) and the heuristic solution approach CCARP (1.281 seconds) on the numerical example shows that the quality of the solution does not get harmed much when using the heuristic approach and may not justify the additional computational time. In the next section, we develop an experimental design based on several parameters to evaluate and compare the performances of the model and the heuristic solution approach.

\subsection{Multi-Objective}

In this section, we consider multiple goals in our developed single objective model for practical considerations. The integrated multi-objective model in formulated such that it assigns students to schools and generate efficient routes while minimizing the number of buses and maximum ride distance for each individual as well as the total travel distance travel. 


\subsubsection{Mathematical Modeling}

The integrated multi-objective model is called Model III is nonlinear because of the nonlinear objective function that minimizes the maximum ride distance. Model IV is then presented which is the linear form of Model III.

\section{Model III - Multi-objective SSA-SBRP-SNS}

It is more practical to not solely consider minimizing the total travel distance as the objective function of the SSA-SBRP-SNS problem. A multi-objective SSA-SBRP-SNS called Model III is next developed in this section to address other concerns of the school officials as well as minimizing the total distance. Among several potential objectives in the literature, we selected minimization of the number of buses, and minimization of the maximum ride distance for each individual. To develop the beforementioned objective functions, additional variables, and parameters must be introduced to Model III.

\section{New Variables}

$\gamma_{k}=\left\{\begin{array}{rr}1 & \text { if bus } k \text { is used } \\ 0 & \text { Otherwise }\end{array}\right.$

$R D_{\text {qik }}=$ Ride distance of student $q$ up to node $i$ on the route of the $k^{\text {th }}$ bus

$f_{3}=$ maximum ride distance

\section{Model III}

$$
\operatorname{minimize}\left(f_{1}\right)=\sum_{i \in N} \sum_{j \in N} \sum_{k \in B} d_{i j} x_{i j k}+\frac{1}{M} \sum_{i \in N} \sum_{k \in B} w_{i k}
$$


$\operatorname{minimiz}\left(f_{2}\right)=\sum_{k \in B} \gamma_{k}$

$\operatorname{minimize}\left(f_{3}\right)=\max _{q \in T}\left\{\sum_{i \in S} \sum_{k \in B} R D_{q i k}\right\}$

S.T.

$\sum_{j \in S \cup T} \sum_{k \in B} x_{i j k}=1 \quad i \in T$

$\sum_{i \in D \cup T} \sum_{k \in B} x_{i j k}=1 \quad j \in T$

$\sum_{j \in S \cup T} x_{i j k}=y_{i k} \quad i \in T, k \in B$

$\sum_{j \in D \cup T} x_{j i k}=y_{i k} \quad i \in T, k \in B$

$\sum_{i \in D} \sum_{j \in T} x_{i j k}=\gamma_{k} \quad k \in B$

$\sum_{i \in S} \sum_{j \in D} x_{i j k}=\gamma_{k} \quad k \in B$

$\sum_{j \in D \cup S} x_{i j k}=z_{i k} \quad i \in S, k \in B$

$\sum_{j \in S \cup T} x_{j i k}=z_{i k} \quad i \in S, k \in B$

$x_{i i k}=0 \quad i \in N, k \in B$

$w_{i k}=\gamma_{k} \quad i \epsilon D, k \in B$

$w_{j k} \geq w_{i k}+1-n *\left(1-x_{i j k}\right) \quad i \in N, j \in S \cup T, j \neq i, k \in B$ 


$$
\begin{aligned}
& \sum_{j \in S} l_{i j}=1 \quad i \epsilon T \\
& \sum_{i \in T} l_{i j} g_{i m} \leq a_{j m} \quad j \in S, m \epsilon C \\
& V_{i j k}+z_{j k} \leq w_{j k} \quad i \epsilon T, j \epsilon S, k \in B \\
& V_{i j k} \leq M . l_{i j} \quad i \epsilon T, j \in S, k \in B \\
& V_{i j k} \leq w_{i k} \quad i \in T, j \in S, k \in B \\
& V_{i j k} \geq w_{i k}-\left(1-l_{i j}\right) * M \quad i \epsilon T, j \epsilon S, k \epsilon B \\
& \mu_{i j k} \leq z_{j k} \quad i \epsilon T, j \in S, k \in B \\
& \mu_{i j k} \leq l_{i j} \quad i \epsilon T, j \in S, k \in B \\
& \mu_{i j k} \leq y_{i k} \quad i \in T, j \in S, k \in B \\
& \mu_{i j k} \geq l_{i j}+y_{i k}-1 \quad i \epsilon T, j \epsilon S, k \in B \\
& \sum_{j \in T} y_{j k} \leq C_{k} \cdot \gamma_{k} \quad k \epsilon B \\
& R D_{q j k} \geq R D_{q i k}+d_{i j} \cdot y_{q k}-M\left(1-x_{i j k}\right) \quad q \epsilon T, i \epsilon T, j \epsilon S \cup T, j \neq i, q, k \epsilon B \\
& R D_{q j k} \geq R D_{q i k}+d_{i j} \cdot y_{q k}-M\left(1-x_{i j k}+l_{q i}\right) \quad q \epsilon T, i \in S, j \epsilon S, j \neq i, k \epsilon B \\
& R D_{q q k}=0 \quad q \epsilon T, \quad k \in B
\end{aligned}
$$

Objective function (54) minimizes the total travel distance as seen in Model I. Additional objective functions (55) and (56) minimize the number of vehicles, and minimize the maximum 
ride distance for any student; respectively. Constraints (57)-(78) are all previously defined in Model I and Model II which will be used in Model III with no changes. The only changes are in constrains (61) and (62) that ensure a bus leaves the depot and picks up a student only if it is supposed to be used in the network. In previous models however, an equal to 1 in constraints (6) and (7) in Model I, and (31) and (32) in Model II forces all the existing buses to be used in the routing problem. This is one of the advantages of using Model III over the previous versions because it gives the school administrators more flexibility in deciding and planning. Constraint (66) is another discrepancy between this model and both Models I and II. This set of constraint assures that the bus starts its trip from the depot if it is supposed to be utilized. Constraint set (78) make sure the capacity of the bus is not violated at any time if the bus is being used in the network. Constraints (79), (80), and (81) are used to correctly update ride distance of any student at any node on each bus. Lastly, constraint set (81) ensures that the ride distance of any student is set to be initially 0 so the update process in the above constraints is correctly implemented. This model is nonlinear due to the fact that objective function (56) which is minimization of maximum ride distance is nonlinear. Therefore, this model will be linearized for better solvability in the next section.

\section{Model IV - Linearized Multi-objective SSA-SBRP-SNS}

Model III is a nonlinear multi-objective model because the decision variable $f_{3}$ is calculated using a nonlinear term shown in equation (56). Therefore, an additional variable should be introduced for linearization of this equation. The new model called Model IV which is the linear form of multi-objective SSA-SBRP-SNS is presented in this section. Goal programming is 
adopted to formulate Model IV. The new variable $R_{q j k}$ shows the miles that student $q$ is on bus $k$ until he/she is dropped at his/her designated school $j$. Therefore, this variable contains significant amount of information including the school and bus assignments for each student as well as the individual's ride distance.

\section{New Variable}

$R_{q j k}=$ Ride distance of student $q$ at his/her designated school $j$ on bus $k$

To formulate the problem using goal programming, a set of goals must be defined for all objective functions in Model III. Three goals $G_{1}, G_{2}$, and $G_{3}$ are defined and shown in equations (84) through (86) for the first (total miles), second (number of busses), and third (maximum ride distance) objectives; respectively. The relationship between the newly defined and previous variables is shown in equation (82) which must be added an a constraint to Model III. Because we have already defined the variable $\mu_{q i k}=l_{q i} \cdot y_{q k}$ in section 3.1, the multiplication of three decision variables can still be reduced to multiplication of two decision variables.

$$
R_{q i k}=R D_{q i k} \cdot l_{q i} \cdot y_{q k}=R D_{q i k} \cdot \mu_{q i k}
$$

This equation will force the variable $R_{q i k}$ to record the ride distance of student $q$ at school $i$ on bus $k$ only if student $q$ is assigned to school $i$ (meaning that $l_{q i}=1$ ), and student $q$ is picked up by bus $k$ (meaning that $y_{q k}=1$ ). In other words, $R_{q j k}=0$ means that student $q$ is not assigned to school $j$ and bus $k$ at the same time. 


$$
R_{q j k}= \begin{cases}R D_{q j k} & \text { if } l_{q j}=1 \text { and } y_{q k}=1 \\ 0 & \text { if } l_{q j}=o \text { or } y_{q k}=0\end{cases}
$$

\section{New Parameters}

$G_{1}$ : Goal for objective 1 that minimizes the total travel distance

$$
f_{1}=\sum_{i \in N} \sum_{j \in N} \sum_{k \in B} d_{i j} x_{i j k}+\frac{1}{M} \sum_{i \in N} \sum_{k \in B} w_{i k} \leq G_{1}
$$

$G_{2}$ : Goal for objective 2 that minimizes the number of buses

$$
f_{2}=\sum_{k \in B} \gamma_{k} \leq G_{2}
$$

$G_{3}$ : Goal for objective 3 that minimizes the maximum ride distance

$$
f_{3}=\max _{q \in T}\left\{\sum_{i \in S} \sum_{k \in B} R D_{q i k}\right\} \leq G_{3}
$$

$\omega_{i}$ : Weight associated with objective $i$ (penalty for a unit of deviation from goal $i$ )

$\delta_{i}$ : The deviation between the value of objective $i$ and its defined goal $\left(G_{i}\right)$

\section{Model IV}

minimize $\omega_{1} \delta_{1}+\omega_{2} \delta_{2}+\omega_{3} \delta_{3}$

S.T.

$$
\sum_{i \in N} \sum_{j \in N} \sum_{k \in B} d_{i j} x_{i j k}+\frac{1}{M} \sum_{i \in N} \sum_{k \in B} w_{i k}-\delta_{1}=G_{1}
$$




$$
\begin{aligned}
& \sum_{k \in B} \gamma_{k}-\delta_{2}=G_{2} \\
& f_{3}-\delta_{3}=G_{3} \\
& \sum_{j \in S \cup T} \sum_{k \in B} x_{i j k}=1 \quad i \in T \\
& \sum_{i \in D \cup T} \sum_{k \in B} x_{i j k}=1 \quad j \in T \\
& \sum_{j \in S \cup T} x_{i j k}=y_{i k} \quad i \in T, k \in B \\
& \sum_{j \in D \cup T} x_{j i k}=y_{i k} \quad i \in T, k \epsilon B \\
& \sum_{i \in D} \sum_{j \in T} x_{i j k}=\gamma_{k} \quad k \in B \\
& \sum_{i \in S} \sum_{j \in D} x_{i j k}=\gamma_{k} \quad k \in B \\
& \sum_{j \in D \cup S} x_{i j k}=z_{i k} \quad i \in S, k \in B \\
& \sum_{j \in S \cup T} x_{j i k}=z_{i k} \quad i \in S, k \in B \\
& x_{i i k}=0 \quad i \in N, k \in B \\
& w_{i k}=\gamma_{k} \quad i \epsilon D, k \in B \\
& w_{j k} \geq w_{i k}+1-n *\left(1-x_{i j k}\right) \quad i \in N, j \in S \cup T, j \neq i, k \in B \\
& \sum_{j \in S} l_{i j}=1 \quad i \epsilon T
\end{aligned}
$$




$$
\begin{aligned}
& \sum_{i \in T} l_{i j} g_{i m} \leq a_{j m} \quad j \in S, m \in C \\
& V_{i j k}+z_{j k} \leq w_{j k} \quad i \epsilon T, j \in S, k \in B \\
& V_{i j k} \leq M . l_{i j} \quad i \epsilon T, j \in S, k \epsilon B \\
& V_{i j k} \leq w_{i k} \quad i \epsilon T, j \in S, k \in B \\
& V_{i j k} \geq w_{i k}-\left(1-l_{i j}\right) * M \quad i \in T, j \in S, k \in B \\
& \mu_{i j k} \leq z_{j k} \quad i \epsilon T, j \in S, k \in B \\
& \mu_{i j k} \leq l_{i j} \quad i \in T, j \in S, k \in B \\
& \mu_{i j k} \leq y_{i k} \quad i \epsilon T, j \in S, k \in B \\
& \mu_{i j k} \geq l_{i j}+y_{i k}-1 \quad i \epsilon T, j \in S, k \in B \\
& \sum_{j \in T} y_{j k} \leq C_{k} \cdot \gamma_{k} \quad k \in B \\
& R D_{q j k} \geq R D_{q i k}+d_{i j} y_{q k}-M\left(1-x_{i j k}\right) \quad i \epsilon T, q \epsilon T, j \epsilon S \cup T, j \neq i, q, k \epsilon B \\
& R D_{q j k} \geq R D_{q i k}+d_{i j} y_{q k}-M\left(1-x_{i j k}+l_{q i}\right) \quad q \epsilon T, i \epsilon S, j \epsilon S, j \neq i, k \epsilon B \\
& R D_{q q k}=0 \quad q \epsilon T, \quad k \in B \\
& R_{q i k} \leq M . \mu_{q i k} \quad q \epsilon T, i \epsilon S, k \in B \\
& R_{q i k} \leq R D_{q i k} \quad q \in T, i \in S, k \in B \\
& R_{q i k} \geq R D_{q i k}-M\left(1-\mu_{q i k}\right) \quad q \epsilon T, i \epsilon S, k \in B
\end{aligned}
$$




$$
\sum_{j \in S} \sum_{k \in B} R D_{q j k} \leq f_{3} \quad q \epsilon T
$$

Objective function (87) minimizes the total deviation from the goals with pre-assigned weights for each goal. Constraints (88), (89), and (90) calculate the deviations between the aspiration levels and the actual value of each objective function. These deviations are to be minimized in the goal programming objective (87). Constraints (91)-(115) are defined similar to Model I. Constraints (116) - (118) are the linear constraints that replace the nonlinear set of constraints (82). Finally, constraint (119) is introduced to linearize the nonlinear objective function (86). Other constraints are not described in this section as they have already been described in page 18 where Model I is first described.

\subsubsection{Validation}

The model developed in section 3.2.1 also called Model IV has a number of parameters that need to be smartly selected. The goals for all three objective functions $\left(G_{1}, G_{2}, G_{3}\right)$ are the main parameters that have to be determined before solving Model IV.

In order to obtain acceptable goals, we solve single objective models three times for each case considering first, second, and third objectives presented by equations (84), (85), and (86); respectively. We consider the optimum value for the objective function as the goal for that objective. To clarify, three single objective models are solved one at a time and the optimum value is recorded as the goal because the value of objectives in the multi-objective model cannot get any better than the optimum of the single objective models. We use $f_{1}^{*}, f_{2}^{*}$, and $f_{3}^{*}$ to represent the optimum values obtained for the first (minimize total traveled distance), second (minimize number of buses), and third objectives (minimize the maximum ride distance); respectively. 


\begin{tabular}{ccc}
$G_{1}=f_{1}^{*}$ & $G_{2}=f_{2}^{*}$ & $G_{3}=f_{3}^{*}$ \\
\hline Minimize $f_{1}$ & Minimize $f_{2}$ & Minimize $f_{3}$ \\
S.T. & S.T. & S.T. \\
$(91)-(119)$ & $(91)-(119)$ & $(91)-(119)$
\end{tabular}

The first two models quickly solve to optimality for most of the random cases; however, the third single objective model that minimizes the maximum ride distance takes quite long to solve. Therefore, we put a set of stopping criteria to make sure we obtain an acceptable upper bound for the third goal in a shorter amount of time if needed. This model either stops at 600 seconds or if it reached to the optimality gap of $90 \%$. Once the goals (upper bounds) for three objectives are defined, we solve the GP model for each case using the obtained goals $\left(f_{1}^{*}, f_{2}^{*}\right.$, and $\left.f_{3}^{*}\right)$. The largest instance that is solvable in a two-hour time limit is an example with 16 nodes (12 students, 4 schools). 
Table 10 - Goal Programming model validation using randomly generated instances

\begin{tabular}{|c|c|c|c|c|c|c|c|c|c|c|c|}
\hline & \multicolumn{4}{|c|}{ Parameters } & \multicolumn{3}{|c|}{ Single Objective } & \multicolumn{4}{|c|}{ Goal Programming } \\
\hline Case \# & Student & School & Bus & Class type & $\mathrm{f}^{*}{ }_{1}$ & $\mathrm{f}_{2}^{*}$ & $\mathrm{f}_{3}^{*}$ & $\mathrm{f}_{1}$ & $\mathrm{f}_{2}$ & $\mathrm{f}_{3}$ & $\begin{array}{c}\text { Computational } \\
\text { Time (s) }\end{array}$ \\
\hline case 1 & 2 & 2 & 2 & 2 & 27.13 & 1 & 5.02 & 27.14 & 2 & 5.02 & 0.058 \\
\hline case 2 & 4 & 2 & 2 & 2 & 23 & 1 & 12.26 & 22.99 & 1 & 13.67 & 0.153 \\
\hline case 3 & 5 & 2 & 2 & 2 & 29.51 & 1 & 10.18 & 34.43 & 2 & 10.18 & 0.658 \\
\hline case 4 & 5 & 3 & 2 & 2 & 32.39 & 1 & 9.53 & 38.01 & 2 & 9.53 & 0.806 \\
\hline case 5 & 6 & 2 & 2 & 2 & 32.64 & 1 & 16.83 & 33.27 & 1 & 20.48 & 0.607 \\
\hline case 6 & 6 & 2 & 3 & 2 & 32.64 & 1 & 14.21 & 33.27 & 1 & 20.48 & 1.749 \\
\hline case 7 & 7 & 2 & 2 & 2 & 32 & 1 & 10.37 & 35.99 & 2 & 10.37 & 0.931 \\
\hline case 8 & 7 & 3 & 2 & 2 & 30.68 & 1 & 9.87 & 35.51 & 2 & 11.41 & 52.25 \\
\hline case 9 & 8 & 2 & 2 & 2 & 29.44 & 1 & 10.22 & 33.19 & 2 & 10.22 & 1.674 \\
\hline case 10 & 8 & 3 & 2 & 2 & 33.7 & 1 & 11.94 & 33.69 & 2 & 11.93 & 2.55 \\
\hline case 11 & 8 & 3 & 3 & 2 & 33.7 & 1 & 6.69 & 33.69 & 2 & 11.77 & 4.185 \\
\hline case 12 & 9 & 3 & 2 & 2 & 35.99 & 1 & 11.11 & 36.98 & 2 & 11.46 & 4.246 \\
\hline case 13 & 10 & 3 & 2 & 2 & 32.27 & 1 & 14.88 & 33.98 & 2 & 14.82 & 5.296 \\
\hline case 14 & 10 & 3 & 3 & 2 & 32.27 & 1 & 14.82 & 33.98 & 2 & 14.82 & 220.852 \\
\hline case 15 & 10 & 3 & 3 & 3 & 37.28 & 1 & 11.71 & 44.37 & 2 & 12.92 & 1269.517 \\
\hline case 16 & 10 & 4 & 3 & 2 & 36.17 & 2 & 9.05 & 36.17 & 2 & 11.07 & 1212.812 \\
\hline case 17 & 11 & 4 & 2 & 2 & 37.98 & 1 & 19.55 & 40.89 & 2 & 19.55 & 151.05 \\
\hline case 18 & 11 & 4 & 3 & 2 & 39.98 & 1 & 11.5 & 43.78 & 3 & 10.88 & 3659.62 \\
\hline case 19 & 12 & 3 & 2 & 2 & 36.88 & 1 & 20.25 & 38.8 & 2 & 20.65 & 444.275 \\
\hline case 20 & 12 & 4 & 2 & 2 & 43.32 & 1 & 18.85 & 43.32 & 2 & 15.46 & 299.825 \\
\hline
\end{tabular}

In this method, it takes quite a long time to solve the third objective function that minimizes the maximum ride distance which determines the goal related to the third objective function in goal programming model. Therefore, we perform another experiment in which a value of 0 is used as the goal of all three objectives. The computational time to solve goal programming using goals of 0 decrease significantly and we believe that this is because the model does not have to try hard to achieve the non-zero goal that is calculated using a formula. We design 20 different cases starting from 4 nodes ( 2 students and 2 schools) to 16 nodes (12 students and 4 schools). We generate 10 random instances for each of these cases by generating random uniformly distributed locations for students and schools. Obviously, the ride distance from the single objective model is 
greater than or equal to the ride distance from the multi-objective model because the goal programming model focuses on minimizing it in the multi-objective model. Therefore, a saving on each run is defined by subtracting the ride distance obtained from the single objective from the ride distance obtained from the single objective model and divide the deviation by the ride distance from the single objective model. Table 11 shows these savings for all ten different random instances for each case along with the size of the problem in each case.

Table 11 - Maximum ride distance savings when comparing multi-objective and single objective models

\begin{tabular}{|c|c|c|c|c|c|}
\hline Case Number & Student & School & Bus & Class type & $\begin{array}{c}\text { Average Savings } \\
\text { on 10 runs }\end{array}$ \\
\hline Case 1 & 2 & 2 & 2 & 2 & $4 \%$ \\
\hline Case 2 & 4 & 2 & 2 & 2 & $12 \%$ \\
\hline Case 3 & 5 & 2 & 2 & 2 & $12 \%$ \\
\hline Case 4 & 5 & 3 & 2 & 2 & $15 \%$ \\
\hline Case 5 & 6 & 2 & 2 & 2 & $18 \%$ \\
\hline Case 6 & 6 & 2 & 3 & 2 & $14 \%$ \\
\hline Case 7 & 7 & 2 & 2 & 2 & $8 \%$ \\
\hline Case 8 & 7 & 3 & 2 & 2 & $15 \%$ \\
\hline Case 9 & 8 & 2 & 2 & 2 & $23 \%$ \\
\hline Case 10 & 8 & 3 & 2 & 2 & $27 \%$ \\
\hline Case 11 & 8 & 3 & 3 & 2 & $29 \%$ \\
\hline Case 12 & 9 & 3 & 2 & 2 & $28 \%$ \\
\hline Case 13 & 10 & 3 & 2 & 2 & $22 \%$ \\
\hline Case 14 & 10 & 3 & 3 & 2 & $16 \%$ \\
\hline Case 15 & 10 & 3 & 3 & 3 & $22 \%$ \\
\hline Case 16 & 10 & 4 & 3 & 2 & $27 \%$ \\
\hline Case 17 & 11 & 4 & 2 & 2 & $28 \%$ \\
\hline Case 18 & 11 & 4 & 3 & 2 & $29 \%$ \\
\hline Case 19 & 12 & 3 & 2 & 2 & $39 \%$ \\
\hline Case 20 & 12 & 4 & 2 & 2 & $28 \%$ \\
\hline
\end{tabular}

These savings are also shown in Figure 3 which also indicates an increasing trend on the saving as the problem size grows. Therefore, it verifies that considering minimization of the maximum ride distance as an objective function in the model significantly help special needs students to have 
a lower ride distance which results in a lower ride time even though the total miles driven by buses is sacrificed.

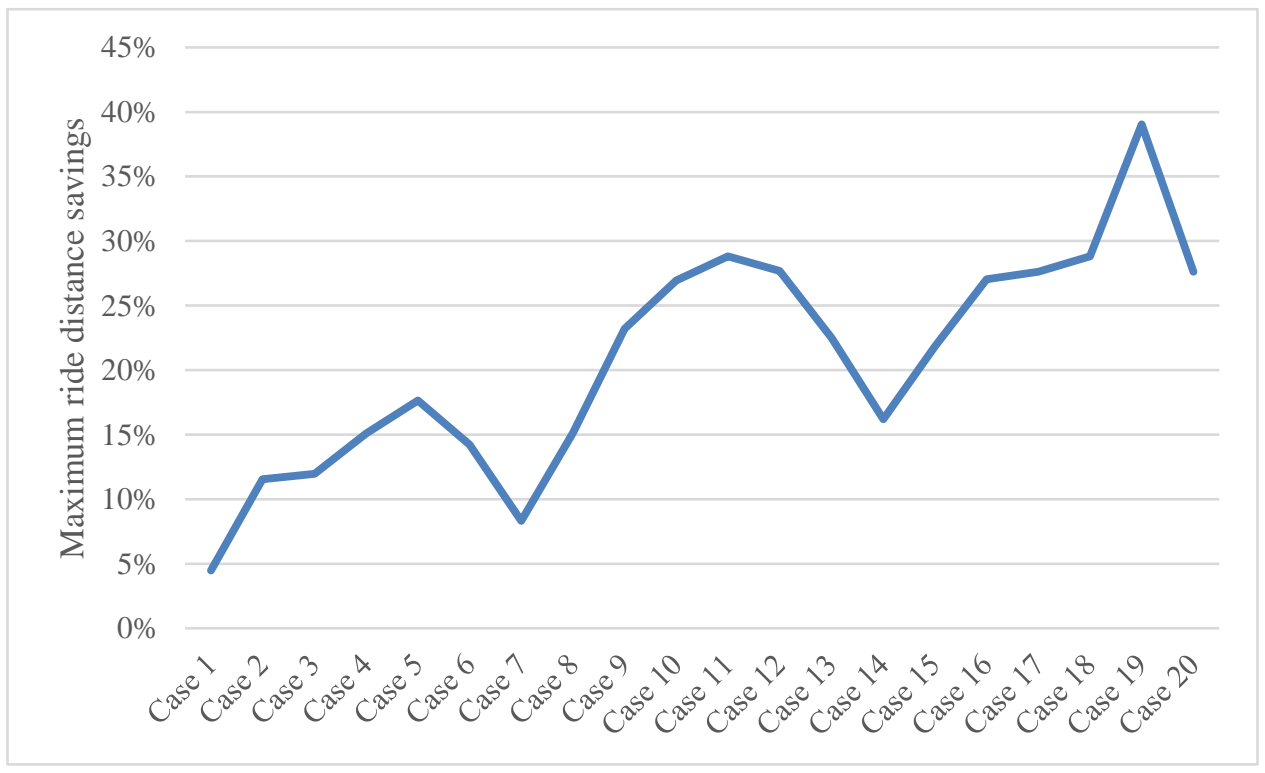

Figure 3 - Maximum Ride Distance savings

\subsubsection{Numerical Example}

To illustrate, the same numerical example for the single objective model described in section 3.1.4 is used for the multi-objective model and compared with the result of the single objective model. The optimum total travel distance obtained by Gurobi for the numerical example is 65.74 miles for the single objective model. In the post process analysis, the ride distance for each student is calculated and shown in Figure 4. The maximum ride distance is this case is calculated to be 30.54 miles without considering that as an objective function. 


\section{Single Objective}

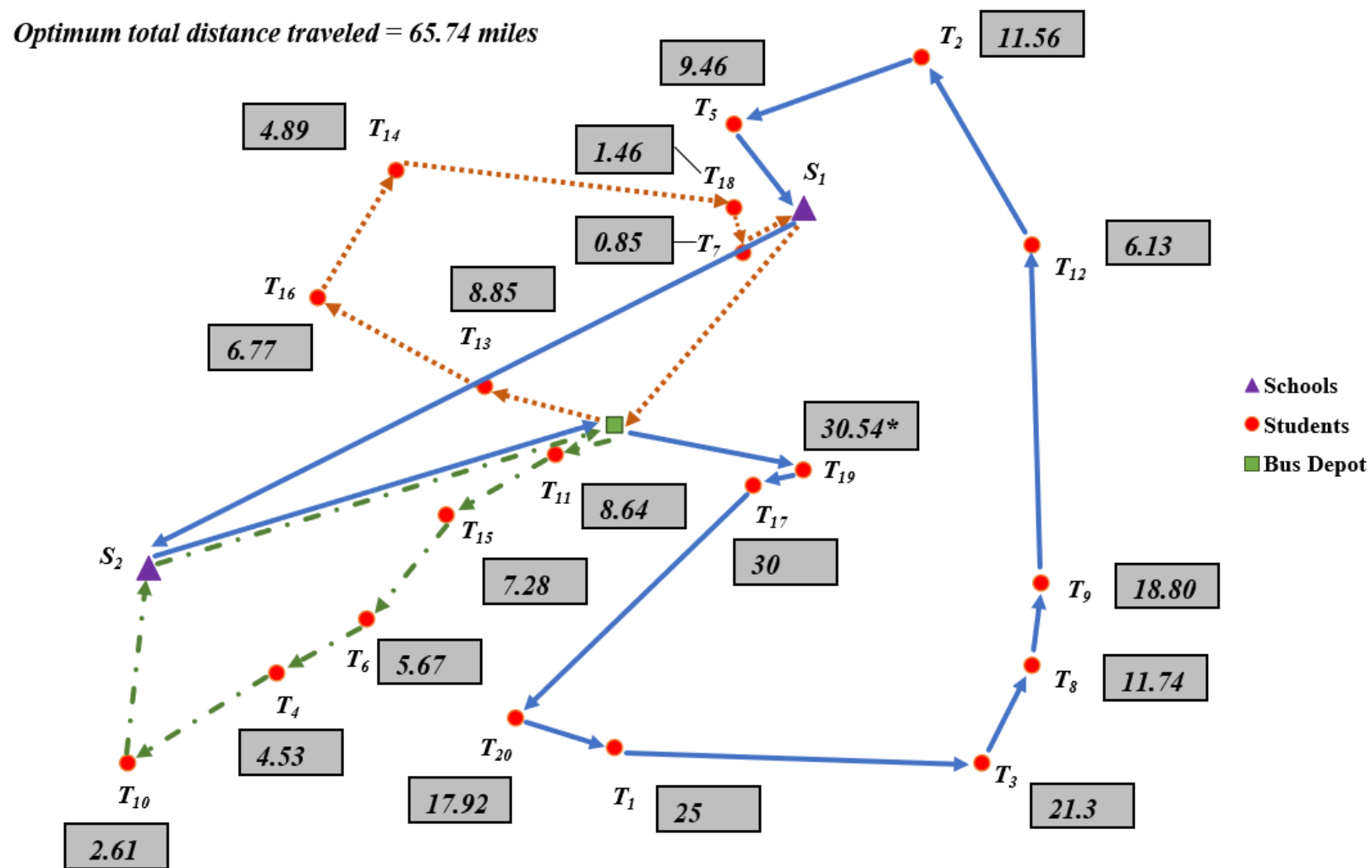

Figure 4 - Ride distances calculated for the optimum solution obtained from Model II using the numerical example

Based on the results of the goal programing model validation, this example is too large to be solved to optimality in a multi-objective setting. However, it can generate a solution within a specific time limit. We consider a one-hour time limit for this example. The total travel distance in this case is 66.65 miles which is $1.48 \%$ worse than the best total distance possible, however the maximum ride distance obtained from the goal programing model shown in Figure 5 belongs to student $T_{17}$ which is 20.53 miles whereas 30.54 miles in the single objective model. 


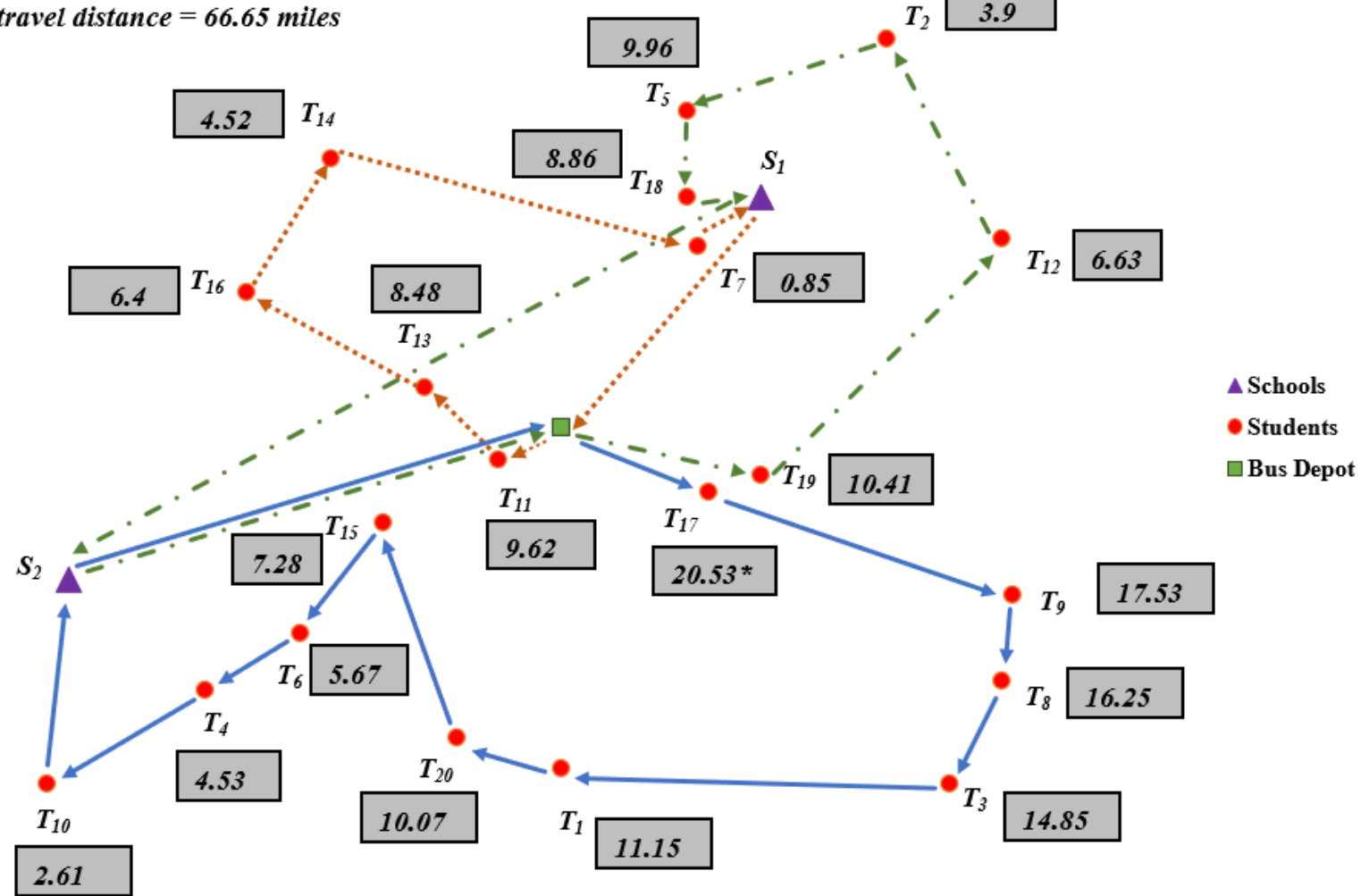

Figure 5 - Solution obtained from Goal Programming model in the 1-hour time limit using the numerical example

The student to school and school to bus assignments are shown and compared in Table 12 for both the single objective and multi-objective models. The ride distances are calculated for Model II after the optimum is obtained however, the ride distances for the multi-objective model are decision variables in Model IV obtained by Gurobi. 
Table 12 - Assignments obtained from Model II and Model IV for the numerical example

\begin{tabular}{|c|c|c|c|c|c|c|}
\cline { 2 - 7 } \multicolumn{1}{c|}{} & \multicolumn{3}{c|}{$\begin{array}{c}\text { Single Objective } \\
\text { (Model II) }\end{array}$} & \multicolumn{3}{c|}{$\begin{array}{c}\text { Multi-Objective } \\
\text { (Model IV) }\end{array}$} \\
\cline { 2 - 7 } \multicolumn{1}{c|}{} & Bus & School & $\begin{array}{c}\text { Ride Distance } \\
\text { (mile) }\end{array}$ & Bus & School & $\begin{array}{c}\text { Ride Distance } \\
\text { (mile) }\end{array}$ \\
\hline $\mathrm{T}_{1}$ & $\mathrm{~B}_{3}$ & $\mathrm{~S}_{2}$ & 25 & $\mathrm{~B}_{3}$ & $\mathrm{~S}_{2}$ & 11.15 \\
\hline $\mathrm{T}_{2}$ & $\mathrm{~B}_{3}$ & $\mathrm{~S}_{2}$ & 11.56 & $\mathrm{~B}_{1}$ & $\mathrm{~S}_{1}$ & 3.9 \\
\hline $\mathrm{T}_{3}$ & $\mathrm{~B}_{3}$ & $\mathrm{~S}_{2}$ & 21.3 & $\mathrm{~B}_{3}$ & $\mathrm{~S}_{2}$ & 14.85 \\
\hline $\mathrm{T}_{4}$ & $\mathrm{~B}_{1}$ & $\mathrm{~S}_{2}$ & 4.53 & $\mathrm{~B}_{3}$ & $\mathrm{~S}_{2}$ & 4.53 \\
\hline $\mathrm{T}_{5}$ & $\mathrm{~B}_{3}$ & $\mathrm{~S}_{2}$ & 9.46 & $\mathrm{~B}_{1}$ & $\mathrm{~S}_{2}$ & 9.96 \\
\hline $\mathrm{T}_{6}$ & $\mathrm{~B}_{1}$ & $\mathrm{~S}_{2}$ & 5.67 & $\mathrm{~B}_{3}$ & $\mathrm{~S}_{2}$ & 5.67 \\
\hline $\mathrm{T}_{7}$ & $\mathrm{~B}_{2}$ & $\mathrm{~S}_{1}$ & 0.85 & $\mathrm{~B}_{2}$ & $\mathrm{~S}_{1}$ & 0.85 \\
\hline $\mathrm{T}_{8}$ & $\mathrm{~B}_{3}$ & $\mathrm{~S}_{1}$ & 11.74 & $\mathrm{~B}_{3}$ & $\mathrm{~S}_{2}$ & 16.25 \\
\hline $\mathrm{T}_{9}$ & $\mathrm{~B}_{3}$ & $\mathrm{~S}_{2}$ & 18.8 & $\mathrm{~B}_{3}$ & $\mathrm{~S}_{2}$ & 17.53 \\
\hline $\mathrm{T}_{10}$ & $\mathrm{~B}_{1}$ & $\mathrm{~S}_{2}$ & 2.61 & $\mathrm{~B}_{3}$ & $\mathrm{~S}_{2}$ & 2.61 \\
\hline $\mathrm{T}_{11}$ & $\mathrm{~B}_{1}$ & $\mathrm{~S}_{2}$ & 8.64 & $\mathrm{~B}_{2}$ & $\mathrm{~S}_{1}$ & 9.62 \\
\hline $\mathrm{T}_{12}$ & $\mathrm{~B}_{3}$ & $\mathrm{~S}_{1}$ & 6.13 & $\mathrm{~B}_{1}$ & $\mathrm{~S}_{1}$ & 6.63 \\
\hline $\mathrm{T}_{13}$ & $\mathrm{~B}_{2}$ & $\mathrm{~S}_{1}$ & 8.85 & $\mathrm{~B}_{2}$ & $\mathrm{~S}_{1}$ & 8.48 \\
\hline $\mathrm{T}_{14}$ & $\mathrm{~B}_{2}$ & $\mathrm{~S}_{1}$ & 4.89 & $\mathrm{~B}_{2}$ & $\mathrm{~S}_{1}$ & 4.52 \\
\hline $\mathrm{T}_{15}$ & $\mathrm{~B}_{1}$ & $\mathrm{~S}_{2}$ & 7.28 & $\mathrm{~B}_{3}$ & $\mathrm{~S}_{2}$ & 7.28 \\
\hline $\mathrm{T}_{16}$ & $\mathrm{~B}_{2}$ & $\mathrm{~S}_{1}$ & 6.77 & $\mathrm{~B}_{2}$ & $\mathrm{~S}_{1}$ & 6.4 \\
\hline $\mathrm{T}_{17}$ & $\mathrm{~B}_{3}$ & $\mathrm{~S}_{2}$ & 30 & $\mathrm{~B}_{3}$ & $\mathrm{~S}_{2}$ & 20.53 \\
\hline $\mathrm{T}_{18}$ & $\mathrm{~B}_{2}$ & $\mathrm{~S}_{1}$ & 1.46 & $\mathrm{~B}_{1}$ & $\mathrm{~S}_{2}$ & 8.86 \\
\hline $\mathrm{T}_{19}$ & $\mathrm{~B}_{3}$ & $\mathrm{~S}_{2}$ & 30.54 & $\mathrm{~B}_{1}$ & $\mathrm{~S}_{1}$ & 10.41 \\
\hline $\mathrm{T}_{20}$ & $\mathrm{~B}_{3}$ & $\mathrm{~S}_{1}$ & 17.92 & $\mathrm{~B}_{3}$ & $\mathrm{~S}_{2}$ & 10.07 \\
\hline
\end{tabular}

The solution obtained from Model II results in lower total distance (65.74 miles) compared to that obtained from Model IV (66.65 miles) because the focus of Model II is to minimize this objective function. Student T19 is picked up by bus 3 and is on the bus for 30.54 miles that makes it the maximum ride distance. However, the maximum ride distance for this example when Model IV is solved is 20.53 for student T17 on bus 3 as minimizing the maximum ride distance is one of the objectives in the goal programming model. The average ride distances calculated based on these ride distances provided in Table 12 are 11.7 miles and 9.01 miles for Model II and Model 
IV; respectively. Therefore, it can be concluded that the average ride distances reduced by almost $30 \%$ when minimizing the maximum ride distance is also considered as an objective function in SSA-SBRP-SNS model. 


\section{Chapter 4: Case Study}

In this chapter, we apply Model II and the developed heuristic solution approach and to a real-world case study and evaluate the performance of both. The cases presented in this work are carried out on a system with an Intel Core i7 processor with eight $2.70 \mathrm{GHz}$ cores and $16 \mathrm{GBs}$ of RAM. Model II and the CCARP algorithm are coded in Python 3 and solved using Gurobi Optimizer version 9.1.0. We assume three class types (service levels) for the special needs students in all of our instances in this work.

\subsection{Case Study Description}

Now that the performance of the model and CCARP heuristic approach is evaluated, we use a real-world case study in Fort Smith School Public School (FSPS) located at the state of Arkansas. We pick the same case study Kamali, Mason [43] use to be able to make a fair comparison. Overall, there are 111 special needs students in the school district that are to be assigned to 9 schools. These students consist of 19, 33, and 59 special needs students at junior high school, senior high school, and elementary school; respectively. Among these 9 schools, 2 schools are junior high school, 2 are senior high school, and 5 are elementary schools.

There are three types of service available to students based on their needs, the schools with teacher-to-student ratios of 1:6, 1:10, and 1:15 meaning that for each teacher there should be 6,10 , or 15 students exist; respectively. The students are assigned to these classes depending on how severe their needs are. For each school level, there are 4 different cases by changing the number of buses. For example, for junior high school with 19 students, the scenarios are generated by 
varying number of buses from 1 to 4 with 20 available seats each. We therefore use the same parameters and to be able to compare the results case by case with the literature.

\subsection{Single Objective}

\subsubsection{Results}

The computational time and the objective function values when solving Model II using Gurobi and CCARP are compared with the results of the model developed by Kamali, Mason [43] and are shown in Table 13. The time to solve the larger cases to optimality increases significantly which is an indicator of a definite need for developing a heuristic solution approach. The largest case we solve in this study has 59 students and 5 schools (Elementary school cases). However, there might be larger network in other school district areas, therefore, it would be very helpful to develop a heuristic approach that performs well on smaller cases.

Table 13 - Comparison of the results and performances of CCARP and IH2 developed by Kamali, Mason [43]

\begin{tabular}{|c|c|c|c|c|c|c|c|c|c|c|}
\hline \multirow[b]{2}{*}{$\begin{array}{c}\text { School } \\
\text { Level }\end{array}$} & \multirow[b]{2}{*}{$\begin{array}{l}\text { Number } \\
\text { of Buses }\end{array}$} & \multirow[b]{2}{*}{ Scenario } & \multicolumn{3}{|c|}{ Total Distance (miles) } & \multicolumn{3}{|c|}{ Computational Time (seconds) } & \multicolumn{2}{|c|}{ Performance Ratio } \\
\hline & & & Optimum & IH2 & CCARP & Optimum & IH2 & CCARP & $\mathrm{IH} 2$ & CCARP \\
\hline \multirow{4}{*}{$\begin{array}{c}\text { Junior } \\
\text { High } \\
\text { School }\end{array}$} & 1 & JH1 & 36.4 & 47 & 36.4 & 0.42 & $<2$ & 1.36 & 1.29 & 1 \\
\hline & 2 & $\mathrm{JH} 2$ & 33.4 & 40.4 & 33.4 & 5.89 & $<2$ & 1.24 & 1.21 & 1 \\
\hline & 3 & JH3 & 32.5 & 44 & 33.2 & 13.67 & $<2$ & 1.11 & 1.35 & 1.02 \\
\hline & 4 & $\mathrm{JH} 4$ & 33.2 & 44.3 & 33.4 & 30.22 & $<2$ & 0.73 & 1.33 & 1.01 \\
\hline \multirow{4}{*}{$\begin{array}{c}\text { Senior } \\
\text { High } \\
\text { School }\end{array}$} & 2 & SH1 & 41.2 & 48.2 & 42.6 & 91.2 & $<2$ & 5.35 & 1.17 & 1.03 \\
\hline & 3 & $\mathrm{SH} 2$ & 39.8 & 50.4 & 42.6 & 59.07 & $<2$ & 5.27 & 1.27 & 1.07 \\
\hline & 4 & SH3 & 39.4 & 64.6 & 43.9 & 114.04 & $<2$ & 2.96 & 1.64 & 1.11 \\
\hline & 5 & SH4 & 39.7 & 51.8 & 44.6 & 125.89 & $<2$ & 1.43 & 1.30 & 1.12 \\
\hline \multirow{4}{*}{$\begin{array}{c}\text { Elementary } \\
\text { School }\end{array}$} & 3 & E1 & 46.97 & 70.6 & 48.97 & 121,398 & $<2$ & 22.27 & 1.50 & 1.04 \\
\hline & 4 & $\mathrm{E} 2$ & 45.97 & 74.9 & 54.67 & 186,043 & $<2$ & 12.54 & 1.63 & 1.19 \\
\hline & 5 & E3 & 45.67 & 74.7 & 51.27 & 132,768 & $<2$ & 9.73 & 1.64 & 1.12 \\
\hline & 6 & $\mathrm{E} 4$ & 45.57 & 80.1 & 52.37 & 199,249 & $<2$ & 10.64 & 1.76 & 1.15 \\
\hline
\end{tabular}


IH2 is the best heuristic available in the literature [43] that was applied to the same FSPS case study. So, we use that result to compare with the result of our developed heuristic approach on the same case study to be able to compare. It takes longer to run CCARP compared to IH2 on each case which might be because of multiple iterations we use for CCARP but the objective function values we get from CCARP are significantly better and therefore the performance ratios are superior.

We use the optimum values for the total distance we obtain from Gurobi to recalculate the performance ratios of $\mathrm{IH} 2$ instead of using their calculated performance ratios. With doing that, it makes more sense to compare the performance ratios between IH2 and CCARP as the denominator of both ratios are exactly the same for each scenario. The comparison between the performance ratios shown in Table 13 indicates that CCARP outperforms IH2 which is the best previously developed heuristic approach on this data set.

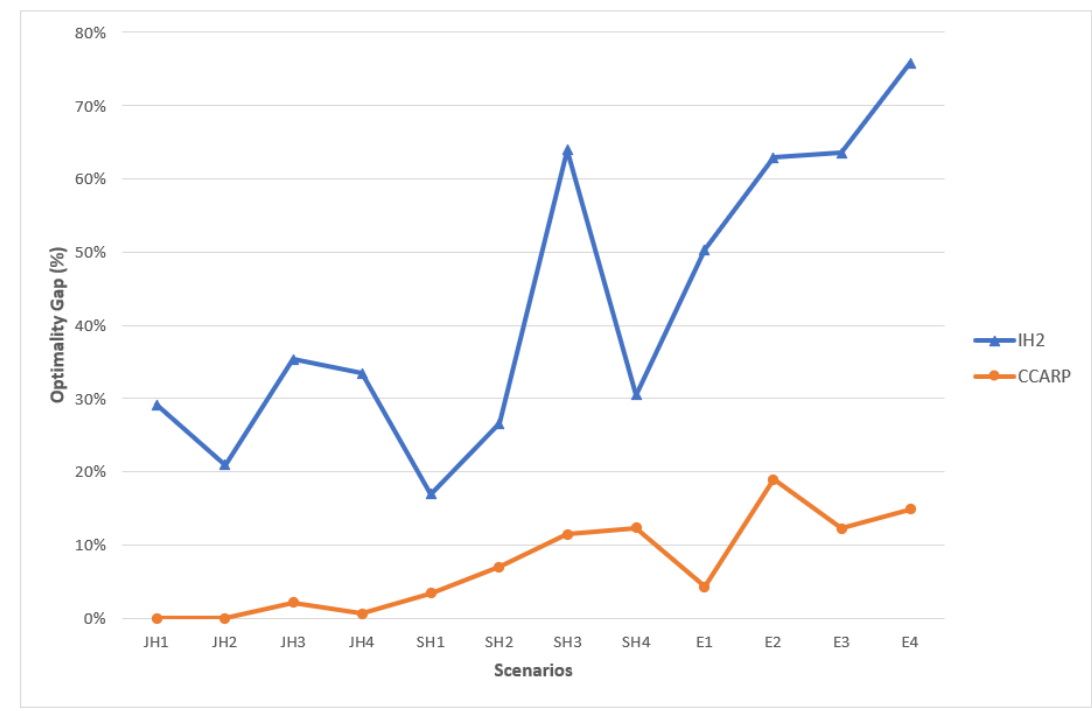

Figure 6 - Gaps between results obtained using heuristic approaches and optimal results for each scenario 
The optimality gaps are also calculated for each scenario that is depicted in Figure 6 which shows that the largest gap is almost $75 \%$ for IH2 whereas $19 \%$ for CCARP. Again, the optimality gaps are calculated for both IH2 and CCARP using the optimum values obtained from Gurobi for each scenario. For example, for scenario E2 (our worst case scenario) which is the elementary school with 4 buses, the optimum distance obtained from Gurobi is 45.97 miles, however the results obtained from heuristic approaches IH2 and CCARP are 74.9 miles and 54.67 miles as shown in Table 13. Therefore, the optimality gaps for this scenario can be calculated as $\frac{74.9-45.97}{45.97}=$ $62.9 \%$ for IH 2 and $\frac{54.67-45.97}{45.97}=18.9 \%$ for CCARP.

\subsubsection{Discussion and Analysis}

As described in section 3.1.2, the centroids in the CCARP algorithm are selected at random at each iteration. There are several choices for this selection which is $\mathrm{C}(|\mathrm{T}|,|\mathrm{B}|)$ where $|\mathrm{T}|$ is the size of the set of students (number of students) and $|\mathrm{B}|$ is the size of the set of buses (number of buses). It can be a concern that performing five iterations will only evaluate five selections among different combinations of $\mathrm{C}(|\mathrm{T}|,|\mathrm{B}|)$ which may not result in good quality solutions.

We initially started with random centroid selection with higher number of iterations and tested numerous examples to identify a suitable number of iterations to ensure high quality solutions. Even though more iterations could potentially improve the quality of the solutions, based on our experimental results, the benefits of improved quality beyond five iterations wouldn't justify the additional computational resources. However, we also implemented CCARP on the FSPS cases study using 15 iterations to see how it affects the results. The results will be discussed in Table 17. 
Table 14 - Result of three heuristic approaches on FPSP case study

\begin{tabular}{|c|c|c|c|c|c|c|c|}
\cline { 3 - 8 } \multicolumn{1}{c|}{} & \multicolumn{3}{c|}{ 5 Iterations } & \multicolumn{3}{c|}{ 15 Iterations } \\
\cline { 2 - 8 } \multicolumn{1}{c|}{} & Optimum & CCARP & CCARP II & CCARP III & CCARP & CCARP II & CCARP III \\
\hline JH1 & 36.4 & 36.4 & 36.4 & 36.4 & 36.4 & 36.4 & 36.4 \\
\hline JH2 & 33.4 & 33.4 & 34.8 & 35.8 & 33.4 & 33.4 & 34.8 \\
\hline JH3 & 32.5 & 33.2 & 34.3 & 34.3 & 33.2 & 34.3 & 34.3 \\
\hline JH4 & 33.2 & 33.4 & 36.1 & 37.3 & 33.4 & 36.1 & 37.2 \\
\hline SH1 & 41.2 & 42.6 & 42.6 & 43.9 & 42.6 & 42.6 & 43.7 \\
\hline SH2 & 39.8 & 42.6 & 44 & 41.8 & 42.6 & 43.9 & 41.8 \\
\hline SH3 & 39.4 & 43.9 & 43.9 & 45.6 & 43.2 & 43.9 & 45 \\
\hline SH4 & 39.7 & 44.6 & 46.8 & 50 & 44.6 & 46.8 & 48.2 \\
\hline E1 & 46.97 & 48.97 & 55.97 & 49.37 & 48.97 & 54.17 & 48.57 \\
\hline E2 & 45.97 & 54.67 & 52.57 & 50.87 & 51.47 & 50.97 & 50.87 \\
\hline E3 & 45.67 & 51.27 & 55.37 & 57.27 & 51.27 & 51.87 & 56.27 \\
\hline E4 & 45.57 & 52.37 & 56.67 & 62.27 & 52.37 & 56.37 & 58.67 \\
\hline
\end{tabular}

To generate more diverse solutions, we implement two alternative algorithms, CCARP II and CCARP III which are described in Table 15 and Table 16; respectively. The differences between these algorithms and the original CCARP are underlined in these tables.

\section{CCARP II}

In this approach, we follow the same procedure as in CCARP to select random centroids and then start the second phase of the solution approach from the largest cluster to the smallest when solving model II. 


\section{CCARP II Algorithm}

I Select number of iterations (IT) and set iter $=1$, and set Best=M (Significantly large number) While iter $\leq I T$

\section{Initialization}

II $\quad$ Select $|\mathrm{B}|$ students randomly as initial centroids

III Generate distance matrix $\left(\theta_{i k}\right)$ using the distances from student $\mathrm{i}$ to centroid of cluster $\mathrm{k}$

IV Solve CCP to form clusters

\section{Main Loop}

$\mathrm{V} \quad$ Sort the formed clusters from the largest to smallest

VI Set $\mathrm{k}=$ (largest bus with largest cluster size),$Z_{i t e r}=0$, and $a^{(k)}=$ updated school capacity for cluster $\mathrm{k}$

VII Set $t^{(k)}=$ number of students assigned to cluster $\mathrm{k}$ from part IV

VIII Set $l_{i j}^{(k)}$ binary variable representing the assignment of student $\mathrm{i}$ to school $\mathrm{j}$ at cluster $\mathrm{k}$

IX Set $a_{j m}^{(k)}=$ remaining capacity of class type $\mathrm{m}$ in school $\mathrm{j}$ at cluster $\mathrm{k}$

While $k \leq|B|$ :

X $\quad$-Solve Model II for cluster k with $t^{(k)}$ students, $|\mathrm{S}|$ schools with capacity $a^{(k)}$, and 1 bus to get $Z(k)$

-Update school capacity: $a_{j m}^{(k)}=a_{j m}^{(k)}-\sum_{i \epsilon T} g_{i m} l_{i j}^{(k)} \quad \forall j \epsilon S, m \epsilon R$

-Update the distance at the end of each loop: $Z_{i t e r}=Z_{\text {iter }}+Z(k)$

-Change $\mathrm{k}$ to the next largest cluster

XI If $Z_{\text {iter }} \leq$ Best: Best $=Z_{\text {iter }}$

$\mathrm{XII} \quad$ iter $=$ iter +1

\section{CCARP III}

CCARP III selects the centroids more smartly and not purely random. A random student is selected as the first centroid but farthest students from the first centroid will be selected for the remaining cluster centroids. 
Table 16 - Pseudo code for CCARP III algorithm

\begin{tabular}{ll}
\hline CCARP III Algorithm \\
\hline I $\quad$ Select number of iterations (IT) and set $i t e r=1$, and set Best=M (Significantly large number) \\
$\quad$ While iter $\leq I T$
\end{tabular}

\section{Initialization}

II Select one student randomly as the first centroid

Calculate the distances between other students and the selected student in (a)

Select the farthest student from the previously selected centroid(s)

Use the maximum sum of distances from the previously selected centroids for future centroids

Repeat until $|\mathrm{B}|$ centroids are identified

III Generate distance matrix $\left(\theta_{i k}\right)$ using the distances from student $\mathrm{i}$ to centroid of cluster $\mathrm{k}$

IV Solve CCP to form clusters

\section{Main Loop}

$\mathrm{V} \quad$ Sort the formed clusters from the largest to smallest

VI Set k= (largest bus with largest cluster size), $Z_{i t e r}=0$, and $a^{(k)}=$ updated school capacity for cluster $\mathrm{k}$

VII Set $t^{(k)}=$ number of students assigned to cluster $\mathrm{k}$ from part IV

VIII Set $l_{i j}^{(k)}$ binary variable representing the assignment of student $\mathrm{i}$ to school $\mathrm{j}$ at cluster $\mathrm{k}$

IX Set $a_{j m}^{(k)}=$ remaining capacity of class type $\mathrm{m}$ in school $\mathrm{j}$ at cluster $\mathrm{k}$

While $k \leq|B|$ :

X $\quad$-Solve Model II for cluster k with $t^{(k)}$ students, $|\mathrm{S}|$ schools with capacity $a^{(k)}$, and 1 bus to get $Z(k)$

-Update school capacity: $a_{j m}^{(k)}=a_{j m}^{(k)}-\sum_{i \epsilon T} g_{i m} l_{i j}^{(k)} \quad \forall j \epsilon S, m \in R$

-Update the distance at the end of each loop: $Z_{i t e r}=Z_{i t e r}+Z(k)$

-Change $\mathrm{k}$ to the next largest cluster

XI If $Z_{\text {iter }} \leq$ Best: $B$ Best $=Z_{\text {iter }}$

$\mathrm{XII} \quad$ iter $=$ iter +1

We use a simple example to further explain the steps of CCARP III algorithm. Assume student T4 has been randomly selected as the first centroid. The distances between all students and T4 will be calculated and student $\mathrm{T} 1$ is the farthest from $\mathrm{T} 4$, so $\mathrm{T} 1$ will be selected as the second centroid. Then the distances from all other students to $\mathrm{T} 4$, and $\mathrm{T} 1$ will be calculated and added up. The 
student that has the maximum sum of distances from $\mathrm{T} 4$, and $\mathrm{T} 1$ will be selected as the third centroid and so on until we select a student (centroid) for each cluster.

The three proposed solution approaches were implemented and compared on all scenarios of FSPS case study using 5 and 15 iterations (IT=5, and IT=15). Table 17 shows the obtained total travel distances by the three heuristic approaches.

Table 17 - Result of three heuristic approaches on FPSP case study

\begin{tabular}{|c|c|c|c|c|c|c|c|}
\cline { 3 - 8 } \multicolumn{1}{c|}{} & \multicolumn{3}{c|}{ 5 Iterations } & \multicolumn{3}{c|}{ 15 Iterations } \\
\cline { 2 - 8 } \multicolumn{1}{c|}{} & Optimum & CCARP & CCARP II & CCARP III & CCARP & CCARP II & CCARP III \\
\hline JH1 & 36.4 & 36.4 & 36.4 & 36.4 & 36.4 & 36.4 & 36.4 \\
\hline JH2 & 33.4 & 33.4 & 34.8 & 35.8 & 33.4 & 33.4 & 34.8 \\
\hline JH3 & 32.5 & 33.2 & 34.3 & 34.3 & 33.2 & 34.3 & 34.3 \\
\hline JH4 & 33.2 & 33.4 & 36.1 & 37.3 & 33.4 & 36.1 & 37.2 \\
\hline SH1 & 41.2 & 42.6 & 42.6 & 43.9 & 42.6 & 42.6 & 43.7 \\
\hline SH2 & 39.8 & 42.6 & 44 & 41.8 & 42.6 & 43.9 & 41.8 \\
\hline SH3 & 39.4 & 43.9 & 43.9 & 45.6 & 43.2 & 43.9 & 45 \\
\hline SH4 & 39.7 & 44.6 & 46.8 & 50 & 44.6 & 46.8 & 48.2 \\
\hline E1 & 46.97 & 48.97 & 55.97 & 49.37 & 48.97 & 54.17 & 48.57 \\
\hline E2 & 45.97 & 54.67 & 52.57 & 50.87 & 51.47 & 50.97 & 50.87 \\
\hline E3 & 45.67 & 51.27 & 55.37 & 57.27 & 51.27 & 51.87 & 56.27 \\
\hline E4 & 45.57 & 52.37 & 56.67 & 62.27 & 52.37 & 56.37 & 58.67 \\
\hline
\end{tabular}

As shown in Table 17, CCARP still performs well on most of the cases. With regards to the number of iterations, even though we tripled the number of iterations, the quality of the solution improved by less than $1 \%$ on average which may not justify the additional computational time.

We have also added a third phase to our heuristic algorithm to see if we can improve the solutions generated using inter-cluster exchanges of students. In this inter-cluster exchange, two clusters are selected at random. If the number of buses (clusters) are even, there will be exactly b/2 swaps but if number of clusters are odd, we will pick b-1 pairs of clusters to swap students between 
them. By looking at the students in each selected pair of clusters, the two candidates for exchange would be selected by identifying the students who are closest to the center of the other cluster in the same pair. There might be a slight chance that the swap is not feasible depending on the need of students selected and the capacities of the schools. In this case, a new student will be selected that has the same level of need to make the swap feasible. CCARP will be implemented on the clusters after the swaps are completed. The steps are as follows:

1. Select random pair of clusters $\left(\frac{b}{2}\right.$ for even clusters and $\frac{b}{2}-1$ for odd number of clusters)

2. Select a student from each cluster in pair who is closest to the center of the other cluster

3. Exchange the selected students between the two clusters

4. If feasible, go to 6

5. If not feasible, select another student in the destination cluster that has the same level of need as the first candidate, if feasible, go to 6

6. Solve Model II on the new clusters

We use this procedure on a solution generated by CCARP on eleven scenarios (all minus JH1) of FSPS case study. As there is only one bus in JH1, there is no chance of inter-cluster exchange. The results are shown in Table 18. 
Table 18 - Results of Inter-cluster student exchanges

\begin{tabular}{|c|c|c|c|}
\hline Scenarios & Number of ex-changes & $\begin{array}{c}\text { CCARP } \\
\text { Solution }\end{array}$ & $\begin{array}{c}\text { Solution after Inter- } \\
\text { cluster exchanges }\end{array}$ \\
\hline JH1 & 0 & 36.4 & - \\
\hline JH2 & 1 & 39.4 & 41.2 \\
\hline JH3 & 1 & 38.8 & 40.6 \\
\hline JH4 & 2 & 38.4 & 51.3 \\
\hline SH1 & 1 & 43.3 & 45.1 \\
\hline SH2 & 1 & 51.1 & 52 \\
\hline SH3 & 2 & 44.4 & 51.5 \\
\hline SH4 & 2 & 48.4 & 53.8 \\
\hline E1 & 1 & 64.17 & 63.87 \\
\hline E2 & 2 & 55.27 & 60.57 \\
\hline E3 & 2 & 58.47 & 73.4 \\
\hline E4 & 3 & 54.17 & 59.87 \\
\hline
\end{tabular}

The results shown in Table 18 depicts that the only improvement occurred in the solutions is in case E1 and even that improvement is not significant. It might be possible to improve the solution at some point if this third phase is iterated but the computational times significantly increase. Assume we implement CCARP algorithm in 5 iterations (10.64 seconds) and in each iteration we perform the third phase for 5 iterations. Considering the fact that we may not even get a better solution, we significantly increase the computational times with no improvement guarantee.

In order to study the impact of changes in parameters of the problem on the outcome of Model II and the heuristic solution approach, we conduct a sensitivity analysis. We specifically focus on the number of buses which we assume to be a parameter for Model II and the choice of cluster centroids in the CCARP approach. First, we study the sensitivity of Model II with respect to the number of buses on the FSPS case study as shown in Figure 7. For Junior high school cases with 
19 students, we solve the problem with 1,2,3, and 4 buses. The results show that using 3 buses results in less total distance (32.5 miles); however, they can save the cost of an additional bus by using 2 buses that travel only about 1 mile more (33.4 miles). For Senior High School case with 33 students, the total distance does not differ much between 3,4 , and 5 buses $(39.8,39.4$, and 39.7 miles respectively); so, it might be practical to select 3 buses for this case. For the cases related to Elementary school, the increase in the number of buses from 5 to 6 does not have a significant impact on the total traveled distance. Therefore, we recommended using 2, 3, and 5 buses for Junior high school, Senior high school, and Elementary school respectively based solely on operational considerations. Considering this may lead to longer ride time for students, therefor a definite recommendation needs further analysis.

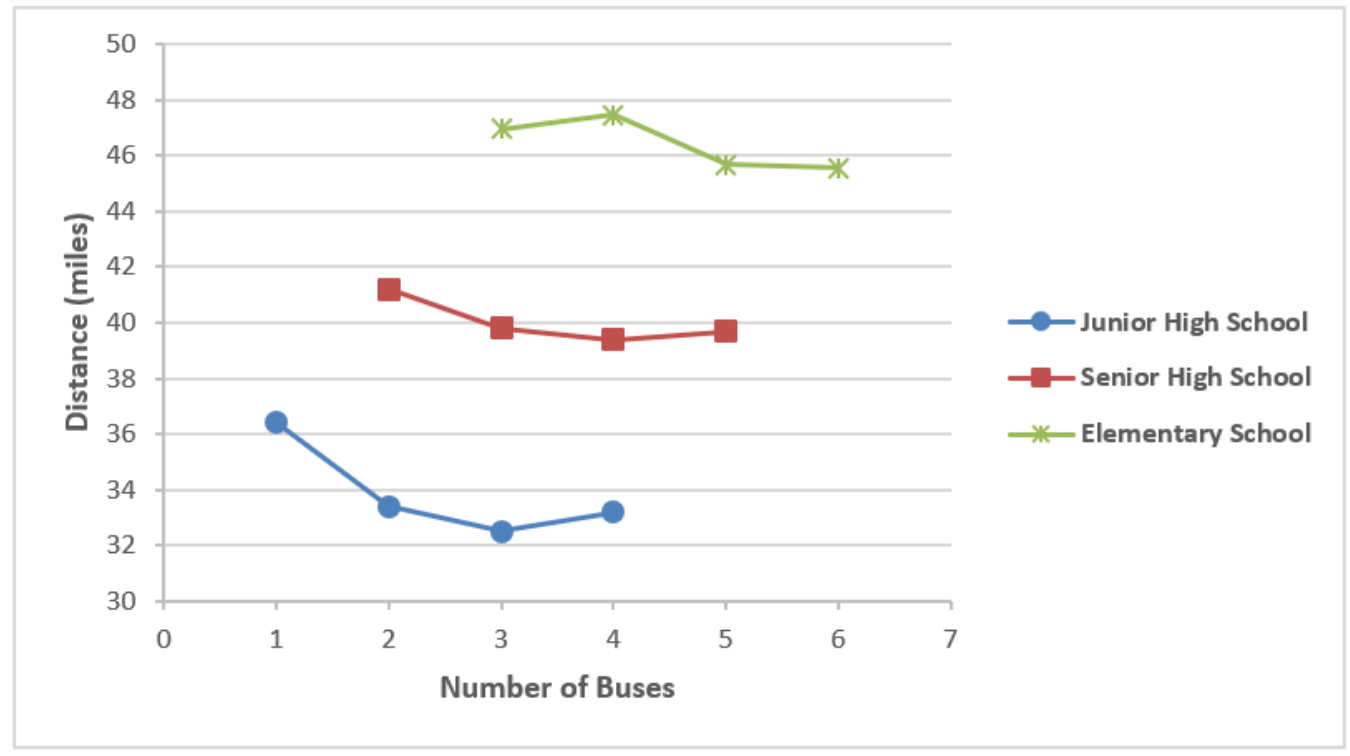

Figure 7 - Model II sensitivity to the number of buses

We also study the sensitivity of the CCARP approach to the selection of the initial centroids for the clustering problem. We solve each case $(\mathrm{JH}, \mathrm{SH}$, and $\mathrm{E}) 10$ times to study the impact of different centroids selected randomly each time. Random selections of centroids for the clusters at 
each iteration yield to different objective values as the clusters formed by CCP will be different. Figure 8, Figure 9, and Figure 10 show the objective value changes using different centroids for the clusters for each scenario related to junior high school, senior highs school, and elementary school; respectively.

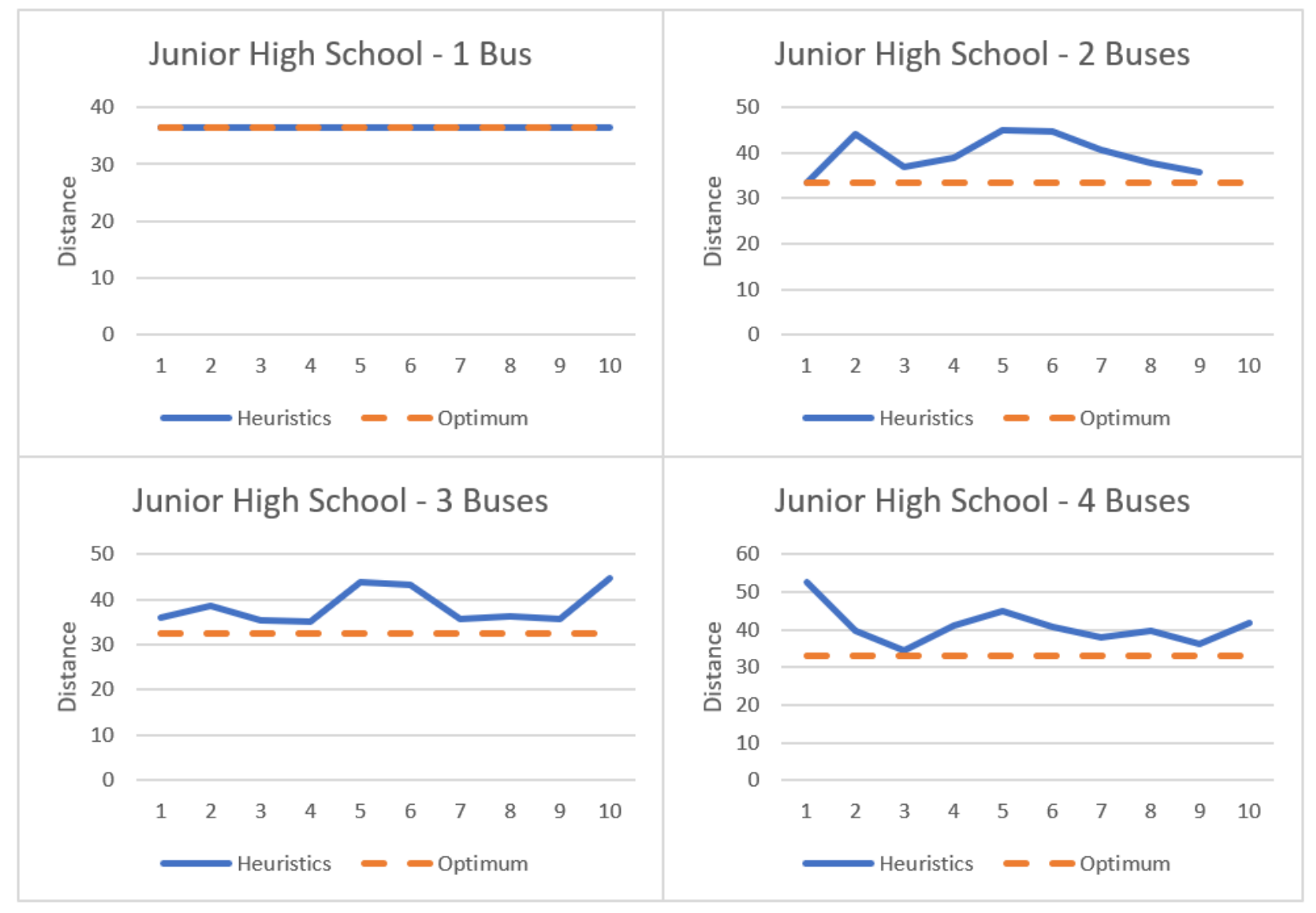

Figure 8 - CCARP algorithm sensitivity to selection of centroids for Junior High School case 


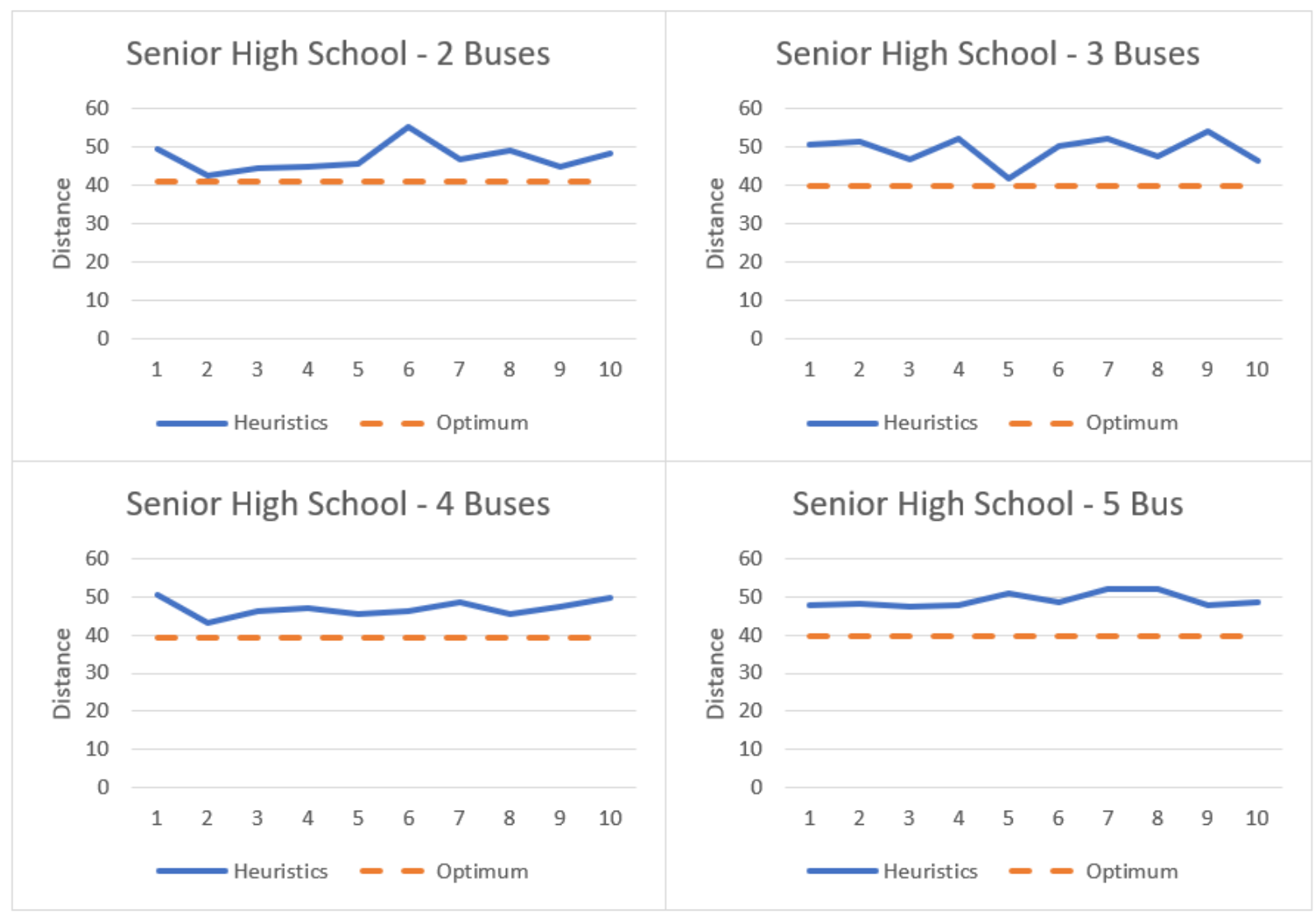

Figure 9 - CCARP algorithm sensitivity to selection of centroids for Senior High School case 


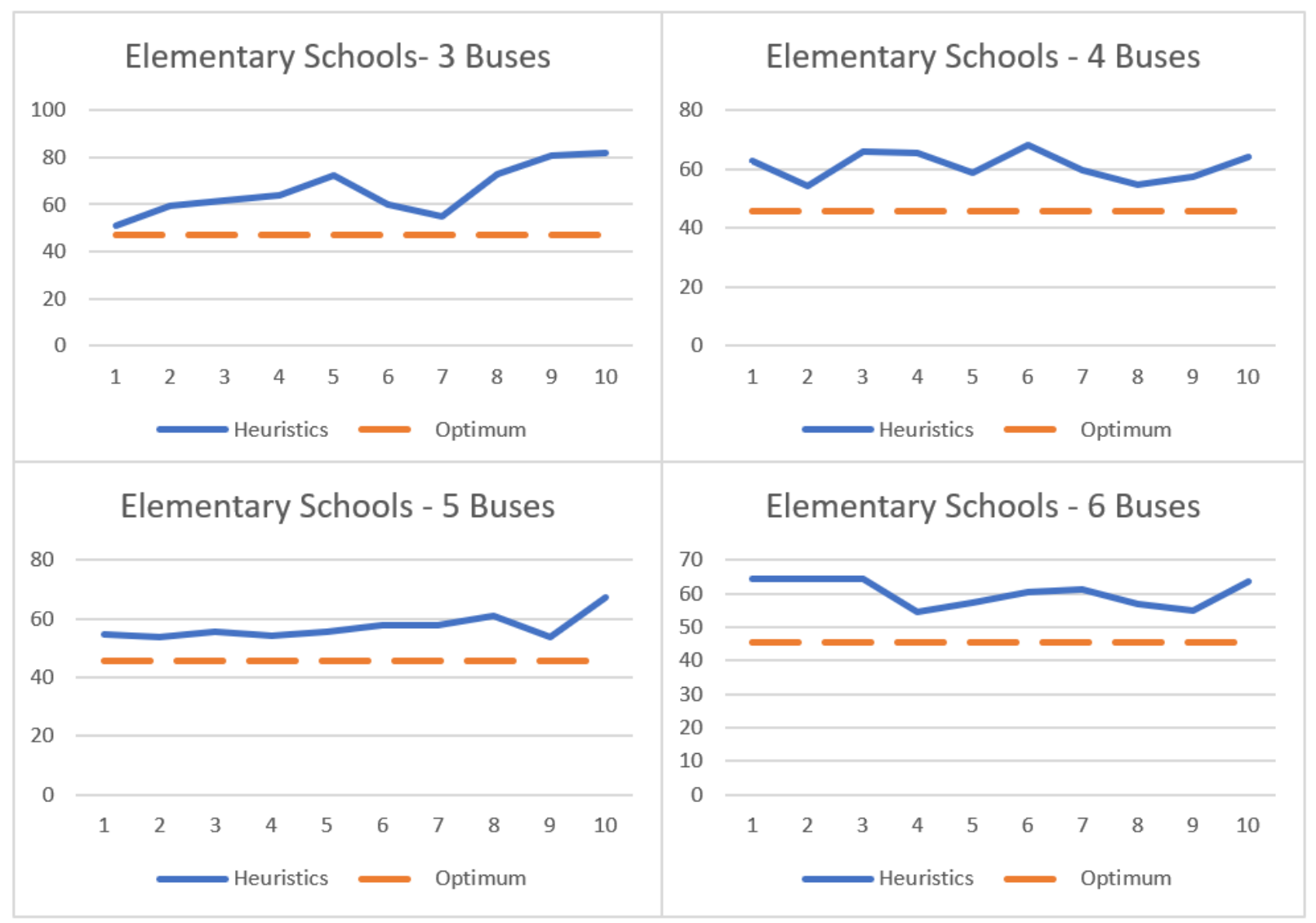

Figure 10 - CCARP algorithm sensitivity to selection of centroids for Elementary School case

Based on the results, the algorithm is sensitive to the selection of the centroids in some cases. The developed approach selects b number (size of set B) of students as the centroids to run CCARP and these results show that the appropriate selection of initial centroids is very crucial. This fact shows that it improves the results if our heuristic approach is run for several iterations since it is very sensitive on the selection of random students as centroids of the clusters although the computation time will increase. Therefore, it is important to balance the tradeoff between the number of iterations (quality of the solution) and computation time. Therefore, to improve the results, we recommend that CCARP approach is run for multiple iterations as long as the computational resources permit to obtain even higher quality results. 


\subsection{Multi-Objective}

Model IV is also applied to the Fort Smith case study however because each school level has a relatively large number of students to be solved by goal programming, optimum assignments are not obtained using Gurobi. This software is used to obtain a solution quickly in a reasonable amount of time which does not guarantee that it is the best solution.

Table 19 - Analysis and result comparison between Model II and Model IV

\begin{tabular}{|c|c|c|c|c|c|}
\hline & \multicolumn{4}{|c|}{ Single Objective } & \multirow{2}{*}{$\begin{array}{c}\text { Multi-Objective } \\
\text { Goal Programming }\end{array}$} \\
\hline Level & $\begin{array}{c}\text { \# of } \\
\text { Buses }\end{array}$ & Optimal & $\begin{array}{l}\text { Maximum } \\
\text { Ride } \\
\text { Distance }\end{array}$ & $\begin{array}{l}\text { Maximum } \\
\text { Ride Time } \\
\text { (minute) }\end{array}$ & \\
\hline \multirow{4}{*}{$\begin{array}{l}\text { Junior } \\
\text { High } \\
\text { School }\end{array}$} & 1 & 36.4 & 34.8 & 135.76 & \multirow{4}{*}{$\begin{array}{ll}\text { - } & 3 \text { Buses (2-hour limit) } \\
\text { - } & \text { Total Distance: } 32.5 \\
\text { - } & \text { Max Ride Distance: } 13.79 \\
\text { - } & \text { Max Ride Time: } 53.8\end{array}$} \\
\hline & 2 & 33.4 & 19.6 & 76.46 & \\
\hline & 3 & 32.5 & 21.6 & 84.27 & \\
\hline & 4 & 33.2 & 21.6 & 84.27 & \\
\hline \multirow{4}{*}{$\begin{array}{l}\text { Senior } \\
\text { High } \\
\text { School }\end{array}$} & 2 & 41.2 & 22.8 & 88.95 & \multirow{4}{*}{$\begin{array}{ll}\text { - } & 3 \text { Buses (2-hour limit) } \\
\text { - } & \text { Total Distance: } 40.4 \\
\text { - } & \text { Max Ride Distance: } 15.6 \\
\text { - } & \text { Max Ride Time: } 60.86\end{array}$} \\
\hline & 3 & 39.8 & 18.4 & 71.78 & \\
\hline & 4 & 39.4 & 18.4 & 71.78 & \\
\hline & 5 & 39.7 & 18.4 & 71.78 & \\
\hline \multirow{4}{*}{$\begin{array}{l}\text { Elementar } \\
\text { y School }\end{array}$} & 3 & 46.97 & 20.5 & 79.97 & \multirow{4}{*}{$\begin{array}{ll}\text { - } & 5 \text { Buses (2-hour limit) } \\
\text { - } & \text { Total Distance: } 78.87 \\
\text { - } & \text { Max Ride Distance: } 32.5 \\
\text { - } & \text { Max Ride Time: } 126.79\end{array}$} \\
\hline & 4 & 45.97 & 19.7 & 76.85 & \\
\hline & 5 & 45.67 & 14.67 & 57.23 & \\
\hline & 6 & 45.57 & 14.2 & 55.40 & \\
\hline
\end{tabular}

The largest case study is elementary school cases and therefore no good quality solution is obtained. This highlights the importance of developing a heuristic method that can provide a good quality solution for this complicated model in a short amount of time.

In all the cases, we use a weight of one for all three objective functions. However, it needs further analysis to determine an acceptable weight for each objective especially when the objectives are of different types. In our developed multi-objective model, two objectives are distance based while the other objective focuses on the number of vehicles. Therefore, it would be 
beneficial to do more analysis on how to determine the weights to get an idea of how many miles is equivalent of utilizing one bus. 


\section{Chapter 5: Potential Applications}

In this chapter, other variations and applications of the integrated assignment and routing are discussed. In section 5.1, a variation of Model II in which the ride time is to be minimized is presented. In section 5.2, a brief description of the traditional ride-sharing problem and a comparison between that and model II are presented. It is also discussed how Model II can be changed to be able to address the ride sharing problem.

\subsection{Model II with ride time component}

Most of the research studies in the literature focus on minimizing the travel distance but Ripplinger and Trb [47] develop a school bus routing for special needs students that minimizes the total ride time. The model we develop in this work minimizes the total travel distance which in a way minimizes the total ride time of the students. However, it can be modified such that it specifically minimizes the time itself. To do so, some additional variables, parameters, and constraints need to be defined.

\section{Additional Decision Variables}

$\beta_{i j}^{q}=\left\{\begin{array}{rr}1 & \text { if student } q \text { travels between node } i \text { and } j \\ 0 & \text { Otherwise }\end{array}\right.$

\section{Additional Parameters}

$t_{\text {max }}:$ Maximum allowable student ride time

$t_{i j}:$ Travel time between nodes $i$ and $j$

The objective function shown in equation (120) minimizes the total travel time by replacing the distance coefficient $\left(d_{i j}\right)$ with the travel time between any two nodes $\left(t_{i j}\right)$. 


$$
\text { Minimize } Z^{\prime}=\sum_{i \in N} \sum_{j \in N} \sum_{k \in V} t_{i j} x_{i j k}+\frac{1}{M} \sum_{i \in N} \sum_{k \in V} w_{i k}
$$

There will be an additional set of constraints shown in equation (121) ensuring that the students are not on the bus for more than a threshold value $\left(t_{\max }\right)$.

$$
\sum_{i \in N} \sum_{j \in N} t_{i j} \cdot \beta_{i j}^{q} \leq t_{\max } \quad q \epsilon T
$$

The overall student to school assignment and bus routing problem for special needs students that minimizes the total travel time will be a combination of objective function (120) and constraints (2) to (17) with the addition of constraint (121). It is possible that students have different allowable ride time depending on their health conditions and needs. In this case, we can change the parameter $t_{\max }$ to $t_{\max }^{q}$ showing the maximum allowable ride time for student q.

A large number of works have been done in the literature of school bus routing problem however, few studies have discussed the nature of transportation networks itself. To the best of my knowledge, most of the works made an assumption that the travel times between the nodes are fixed and deterministic. To address the stochastic and time-varying nature of the arc travel times in the network, define a random variable for travel time between any two nodes. This makes the problem much more complicated however it is more realistic since it considers the traffic congestion as well. They define a variable call $C_{i j}^{t}$ as shown in equation (122) which is the travel time between nodes $i$ and $j$ at time interval $t$. This shows that the travel time may be different at different times of the day. For example, it may take 30 minutes to travel the arc between node $i$ and $j$ starting at 8:00 in the morning however the same route can be traveled in 10 minutes around 11 o'clock in the morning. 


$$
C_{i j}^{t}=R_{i j}^{t}+\tau_{i j}^{t}
$$

Where $R_{i j}^{t}$ is the fixed travel time for arc $(i, j)$ at time interval $t$ and $\tau_{i j}^{t}$ is the random variable which ranges from 0 to $d_{i j}^{t}$ where $d_{i j}^{t}$ is again a fixed predetermined time for arc $(i, j)$ at time interval $t$. This makes the random time dependent variable $C_{i j}^{t}$ to be in the range from $R_{i j}^{t}$ to $R_{i j}^{t}+$ $d_{i j}^{t}$. These concepts and conditions can be added to the SSA-SBRP-SNS single objective and multi-objective models to make them more practical and realistic.

\subsection{Ride Sharing Problem}

Ride-sharing optimization is a very complicated optimization problem which is related to transporting multiple riders by the same vehicle whose driver is willing to share his/her ride. Thus, the ride-sharing problem has three main components: riders (passengers), drivers, and the vehicles. This problem has gained more attention in recent years for several possible objectives including travel cost savings, less traffic congestion, less pollution, less gas consumption and other objectives [48]. Despite all the aforementioned advantages, most people refuse to adopt ridesharing due to several reasons including privacy, social preferences and most importantly lack of efficient ways to share rides between several riders and passengers specially as the network gets larger. Table 20 lists all possible variants of ride-sharing problem. 
Table 20 - Ride-Share Variants [49]

\begin{tabular}{|c|c|c|}
\cline { 2 - 3 } \multicolumn{1}{c|}{ Single Rider } & Multiple Riders \\
\hline Multiple Drivers & $\begin{array}{c}\text { Matching of pairs of drivers } \\
\text { and riders: Easy }\end{array}$ & $\begin{array}{c}\text { Routing of drivers to pick up and } \\
\text { deliver riders: Difficult }\end{array}$ \\
\hline between drivers: Difficult & $\begin{array}{c}\text { Routing of riders and drivers: } \\
\text { Difficult }\end{array}$ \\
\hline
\end{tabular}

An agency is needed to efficiently match the riders and drivers considering different criteria such as departure and arrival time and locations, preferred route, capacity of the vehicles and many more. In other words, an assignment problem must be solved to satisfy all the needs of riders and drivers. It is similar to student to school assignment (SSA) part of our developed model for school bus optimization project (SSA-SBRP-SNS). In SSA, the students are assigned to schools based on their level of needs and school capacities. However, in ride-sharing problem, riders are supposed to be assigned to the vehicle with similar trip (close origin and destinations) if the time of their trips and route preferences match. In the SBRP section of the SSA-SBRP-SNS model, the routes are generated considering the assignment of students to schools, students to buses, and schools to buses. The routing problem is an NP-hard problem itself, but the addition of time window introduces more complexity to the model. We have not considered time window in the model we developed but time is a very important component in ride-sharing problem which makes it different than our model. In both models, there are several nodes that must be visited, and the models determine how many passengers or students get assigned to each vehicle or school depending on the remaining capacities and other factors. Ride-sharing problem can be categorized into two major classes: static and dynamic. In static ridesharing, all customers (passengers) and drivers are known in advance and routes and trips are generated and implemented without any changes while dynamic ride-sharing adapts the planning and routing online and takes care of the new requests arrive at the 
systemin real time. It is important to adjust the route based on the incoming requests on a real-time basis in a reasonable amount of time to avoid delays for the driver in dynamic ride-sharing. The real-time ride-sharing uses GPS and internet services on smartphone devices of both driver and passengers to re-route the vehicles as needed. This is considered as another difference between our model and the ride-sharing problem. Table 21 summarizes the differences and similarities of our model and ride-sharing problem.

Table 21 - Comparison of SSA-SBRP-SNS with Ride-sharing problem

\begin{tabular}{|c|c|c|c|}
\hline & Static Ride-sharing & Dynamic Ride-sharing & SSA-SBRP-SNS \\
\hline Real-time analysis & No & Yes & No \\
\hline Time Window & Yes & Yes & No \\
\hline Assignment & \multicolumn{2}{|c|}{ Customers to drivers (vehicles) } & $\begin{array}{l}\text { - Students to schools } \\
\text { - Students to buses }\end{array}$ \\
\hline Route Generation & Yes & Yes & Yes \\
\hline Solvability & NP-Hard & NP-Hard & NP-Hard \\
\hline Objective & $\begin{array}{l}\text { - Minimize nui } \\
\text { - } \text { Minimize tot } \\
\text { - Maximize the } \\
\text { - Minimize dri } \\
\text { - Minimize cus }\end{array}$ & $\begin{array}{l}\text { er of drivers } \\
\text { raveled distance/time } \\
\text { umber of matched trips } \\
\text { s' trip costs } \\
\text { mers' trip costs }\end{array}$ & $\begin{array}{l}\text { Minimize total } \\
\text { traveled distance }\end{array}$ \\
\hline
\end{tabular}

Reviewing the literature shows that some researchers relax the time constraints in the ridesharing problem. In this case, they assume that the arrival and departure time constraints are always met once they do assignment of passengers to drivers. This model is called simplified ride-sharing problem. Relaxing the time constraints makes the simplified ride-sharing problem very similar to SSA-SBRP-SNS model we developed. Liang [48] further simplified the problem by assuming to 
have single destination for all passengers, no detours for the driver (leaving only one option for every driver), and fixed path (leaving only one option for each trip). This problem is still an NPhard problem which needs evolutionary solution approaches.

To summarize, the main differences between our developed model and ride-sharing problem are:

- Buses start and end at the depot in SSA-SBRP-SNS model while the vehicles start their trip from different locations (drivers' homes or office) in ride-sharing problem;

- We do not consider time in our analysis however in ride sharing problem time is an important factor; and

- Students cannot drive themselves to give ride to other students. Therefore, students are different than the drivers when looking at the SSA-SBRP-SNS model as a ride-sharing problem.

To convert the SSA-SBRP-SNS model to ride sharing problem, we need to assume that the depot is the first student each bus visits (i.e. the distance from depot to the first student on the route for each bus will be zero). In other words, the bus will start its trip from a student's home and end its trip at the same location in the afternoon. This can be done by simply change the values in the distance matrix to reflect 0 from depot to all student nodes. The ride sharing problem consists of a set of drivers and riders. The set of buses in the SSA-SBRP-SNS will be considered as the drivers set and the students are considered the riders in ride sharing problem. The destinations of riders are known in advance, so students need to be assigned to schools before solving the ride sharing problem using an assignment problem. 
Now that the destinations are known, a ride sharing problem can be solved assuming the departure and arrival time constraints are always met as Liang [48] assumed. This is called a simplified ride sharing problem with open time windows.

\section{Sets}

S: Set of destinations $(i, j)$

T: Set of riders'locations $(i, j)$

D: Set of depots $(i, j)$

$N$ : Set of nodes (Union of $S, T$, and D) $(i, j)$

V: Set of vehicles $(k)$

\section{Decision Variables}

$$
\begin{aligned}
& x_{i j k}= \begin{cases}1 & \text { if vehicle } k \text { goes from node i to node } j \\
0 & \text { Otherwise }\end{cases} \\
& y_{i k}= \begin{cases}1 & \text { if rider } i \text { is assigned to vehicle } k \\
0 & \text { Otherwise }\end{cases} \\
& z_{i k}= \begin{cases}1 & \text { if node } j \text { (destination) is visited by vehicle } k \\
0 & \text { Otherwise }\end{cases} \\
& w_{i k}=\text { position of node } i \text { on the route of the } k^{\text {th }} \text { bus }
\end{aligned}
$$

\section{Parameters}

$n:$ Total number of nodes

$d_{i j}$ : Distance between nodes $i$ and $j$

$C_{k}:$ Capacity of vehicle $k$

$a_{i j}=\left\{\begin{array}{rr}1 & \text { if rider } \text { i goes to destination } j \\ 0 & \text { Otherwise }\end{array}\right.$

The distance from depot and rider nodes are assumed to be all zero. That means the first rider on each route will be considered as the driver. 
Minimize $Z=\sum_{i \in N} \sum_{j \in N} \sum_{k \in V} d_{i j} x_{i j k}+\frac{1}{M} \sum_{i \in N} \sum_{k \in V} w_{i k}$

S.T.

$\sum_{j \in S \cup T} \sum_{k \in V} x_{i j k}=1 \quad i \in T$

$\sum_{i \in D \cup T} \sum_{k \in V} x_{i j k}=1 \quad j \in T$

$\sum_{j \in N} x_{i j k}=y_{i k} \quad i \epsilon T, k \in V$

$\sum_{j \in N} x_{j i k}=y_{i k} \quad i \epsilon T, k \epsilon V$

$\sum_{i \in D} \sum_{j \in T} x_{i j k}=1 \quad k \in V$

$\sum_{i \in S} \sum_{j \in D} x_{i j k}=1 \quad k \in V$

$\sum_{i \in T} \sum_{k \in V} x_{i j k}=0 \quad j \in D$

$\sum_{j \in D \cup S} x_{i j k}=z_{i k} \quad i \in S, k \in V$

$\sum_{j \in S \cup T} x_{j i k}=z_{i k} \quad i \in S, k \in V$

$x_{i i k}=0 \quad i \in N, k \in V$

$w_{i k}=1 \quad i \in D, k \in V$

$w_{j k} \geq w_{i k}+1-n *\left(1-x_{i j k}\right) \quad i \epsilon N, j \epsilon S \cup T, j \neq i, k \epsilon V$

$a_{i j} \cdot y_{i k} \leq z_{j k} \quad i \epsilon T, j \in S, k \in V$

$a_{i j} \cdot w_{i k} \leq w_{j k} \quad i \epsilon T, j \in S, k \in V$ 


$$
\begin{array}{ll}
\sum_{i \in T} a_{i j} \cdot y_{i k} \geq z_{j k} & j \epsilon S, k \epsilon V \\
\sum_{j \in T} y_{j k} \leq C_{k} & k \epsilon V
\end{array}
$$

The objective function (123) minimizes the total travel distance that the vehicles make between any two nodes. Constraint (124) forces each driver to visit exactly one node either a student node (rider) or a school node (destination) immediately after visiting a student node. Constraint (125) makes sure that exactly one rider node is visited before each rider visit (i.e. the vehicle does not visit the drop off location before picking up the riders). Constraints sets (126) and (127) update bookkeeping variable $y_{i k}$ by relating it to the main decision variable, $x_{i j k}$. Constraint set (128) force all vehicles to start their daily trips from the origin depot node and go to a rider node right after the depot.

Constraint set (129) ensures that all drivers end their daily trips at the depot. Constraint set (130) verifies that no bus goes directly from a student node to the depot. Constraint sets (131) and (132) update bookkeeping variable $\mathrm{z}_{\mathrm{ik}}$ by relating it to the main decision variable $x_{i j k}$. Constraint set (133) ensures that there is no return travel from a node back to itself. Constraint set (134) sets bookkeeping variable $\mathrm{w}_{\mathrm{ik}}$ for the origin depot node $=1$, thereby forcing the depot to be the first node visited by each vehicle. Constraint sets (135) update bookkeeping variable $\mathrm{w}_{\mathrm{ik}}$ and together disallow sub-tours in the routing model. Constraint set (136) makes sure that each student is picked up by a vehicle that visits his/her assigned school (destination). Constraint set (137) guarantees that a driver picks up riders before that visiting their destination schools. Constraint set (138) is another valid inequality that ensures no student is on a vehicle that does not visit his/her destination 
school. Constraint set (139) makes sure that the students on the bus do not exceed the capacity of the vehicle after departing each node.

This model has not been validated using simulation and/or real-world examples. The validation of this model needs further analysis and generating random small examples that are solvable by hand. This can all be a potential future area for research to use a simple ride sharing problem with open time windows. The number of vehicles can also be set as a decision variable to be minimized in the objective function of the ride sharing problem.

\subsubsection{Ride Sharing Problem with Time Window}

\section{Sets}

K: Set of vehicles

P: Set of pickup locations

D: Set of delivery nodes

$R$ : Set of riders

A: Set of arcs

\section{Decision Variables}

$$
\begin{aligned}
& y^{r}=\left\{\begin{array}{lr}
1 & \text { if rider } r \text { drives himself / herself } \\
0 & \text { Otherwise }
\end{array}\right. \\
& x_{i j}^{d}=\left\{\begin{array}{lr}
1 & \text { if driver } \text { d uses arc }(i, j) \\
0 & \text { Otherwise }
\end{array}\right. \\
& x_{i j}^{r}= \begin{cases}1 & \text { if rider } r \text { uses arc }(i, j) \\
0 & \text { Otherwise }\end{cases}
\end{aligned}
$$

\section{Parameters}


T: The planning horizon

$t_{i j}$ : Travel time between locations $i$ and $j$

$d_{i j}:$ Travel distance between locations $i$ and $j$

$v(d):$ Driver's origin, $v(d) \epsilon P$

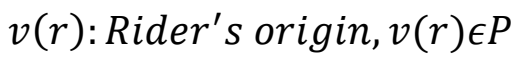

$w(d):$ Driver's destination, $w(d) \epsilon P$

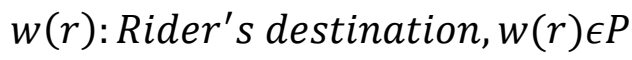

$e(d):$ Earliest time at which driver $d$ can depart from his/her origin $v(d)$

$e(r):$ Earliest time at which rider $r$ can depart from his/her origin $v(r)$

$l(d):$ Latest time at which driver $d$ can arrive at his/her destination $w(d)$

$l(r):$ Latest time at which rider $r$ can arrive at his/her destination $w(r)$

$q(d):$ Sparse seat available for driver $d$

\section{Mathematical model}

$$
\text { Minimize } Z=\sum_{r} t_{(v(r), w(r))} y^{r}+\sum_{d} \sum_{i, j} t_{i j} x_{i j}^{d}
$$

S.T.

$$
\begin{array}{lc}
\sum_{j} x_{(v(r), e(r)), j}^{r}+y^{r}=1 & r \in R \\
\sum_{i} x_{i,(w(r), l(r))}^{r}+y^{r}=1 & r \in R \\
\sum_{j} x_{j i}^{r}=\sum_{j} x_{j i}^{r} & r \in R, i \in N \backslash\{(v(r), e(r)),(w(r), l(r))\}
\end{array}
$$




$$
\begin{array}{lc}
\sum_{j} x_{(v(d), e(d)), j}^{d}=1 & d \epsilon D \\
\sum_{j} x_{i,(w(d), l(d))}^{d}=1 & d \epsilon D \\
\sum_{j} x_{j i}^{d}=\sum_{j} x_{j i}^{d} & d \epsilon D, i \in N \backslash\{(v(d), e(d)),(w(d), l(d))\} \\
\sum_{r} x_{i j}^{r} \leq \sum_{d} q(d) . x_{j i}^{d} & (i, j) \epsilon A
\end{array}
$$

Objective function (140) minimizes the total travel time in the system. Constraints (141) to (143) ensure that the riders get from their origin to their destination. Constraints (144) to (146) assure that the drivers go from their origin to their destination. Constraint (147) ensure that the riders who don't driver themselves are always assigned to a driver.

The assignment of food delivery points to non-profit agencies and scheduling the collections and delivering donations done by Davis, Sengul [50] is another application of our model SSASBRP-SNS. As another area that SSA-SBRP-SNS model can be applied, mid-day food distribution to schools can also be among other applications of our proposed model. In this problem done by Mahadevan, Sivakumar [51], a vehicle is assigned to each school for the purpose of delivering mid-day meals to schools on a daily basis and the routes are generated to do so.

\subsubsection{Flexible Public Transportation Services}

The flex transit services could be considered similar to a ride sharing with more than one independent passengers, like Uber pool, but with a higher number of passengers. A variety of services without fixed route that are not fully demand responsive belong to the group of flexible public transportation services or flexible route networks. These services are a hybrid of the fixed route traditional transportation services and the fully demand responsive services [52]. Public 
transit agencies are typically responsible to operate and serve these customers. These types of services are more practical and more common in rural areas or even small urban areas due to the low demand. Demand responsive services are normally costly which many people cannot afford especially in rural areas. Therefore, flexible public transportation can be such a great and affordable replacement in the areas for even a lower demand mainly used by senior citizens and people with disabilities [53]. The main characteristics of the flexible public transportation services and the differences with other routing models like SSA-SBRP-SNS include the deviations in routes and stopping points. The routes of the vehicles can be determined based on the demand that was received and this is the fact that makes it a flexible transportation service. However, in the traditional routing models, the routes are not changed on a daily basis and are normally implemented for quite a long time (a year or a season). Due to the deviation in the routes, vehicles stop at points that a customer exists and is ready for pickup which can be determined based on the demand. Also, the vehicles stop in response to the customer demand while students are dropped off at the designated schools in groups when the bus arrives that school. 


\section{Chapter 6: Conclusion and Future Work}

This study provides a pragmatic approach for supporting school district practitioners in making important decisions on the arrangements for transportation of special needs students to schools from their home in a cost-effective way without compromising students' needs. In this work, we address the problem of assigning special needs students to schools based on their needs while generating school bus routes. This problem differs from a traditional school bus routing problem as the special needs students must be picked up and dropped off individually at their homes rather than in groups from designated bus stops. This model integrates the student to school assignment and school bus routing problems to assign special needs students to schools based on their needs while providing efficient school bus routes (with minimum travel distance) to transport them to school. We also propose a heuristic solution approach that can solve practical size instances in a reasonable amount of time.

We designed experiments with different parameter values to compare the performance ratios with the literature. The overall ratios of our heuristic approach are lower on average than the best method available in the literature. We show that our solution approach performs well compared to the literature by providing a high-quality solution in a reasonable amount of time for a real-world case study with 111 special needs students and nine schools in Fort Smith, Arkansas.

Our solution approach leads to a $35 \%$ savings in terms of the total distance that is traveled by buses compared to the results available in the literature from Kamali, Mason [43] using the same

data set. A sensitivity analysis was conducted leading to the realization that the selection of 
students as the cluster centroids is important, so it is recommended to run the algorithm multiple times to get the best result possible from the heuristic solution approach as long as resources allow.

Several random instances were designed to validate the goal programming model. The addition of ride distance minimization as an objective function to the single objective model improves it (ride distance) by $21 \%$ on average using these random instances. Therefore, it is worthwhile to consider multi-objective model that minimizes the maximum ride distance along with the total traveled distance. This becomes even more important when dealing with special needs students.

This work is aimed to provide a better guideline for transporting the special needs students to schools based on their needs and school capacities. It helps school district officials to make decisions in both strategic and operational levels which can result in monetary savings. We also showed that the model and solution approach work for real-world cases. However, time constraints must also be taken into consideration as it might be very important for special needs students to avoid sitting on the bus for a long period of time.

Due to the nature of this problem, exact solution approaches are not capable of solving it to optimality particularly when the problem size is very large. Therefore, it is crucial to develop nontraditional ways to obtain a high-quality feasible solution. As a future study, time window can be added to both single objective and multi-objective integrated models to assure that students are not spending more time than a threshold value in the bus. School bell times are also another parameter that can be added to make the model more realistic. This constraint will make sure the buses deliver students to their schools no later than the school bell time. Moreover, it can be investigated if other 
heuristics or meta-heuristic methods can outperform the results provided by our developed heuristic solution approach. 


\section{References}

1. McPherson, M., et al., A new definition of children with special health care needs. Pediatrics, 1998. 102(1): p. 137-139.

2. Park, J. and B.I. Kim, The school bus routing problem: A review. European Journal of Operational Research, 2010. 202(2): p. 311-319.

3. Ellegood, W.A., et al., School bus routing problem: Contemporary trends and research directions. Omega, 2020. 95: p. 102056.

4. Newton, R.M. and W.H. Thomas, Design of school bus routes by computer. SocioEconomic Planning Sciences, 1969. 3(1): p. 75-85.

5. Kumar, Y., S. Jain, and Ieee, School Bus Routing Based on Branch and Bound Approach. 2015 International Conference on Computer, Communication and Control. 2015.

6. Bektas, T. and S. Elmastas, Solving school bus routing problems through integer programming. Journal of the Operational Research Society, 2007. 58(12): p. 1599-1604.

7. Fugenschuh, A., Solving a school bus scheduling problem with integer programming. European Journal of Operational Research, 2009. 193(3): p. 867-884.

8. Kinable, J., F.C.R. Spieksma, and G. Vanden Berghe, School bus routing-a column generation approach. International Transactions in Operational Research, 2014. 21(3): p. 453-478.

9. Riera-Ledesma, J. and J.J. Salazar-Gonzalez, A column generation approach for a school bus routing problem with resource constraints. Computers \& Operations Research, 2013. 40(2): p. 566-583. 
10. Park, J., H. Tae, and B.I. Kim, A post-improvement procedure for the mixed load school bus routing problem. European Journal of Operational Research, 2012. 217(1): p. 204213.

11. Ellegood, W.A., J.F. Campbell, and J. North, Continuous approximation models for mixed load school bus routing. Transportation Research Part B-Methodological, 2015. 77: p. 182-198.

12. Yao, B.Z., et al., A two-stage heuristic algorithm for the school bus routing problem with mixed load plan. Transportation Letters-the International Journal of Transportation Research, 2016. 8(4): p. 205-219.

13. Lima, F.M.S., et al., A mixed load capacitated rural school bus routing problem with heterogeneous fleet: Algorithms for the Brazilian context. Expert Systems with Applications, 2016. 56: p. 320-334.

14. Lima, F.M.D., et al., A multi-objective capacitated rural school bus routing problem with heterogeneous fleet and mixed loads. 4or-a Quarterly Journal of Operations Research, 2017. 15(4): p. 359-386.

15. Karp, R.M., On the computational complexity of combinatorial problems. Networks, 1975. 5(1): p. 45-68.

16. Kumar, R., G. Gopal, and R. Kumar, Novel crossover operator for genetic algorithm for permutation problems. International Journal of Soft Computing and Engineering (IJSCE), 2013. 3(2): p. 252-258.

17. Al-Khatib, R.M. and K.M.O. Nahar, SRT-GA: Smart Real-Time System using A Powerful Genetic Algorithm for School Bus Routing Problem. Proceedings of 2017 2nd 
International Conference on the Applications of Information Technology in Developing Renewable Energy Processes \& Systems, ed. G.F. Issa, et al. 2017.

18. Oluwadare, S.A., I.P. Oguntuyi, and J.C. Nwaiwu, Solving School Bus Routing Problem using Genetic Algorithm-based Model. 2018.

19. Díaz-Parra, O., J.A. Ruiz-Vanoye, and J.C. Zavala-Díaz, School bus routing problem library-SBRPLIB. International Journal of Combinatorial Optimization Problems and Informatics, 2011. 2(1): p. 23-26.

20. Diaz-Parra, O., et al., A Vertical Transfer Algorithm for the School Bus Routing Problem, in Proceedings of the 2012 Fourth World Congress on Nature and Biologically Inspired Computing, A. Gelbukh, et al., Editors. 2012. p. 66-71.

21. Minocha, B. and S. Tripathi, Solving School Bus Routing Problem Using Hybrid Genetic Algorithm: A Case Study, in Proceedings of the Second International Conference on Soft Computing for Problem Solving, B.V. Babu, et al., Editors. 2014. p. 93-103.

22. Phyu, S., G. Srijuntongsiri, and Ieee, A Binary Coded Multi-Parent Genetic Algorithm for Shuttle Bus Routing System in a College Campus. 2016 International Conference on Advanced Informatics - Concepts, Theory and Application. 2016.

23. Zhang, J.J. and Y.G. Li, School Bus Problem and its Algorithm, in International Conference on Future Computer Supported Education, G. Lee, Editor. 2012. p. 8-11.

24. Jaradat, A.S., Solving School Bus Routing Problem by Intelligent Water Drops Algorithm. International journal of trends in computer science, 2020(2).

25. Elgarej, M., K. Mansouri, and M. Youssfi, Route Optimization for School Bus Scheduling Problem Based on a Distributed Ant Colony System Algorithm. 2017 Intelligent Systems and Computer Vision, ed. E. Nfaoui, et al. 2017. 
26. Spada, M., M. Bierlaire, and T.M. Liebling, Decision-aiding methodology for the school bus routing and scheduling problem. Transportation Science, 2005. 39(4): p. 477-490.

27. Galdi, M. and P. Thebpanya, Optimizing School Bus Stop Placement in Howard County, Maryland: A GIS-Based Heuristic Approach. International Journal of Applied Geospatial Research, 2016. 7(1): p. 30-44.

28. Kim, B.I., S. Kim, and J. Park, A school bus scheduling problem. European Journal of Operational Research, 2012. 218(2): p. 577-585.

29. Chen, X.P., et al., Exact and Metaheuristic Approaches for a Bi-Objective School Bus Scheduling Problem. Plos One, 2015. 10(7).

30. Schittekat, P., et al., A metaheuristic for the school bus routing problem with bus stop selection. European Journal of Operational Research, 2013. 229(2): p. 518-528.

31. Faraj, M.F., et al., A Real Geographical Application for the School Bus Routing Problem. 2014 Ieee 17th International Conference on Intelligent Transportation Systems. 2014. 2762-2767.

32. Sarubbi, J.F.M., et al., A Strategy for Clustering Students Minimizing the Number of Bus Stops for Solving the School Bus Routing Problem, in Noms 2016 - 2016 Ieee/Ifip Network Operations and Management Symposium, S.O. Badonnel, et al., Editors. 2016. p. $1175-1180$.

33. Bogl, M., K.F. Doerner, and S.N. Parragh, The School Bus Routing and Scheduling Problem with Transfers. Networks, 2015. 65(2): p. 180-203.

34. Unsal, O. and T. Yigit, Using the Genetic Algorithm for the Optimization of Dynamic School Bus Routing Problem. Brain-Broad Research in Artificial Intelligence and Neuroscience, 2018. 9(2): p. 6-21. 
35. Wang, J.G., X.Q. Huang, and Ieee, Routing School Bus for Better Student Learning, in 2017 25th International Conference on Geoinformatics. 2017.

36. Hashi, E.K., et al., GIS based Heuristic Solution of the Vehicle Routing Problem to Optimize the School Bus Routing and Scheduling, in Proceedings of the 2016 19th International Conference on Computer and Information Technology. 2016. p. 56-60.

37. Parvasi, S.P., M. Mahmoodjanloo, and M. Setak, A bi-level school bus routing problem with bus stops selection and possibility of demand outsourcing. Applied Soft Computing, 2017. 61: p. 222-238.

38. Bouzarth, E.L., et al., Assigning students to schools to minimize both transportation costs and socioeconomic variation between schools. Socio-Economic Planning Sciences, 2018. 64: p. $1-8$.

39. Charnes, A., W.W. Cooper, and R.O. Ferguson, Optimal estimation of executive compensation by linear programming. Management science, 1955. 1(2): p. 138-151.

40. Ghoseiri, K. and S.F. Ghannadpour, Multi-objective vehicle routing problem with time windows using goal programming and genetic algorithm. Applied Soft Computing, 2010. 10(4): p. 1096-1107.

41. Jolai, F., et al., A goal programming model for single vehicle routing problem with multiple routes. Journal of Industrial and Systems Engineering, 2008. 2(2): p. 154-163.

42. Fricker, J. and J.D. Fricker, PRACTICAL APPROACH FOR SOLVING SCHOOL BUS PROBLEMS. Transportation Research Record, 1988(1202).

43. Kamali, B., S.J. Mason, and E.A. Pohl, An Analysis of Special Needs Student Busing. Journal of Public Transportation, 2013. 16(1): p. 21-45. 
44. Caceres, H., R. Batta, and Q. He, Special need students school bus routing: Consideration for mixed load and heterogeneous fleet. Socio-Economic Planning Sciences, 2019. 65: p. 10-19.

45. MacQueen, J. Some methods for classification and analysis of multivariate observations. in Proceedings of the fifth Berkeley symposium on mathematical statistics and probability. 1967. Oakland, CA, USA.

46. Mulvey, J.M. and M.P. Beck, Solving capacitated clustering problems. European Journal of Operational Research, 1984. 18(3): p. 339-348.

47. Ripplinger, D. and Trb, Rural school vehicle routing problem, in Safety: Older Drivers; Traffic Law Enforcement; Management; School Transportation; Emergency Evacuation; Truck and Bus; and Motorcycles. 2005. p. 105-110.

48. Liang, L.J.J., An Algorithmic Study on Ridesharing Problem. 2016, Applied Sciences: School of Computing Science.

49. Agatz, N., et al., Sustainable passenger transportation: Dynamic ride-sharing. 2010.

50. Davis, L.B., et al., Scheduling food bank collections and deliveries to ensure food safety and improve access. Socio-Economic Planning Sciences, 2014. 48(3): p. 175-188.

51. Mahadevan, B., et al., Redesigning midday meal logistics for the Akshaya Patra Foundation: OR at work in feeding hungry school children. Interfaces, 2013. 43(6): p. $530-546$.

52. Fu, L., Planning and design of flex-route transit services. Transportation Research Record, 2002. 1791(1): p. 59-66.

53. Potts, J.F., et al., A guide for planning and operating flexible public transportation services. 2010. 


\section{Appendix A: Detailed Result}


Table 22 - Detailed Result of randomly generated instances

\begin{tabular}{|c|c|c|c|c|c|c|c|c|c|c|c|c|c|c|c|c|}
\hline No & $\begin{array}{c}\text { Case } \\
\text { Number }\end{array}$ & Run & Bus & Students & Schools & Area & $\begin{array}{c}\text { Obj } \\
\text { Value }\end{array}$ & Time Opt & CCARP I & TIME & $\begin{array}{c}\text { CCARP } \\
\text { II }\end{array}$ & TIME & $\begin{array}{c}\text { CCARP } \\
\text { III }\end{array}$ & TIME & Ratio & Gap \% \\
\hline 1 & 1 & run 1 & 2 & 20 & 2 & $100 \mathrm{sq} \mathrm{m}$ & 45.721 & 12.65 & 47.157 & 2.73 & 46.642 & 2 & 51.154 & 1.53 & 1.03 & $3.14 \%$ \\
\hline 2 & 1 & run 2 & 2 & 20 & 2 & $100 \mathrm{sq} \mathrm{m}$ & 52.672 & 2.54 & 53.431 & 1.95 & 55.909 & 1.66 & 53.431 & 3.3 & 1.01 & $1.44 \%$ \\
\hline 3 & 1 & run 3 & 2 & 20 & 2 & $100 \mathrm{sq} \mathrm{m}$ & 45.673 & 4.15 & 46.354 & 1.17 & 50.147 & 2.01 & 46.49 & 1.87 & 1.01 & $1.49 \%$ \\
\hline 4 & 1 & run 4 & 2 & 20 & 2 & $100 \mathrm{sq} \mathrm{m}$ & 46.461 & 4.38 & 47.985 & 1.82 & 46.993 & 2.02 & 46.886 & 1.53 & 1.03 & $3.28 \%$ \\
\hline 5 & 1 & run 5 & 2 & 20 & 2 & $100 \mathrm{sq} \mathrm{m}$ & 48.867 & 1.35 & 53.885 & 1.61 & 53.885 & 1.43 & 54.618 & 1.4 & 1.10 & $10.27 \%$ \\
\hline 6 & 1 & run 6 & 2 & 20 & 2 & $100 \mathrm{sq} \mathrm{m}$ & 48.808 & 5.77 & 52.644 & 3.64 & 52.846 & 2.39 & 53.107 & 1.84 & 1.08 & $7.86 \%$ \\
\hline 7 & 1 & run 7 & 2 & 20 & 2 & $100 \mathrm{sq} \mathrm{m}$ & 50.302 & 5.28 & 53 & 1.59 & 50.301 & 1.51 & 53.29 & 1.34 & 1.05 & $5.36 \%$ \\
\hline 8 & 1 & run 8 & 2 & 20 & 2 & $100 \mathrm{sq} \mathrm{m}$ & 52.974 & 0.67 & 59.31 & 1.31 & 56.662 & 1.1 & 57.87 & 1.06 & 1.12 & $11.96 \%$ \\
\hline 9 & 1 & run 9 & 2 & 20 & 2 & $100 \mathrm{sq} \mathrm{m}$ & 50.123 & 12.11 & 52.969 & 1.33 & 51.818 & 1.59 & 51.575 & 1.61 & 1.06 & $5.68 \%$ \\
\hline 10 & 1 & run 10 & 2 & 20 & 2 & $100 \mathrm{sq} \mathrm{m}$ & 43.002 & 7.31 & 48.493 & 1.51 & 43.002 & 2.56 & 49.385 & 1.89 & 1.13 & $12.77 \%$ \\
\hline 11 & 2 & run 1 & 2 & 20 & 2 & $400 \mathrm{sq} \mathrm{m}$ & 94.914 & 9.19 & 102.079 & 3.46 & 102.656 & 1.61 & 101.922 & 1.62 & 1.08 & $7.55 \%$ \\
\hline 12 & 2 & run 2 & 2 & 20 & 2 & $400 \mathrm{sq} \mathrm{m}$ & 98.832 & 0.42 & 102.933 & 2.48 & 107.316 & 1.2 & 109.545 & 2.05 & 1.04 & $4.15 \%$ \\
\hline 13 & 2 & run 3 & 2 & 20 & 2 & $400 \mathrm{sq} \mathrm{m}$ & 90.1 & 10.88 & 90.1 & 2.15 & 94.2 & 2.26 & 96.052 & 2.62 & 1.00000 & $0.00 \%$ \\
\hline 14 & 2 & run 4 & 2 & 20 & 2 & $400 \mathrm{sq} \mathrm{m}$ & 86.59 & 15.96 & 86.691 & 2.43 & 86.691 & 2.36 & 86.59 & 4.29 & 1.00117 & $0.12 \%$ \\
\hline 15 & 2 & run 5 & 2 & 20 & 2 & $400 \mathrm{sq} \mathrm{m}$ & 84.352 & 2.03 & 94.892 & 1.75 & 92.256 & 1.43 & 92.256 & 1.25 & 1.12 & $12.50 \%$ \\
\hline 16 & 2 & run 6 & 2 & 20 & 2 & $400 \mathrm{sq} \mathrm{m}$ & 93.125 & 1.92 & 96.519 & 1.65 & 100.029 & 1.27 & 96.519 & 2.03 & 1.04 & $3.64 \%$ \\
\hline 17 & 2 & run 7 & 2 & 20 & 2 & $400 \mathrm{sq} \mathrm{m}$ & 107.446 & 9 & 113.225 & 1.6 & 107.446 & 1.4 & 118.25 & 2.08 & 1.05 & $5.38 \%$ \\
\hline 18 & 2 & run 8 & 2 & 20 & 2 & $400 \mathrm{sq} \mathrm{m}$ & 89.215 & 20.65 & 89.215 & 1.77 & 89.215 & 2.13 & 89.36 & 1.92 & 1.00000 & $0.00 \%$ \\
\hline 19 & 2 & run 9 & 2 & 20 & 2 & $400 \mathrm{sq} \mathrm{m}$ & 98.633 & 1.61 & 105.153 & 3.03 & 104.691 & 1.4 & 99.665 & 0.84 & 1.07 & $6.61 \%$ \\
\hline 20 & 2 & run 10 & 2 & 20 & 2 & $400 \mathrm{sq} \mathrm{m}$ & 95.862 & 0.37 & 100.807 & 3.06 & 114.492 & 6.29 & 111.933 & 1.89 & 1.05 & $5.16 \%$ \\
\hline 21 & 3 & run 1 & 2 & 20 & 4 & $100 \mathrm{sq} \mathrm{m}$ & 45.731 & 12.3 & 49.829 & 2.13 & 51.598 & 2.57 & 51.72 & 1.81 & 1.09 & $8.96 \%$ \\
\hline 22 & 3 & run 2 & 2 & 20 & 4 & $100 \mathrm{sq} \mathrm{m}$ & 38.885 & 56.04 & 42.018 & 2.48 & 42.719 & 1.94 & 42.243 & 2.81 & 1.08 & $8.06 \%$ \\
\hline 23 & 3 & run 3 & 2 & 20 & 4 & $100 \mathrm{sq} \mathrm{m}$ & 44.463 & 34.11 & 47.505 & 2.61 & 48.296 & 2.33 & 49.521 & 4.86 & 1.07 & $6.84 \%$ \\
\hline 24 & 3 & run 4 & 2 & 20 & 4 & $100 \mathrm{sq} \mathrm{m}$ & 49.971 & 26.19 & 52.11 & 2.64 & 55.736 & 3.09 & 56.411 & 2.77 & 1.04 & $4.28 \%$ \\
\hline 25 & 3 & run 5 & 2 & 20 & 4 & $100 \mathrm{sq} \mathrm{m}$ & 49.736 & 91.35 & 58.238 & 3.72 & 51.592 & 4.08 & 54.755 & 2.2 & 1.17 & $17.09 \%$ \\
\hline 26 & 3 & run 6 & 2 & 20 & 4 & $100 \mathrm{sq} \mathrm{m}$ & 48.724 & 26.71 & 54.219 & 5.9 & 52.391 & 4.98 & 48.724 & 5.01 & 1.11 & $11.28 \%$ \\
\hline
\end{tabular}




\begin{tabular}{|c|c|c|c|c|c|c|c|c|c|c|c|c|c|c|c|c|}
\hline 27 & 3 & run 7 & 2 & 20 & 4 & $100 \mathrm{sq} \mathrm{m}$ & 55.032 & 29.62 & 59.831 & 1.95 & 59.841 & 2.19 & 57.881 & 2.18 & 1.09 & $8.72 \%$ \\
\hline 28 & 3 & run 8 & 2 & 20 & 4 & $100 \mathrm{sq} \mathrm{m}$ & 53.553 & 127.64 & 55.353 & 2.82 & 55.353 & 2.62 & 59.299 & 2.3 & 1.03 & $3.36 \%$ \\
\hline 29 & 3 & run 9 & 2 & 20 & 4 & $100 \mathrm{sq} \mathrm{m}$ & 50.825 & 276.9 & 50.825 & 3.39 & 54.027 & 10.78 & 54.027 & 3.53 & 1.00000 & $0.00 \%$ \\
\hline 30 & 3 & run 10 & 2 & 20 & 4 & $100 \mathrm{sq} \mathrm{m}$ & 52.787 & 34.62 & 54.979 & 3.31 & 54.979 & 2.47 & 54.979 & 2.38 & 1.04 & $4.15 \%$ \\
\hline 31 & 4 & run 1 & 2 & 20 & 4 & $400 \mathrm{sq} \mathrm{m}$ & 101.585 & 177.03 & 114.749 & 4.91 & 112.17 & 3.14 & 110.541 & 3.64 & 1.13 & $12.96 \%$ \\
\hline 32 & 4 & run 2 & 2 & 20 & 4 & $400 \mathrm{sq} \mathrm{m}$ & 92.121 & 5.39 & 101.486 & 2.37 & 103.304 & 4.63 & 99.071 & 1.73 & 1.10 & $10.17 \%$ \\
\hline 33 & 4 & run 3 & 2 & 20 & 4 & $400 \mathrm{sq} \mathrm{m}$ & 85.958 & 5.1 & 93.665 & 1.79 & 99.565 & 3.5 & 92.703 & 1.84 & 1.09 & $8.97 \%$ \\
\hline 34 & 4 & run 4 & 2 & 20 & 4 & $400 \mathrm{sq} \mathrm{m}$ & 103.557 & 133.43 & 107.861 & 4.51 & 106.622 & 5.05 & 118.674 & 3.19 & 1.04 & $4.16 \%$ \\
\hline 35 & 4 & run 5 & 2 & 20 & 4 & $400 \mathrm{sq} \mathrm{m}$ & 100.086 & 16.43 & 109.586 & 4.93 & 103.034 & 2.73 & 112.72 & 2.37 & 1.09 & $9.49 \%$ \\
\hline 36 & 4 & run 6 & 2 & 20 & 4 & $400 \mathrm{sq} \mathrm{m}$ & 98.314 & 101.63 & 98.314 & 5.54 & 113.47 & 3.32 & 98.314 & 8.97 & 1.00000 & $0.00 \%$ \\
\hline 37 & 4 & run 7 & 2 & 20 & 4 & $400 \mathrm{sq} \mathrm{m}$ & 99.176 & 5.99 & 112.67 & 1.71 & 105.855 & 2.46 & 99.183 & 1.96 & 1.14 & $13.61 \%$ \\
\hline 38 & 4 & run 8 & 2 & 20 & 4 & $400 \mathrm{sq} \mathrm{m}$ & 105.519 & 6.75 & 110.064 & 2.85 & 116.436 & 2.81 & 125.21 & 2.98 & 1.04 & $4.31 \%$ \\
\hline 39 & 4 & run 9 & 2 & 20 & 4 & $400 \mathrm{sq} \mathrm{m}$ & 89.439 & 19.33 & 94.038 & 3.12 & 98.031 & 3.33 & 96.227 & 2.36 & 1.05 & $5.14 \%$ \\
\hline 40 & 4 & run 10 & 2 & 20 & 4 & $400 \mathrm{sq} \mathrm{m}$ & 104.677 & 22.97 & 117.747 & 3.49 & 119.53 & 2.36 & 122.256 & 2.43 & 1.12 & $12.49 \%$ \\
\hline 41 & 5 & run 1 & 2 & 20 & 6 & $100 \mathrm{sq} \mathrm{m}$ & 57.032 & 21.92 & 58.961 & 3.71 & 57.032 & 3.48 & 64.331 & 3.37 & 1.03 & $3.38 \%$ \\
\hline 42 & 5 & run 2 & 2 & 20 & 6 & $100 \mathrm{sq} \mathrm{m}$ & 50.158 & 402.93 & 55.846 & 4.82 & 50.158 & 5.28 & 55.099 & 4.62 & 1.11 & $11.34 \%$ \\
\hline 43 & 5 & run 3 & 2 & 20 & 6 & $100 \mathrm{sq} \mathrm{m}$ & 47.31 & 92.56 & 51.347 & 4.73 & 51.024 & 10.94 & 51.014 & 8.27 & 1.09 & $8.53 \%$ \\
\hline 44 & 5 & run 4 & 2 & 20 & 6 & $100 \mathrm{sq} \mathrm{m}$ & 48.416 & 33.51 & 52.874 & 5.02 & 54.627 & 6.83 & 54.627 & 4.1 & 1.09 & $9.21 \%$ \\
\hline 45 & 5 & run 5 & 2 & 20 & 6 & $100 \mathrm{sq} \mathrm{m}$ & 45.607 & 230.29 & 46.151 & 6.1 & 46.769 & 11.77 & 48.05 & 5.82 & 1.01 & $1.19 \%$ \\
\hline 46 & 5 & run 6 & 2 & 20 & 6 & $100 \mathrm{sq} \mathrm{m}$ & 51.39 & 180.89 & 56.41 & 4.25 & 51.39 & 3.96 & 51.39 & 3.97 & 1.10 & $9.77 \%$ \\
\hline 47 & 5 & run 7 & 2 & 20 & 6 & $100 \mathrm{sq} \mathrm{m}$ & 53.476 & 29.88 & 59.365 & 2.76 & 59.365 & 3.18 & 60.359 & 4.65 & 1.11 & $11.01 \%$ \\
\hline 48 & 5 & run 8 & 2 & 20 & 6 & $100 \mathrm{sq} \mathrm{m}$ & 52.053 & 77.76 & 54.076 & 4.62 & 53.943 & 5.58 & 58.051 & 5.42 & 1.04 & $3.89 \%$ \\
\hline 49 & 5 & run 9 & 2 & 20 & 6 & $100 \mathrm{sq} \mathrm{m}$ & 48.986 & 224.97 & 52.064 & 13.52 & 51.053 & 9.48 & 56.784 & 12.84 & 1.06 & $6.28 \%$ \\
\hline 50 & 5 & run 10 & 2 & 20 & 6 & $100 \mathrm{sq} \mathrm{m}$ & 50.897 & 12.92 & 53.62 & 3.42 & 50.896 & 2.83 & 52.661 & 3.06 & 1.05 & $5.35 \%$ \\
\hline 51 & 6 & run 1 & 2 & 20 & 6 & $400 \mathrm{sq} \mathrm{m}$ & 108.805 & 54.42 & 117.006 & 3.37 & 114.392 & 3.2 & 115.524 & 4.72 & 1.08 & $7.54 \%$ \\
\hline 52 & 6 & run 2 & 2 & 20 & 6 & $400 \mathrm{sq} \mathrm{m}$ & 87.213 & 30.9 & 90.975 & 3.61 & 87.851 & 3.99 & 93.159 & 3.55 & 1.04 & $4.31 \%$ \\
\hline 53 & 6 & run 3 & 2 & 20 & 6 & $400 \mathrm{sq} \mathrm{m}$ & 94.451 & 49.98 & 104.145 & 13.34 & 104.145 & 8.21 & 100.762 & 3.23 & 1.10 & $10.26 \%$ \\
\hline 54 & 6 & run 4 & 2 & 20 & 6 & $400 \mathrm{sq} \mathrm{m}$ & 97.547 & 31.11 & 108.418 & 4.03 & 97.547 & 2.69 & 97.547 & 2.62 & 1.11 & $11.14 \%$ \\
\hline 55 & 6 & run 5 & 2 & 20 & 6 & $400 \mathrm{sq} \mathrm{m}$ & 105.274 & 39.43 & 107.97 & 3.6 & 116.356 & 3.45 & 112.128 & 4.33 & 1.03 & $2.56 \%$ \\
\hline
\end{tabular}




\begin{tabular}{|c|c|c|c|c|c|c|c|c|c|c|c|c|c|c|c|c|}
\hline 56 & 6 & run 6 & 2 & 20 & 6 & $400 \mathrm{sq} \mathrm{m}$ & 90.215 & 121.77 & 90.342 & 4.64 & 90.342 & 4.18 & 90.342 & 4.96 & 1.00141 & $0.14 \%$ \\
\hline 57 & 6 & $\operatorname{run} 7$ & 2 & 20 & 6 & $400 \mathrm{sq} \mathrm{m}$ & 109.313 & 63.13 & 117.966 & 4.52 & 117.966 & 15.47 & 122.225 & 5.44 & 1.08 & $7.92 \%$ \\
\hline 58 & 6 & $\operatorname{run} 8$ & 2 & 20 & 6 & $400 \mathrm{sq} \mathrm{m}$ & 98.631 & 146.57 & 108.954 & 7.65 & 106.645 & 10.35 & 101.441 & 11.39 & 1.10 & $10.47 \%$ \\
\hline 59 & 6 & run 9 & 2 & 20 & 6 & $400 \mathrm{sq} \mathrm{m}$ & 98.172 & 74.24 & 108.677 & 7.39 & 106.85 & 6.72 & 106.85 & 5.84 & 1.11 & $10.70 \%$ \\
\hline 60 & 6 & run 10 & 2 & 20 & 6 & $400 \mathrm{sq} \mathrm{m}$ & 80.943 & 47.1 & 85.292 & 5.48 & 86.454 & 4.21 & 86.454 & 4.21 & 1.05 & $5.37 \%$ \\
\hline 61 & 7 & run 1 & 2 & 40 & 2 & $100 \mathrm{sq} \mathrm{m}$ & 57.831 & 247.19 & 59.447 & 12.79 & 59.436 & 9.89 & 59.447 & 11 & 1.03 & $2.79 \%$ \\
\hline 62 & 7 & run 2 & 2 & 40 & 2 & $100 \mathrm{sq} \mathrm{m}$ & 60.99 & Time Limit & 63.136 & 10.62 & 62.348 & 86.99 & 64.071 & 55.61 & 1.04 & $3.52 \%$ \\
\hline 63 & 7 & run 3 & 2 & 40 & 2 & $100 \mathrm{sq} \mathrm{m}$ & 62.06 & 392.51 & 66.119 & 4.82 & 62.9 & 8.13 & 63.529 & 6.56 & 1.07 & $6.54 \%$ \\
\hline 64 & 7 & run 4 & 2 & 40 & 2 & $100 \mathrm{sq} \mathrm{m}$ & 63.917 & Time Limit & 63.916 & 8.02 & 63.916 & 10.84 & 65.461 & 9.11 & 0.99998 & $0.00 \%$ \\
\hline 65 & 7 & run 5 & 2 & 40 & 2 & $100 \mathrm{sq} \mathrm{m}$ & 64.074 & 1964.84 & 64.689 & 8.64 & 66.331 & 10.1 & 65.385 & 6.74 & 1.01 & $0.96 \%$ \\
\hline 66 & 7 & run 6 & 2 & 40 & 2 & $100 \mathrm{sq} \mathrm{m}$ & 64.13 & 338.95 & 68.805 & 13.45 & 65.473 & 14.29 & 71.476 & 24.02 & 1.07 & $7.29 \%$ \\
\hline 67 & 7 & run 7 & 2 & 40 & 2 & $100 \mathrm{sq} \mathrm{m}$ & 63.539 & 3256.26 & 64.341 & 12.49 & 63.632 & 7.17 & 66.647 & 14 & 1.01 & $1.26 \%$ \\
\hline 68 & 7 & run 8 & 2 & 40 & 2 & $100 \mathrm{sq} \mathrm{m}$ & 60.524 & 99.43 & 64.623 & 7.33 & 65.346 & 7.59 & 65.298 & 9.47 & 1.07 & $6.77 \%$ \\
\hline 69 & 7 & run 9 & 2 & 40 & 2 & $100 \mathrm{sq} \mathrm{m}$ & 64.949 & Time Limit & 68.519 & 16.19 & 64.947 & 12.15 & 64.947 & 9.32 & 1.05 & $5.50 \%$ \\
\hline 70 & 7 & run 10 & 2 & 40 & 2 & $100 \mathrm{sq} \mathrm{m}$ & 66.481 & Time Limit & 66.654 & 41.1 & 67.076 & 20.69 & 66.654 & 19.51 & 1.00260 & $0.26 \%$ \\
\hline 71 & 8 & run 1 & 2 & 40 & 2 & $400 \mathrm{sq} \mathrm{m}$ & 120.544 & 700 & 120.543 & 13.26 & 120.543 & 15.32 & 124.208 & 14.98 & 0.99999 & $0.00 \%$ \\
\hline 72 & 8 & run 2 & 2 & 40 & 2 & $400 \mathrm{sq} \mathrm{m}$ & 132.391 & Time Limit & 135.337 & 10.17 & 136.907 & 13.46 & 139.059 & 12.64 & 1.02 & $2.23 \%$ \\
\hline 73 & 8 & run 3 & 2 & 40 & 2 & $400 \mathrm{sq} \mathrm{m}$ & 119.97 & 1395 & 139.964 & 9.5 & 135.254 & 12.7 & 135.735 & 20.15 & 1.17 & $16.67 \%$ \\
\hline 74 & 8 & run 4 & 2 & 40 & 2 & $400 \mathrm{sq} \mathrm{m}$ & 122.734 & Time Limit & 129.453 & 15.47 & 133.538 & 28.22 & 122.231 & 15.86 & 1.05 & $5.47 \%$ \\
\hline 75 & 8 & run 5 & 2 & 40 & 2 & $400 \mathrm{sq} \mathrm{m}$ & 122.408 & 1490.06 & 122.409 & 12.65 & 125.647 & 17 & 126.515 & 16.02 & 1.00001 & $0.00 \%$ \\
\hline 76 & 8 & run 6 & 2 & 40 & 2 & $400 \mathrm{sq} \mathrm{m}$ & 132.347 & 350.96 & 139.868 & 7.57 & 133.123 & 6.29 & 141.903 & 5.82 & 1.06 & $5.68 \%$ \\
\hline 77 & 8 & run 7 & 2 & 40 & 2 & $400 \mathrm{sq} \mathrm{m}$ & 121.629 & 1847.45 & 123.51 & 12.3 & 127.054 & 16.97 & 127.534 & 15.47 & 1.02 & $1.55 \%$ \\
\hline 78 & 8 & run 8 & 2 & 40 & 2 & $400 \mathrm{sq} \mathrm{m}$ & 111.623 & 1277.73 & 120.638 & 14 & 119.698 & 37.45 & 118.651 & 10.2 & 1.08 & $8.08 \%$ \\
\hline 79 & 8 & run 9 & 2 & 40 & 2 & $400 \mathrm{sq} \mathrm{m}$ & 119.637 & Time Limit & 119.037 & 33.62 & 119.037 & 39.11 & 118.311 & 40.72 & 0.99 & $0.50 \%$ \\
\hline 80 & 8 & run 10 & 2 & 40 & 2 & $400 \mathrm{sq} \mathrm{m}$ & 134.281 & 2264.29 & 143.121 & 9.48 & 141.699 & 23.12 & 143.484 & 22.18 & 1.07 & $6.58 \%$ \\
\hline 81 & 9 & run 1 & 2 & 40 & 4 & $100 \mathrm{sq} \mathrm{m}$ & 65.502 & 2269.47 & 68.785 & 15.7 & 68.633 & 16.63 & 68.785 & 17.99 & 1.05 & $5.01 \%$ \\
\hline 82 & 9 & run 2 & 2 & 40 & 4 & $100 \mathrm{sq} \mathrm{m}$ & 63.943 & Time Limit & 64.832 & 43.06 & 65.459 & 15.06 & 64.832 & 25.06 & 1.01 & $1.39 \%$ \\
\hline 83 & 9 & run 3 & 2 & 40 & 4 & $100 \mathrm{sq} \mathrm{m}$ & 64.048 & 1882.81 & 65.916 & 22.87 & 66.481 & 50.19 & 65.558 & 33.26 & 1.03 & $2.92 \%$ \\
\hline 84 & 9 & run 4 & 2 & 40 & 4 & $100 \mathrm{sq} \mathrm{m}$ & 64.891 & Time Limit & 65.115 & 40.23 & 64.457 & 43.86 & 67.31 & 54.66 & 1.00345 & $0.35 \%$ \\
\hline
\end{tabular}




\begin{tabular}{|c|c|c|c|c|c|c|c|c|c|c|c|c|c|c|c|c|}
\hline 85 & 9 & run 5 & 2 & 40 & 4 & $100 \mathrm{sq} \mathrm{m}$ & 67.392 & 1100.83 & 68.884 & 20.4 & 70.215 & 19.24 & 70.103 & 16.54 & 1.02 & $2.21 \%$ \\
\hline 86 & 9 & run 6 & 2 & 40 & 4 & $100 \mathrm{sq} \mathrm{m}$ & 66.266 & Time Limit & 66.875 & 18.7 & 66.875 & 26.4 & 67.598 & 31.89 & 1.01 & $0.92 \%$ \\
\hline 87 & 9 & run 7 & 2 & 40 & 4 & $100 \mathrm{sq} \mathrm{m}$ & 66.053 & 3292.6 & 67.354 & 27.51 & 68.964 & 19.66 & 69.048 & 30.6 & 1.02 & $1.97 \%$ \\
\hline 88 & 9 & run 8 & 2 & 40 & 4 & $100 \mathrm{sq} \mathrm{m}$ & 67.018 & 1291.43 & 70.783 & 31.72 & 70.299 & 53.78 & 71.725 & 11.64 & 1.06 & $5.62 \%$ \\
\hline 89 & 9 & run 9 & 2 & 40 & 4 & $100 \mathrm{sq} \mathrm{m}$ & 63.121 & Time Limit & 61.166 & 34.17 & 60.289 & 22.95 & 63.714 & 39.18 & 0.97 & $3.10 \%$ \\
\hline 90 & 9 & run 10 & 2 & 40 & 4 & $100 \mathrm{sq} \mathrm{m}$ & 67.775 & Time Limit & 67.775 & 19.09 & 67.775 & 42.22 & 69.489 & 31.73 & 1.00000 & $0.00 \%$ \\
\hline 91 & 10 & run 1 & 2 & 40 & 4 & $400 \mathrm{sq} \mathrm{m}$ & 121.976 & 1742.07 & 124.802 & 29.69 & 129.467 & 23.46 & 128.328 & 17.73 & 1.02 & $2.32 \%$ \\
\hline 92 & 10 & run 2 & 2 & 40 & 4 & $400 \mathrm{sq} \mathrm{m}$ & 130.35 & Time Limit & 134.849 & 64.36 & 130.081 & 12.48 & 135.912 & 52.17 & 1.03 & $3.45 \%$ \\
\hline 93 & 10 & run 3 & 2 & 40 & 4 & $400 \mathrm{sq} \mathrm{m}$ & 129.131 & Time Limit & 124.236 & 22.94 & 126.266 & 195.31 & 123.419 & 26.3 & 0.96 & $3.79 \%$ \\
\hline 94 & 10 & run 4 & 2 & 40 & 4 & $400 \mathrm{sq} \mathrm{m}$ & 139.469 & Time Limit & 136.2 & 48.02 & 137.823 & 28.96 & 136.816 & 38.41 & 0.98 & $2.34 \%$ \\
\hline 95 & 10 & run 5 & 2 & 40 & 4 & $400 \mathrm{sq} \mathrm{m}$ & 116.148 & Time Limit & 119.783 & 29.08 & 118.525 & 24.89 & 118.926 & 66.93 & 1.03 & $3.13 \%$ \\
\hline 96 & 10 & run 6 & 2 & 40 & 4 & $400 \mathrm{sq} \mathrm{m}$ & 126.393 & Time Limit & 134.485 & 50.03 & 133.595 & 102.6 & 127.919 & 58.64 & 1.06 & $6.40 \%$ \\
\hline 97 & 10 & run 7 & 2 & 40 & 4 & $400 \mathrm{sq} \mathrm{m}$ & 139.167 & 879.7 & 145.066 & 17.29 & 146.757 & 8.95 & 146.606 & 14.1 & 1.04 & $4.24 \%$ \\
\hline 98 & 10 & run 8 & 2 & 40 & 4 & $400 \mathrm{sq} \mathrm{m}$ & 126.28 & 532.33 & 132.429 & 16.8 & 134.179 & 39.11 & 130.631 & 21.31 & 1.05 & $4.87 \%$ \\
\hline 99 & 10 & run 9 & 2 & 40 & 4 & $400 \mathrm{sq} \mathrm{m}$ & 131.013 & 1197.41 & 140.085 & 21.43 & 141.708 & 34.72 & 135.499 & 14.43 & 1.07 & $6.92 \%$ \\
\hline 100 & 10 & run 10 & 2 & 40 & 4 & $400 \mathrm{sq} \mathrm{m}$ & 128.496 & Time Limit & 129.927 & 10.44 & 134.938 & 17.09 & 132.229 & 18.98 & 1.01 & $1.11 \%$ \\
\hline 101 & 11 & run 1 & 2 & 40 & 6 & $100 \mathrm{sq} \mathrm{m}$ & 72.571 & Time Limit & 69.114 & 60.41 & 69.543 & 35.29 & 71.572 & 32.74 & 0.95 & $4.76 \%$ \\
\hline 102 & 11 & run 2 & 2 & 40 & 6 & $100 \mathrm{sq} \mathrm{m}$ & 63.936 & Time Limit & 69.076 & 35 & 69.983 & 62.05 & 69.076 & 55.96 & 1.08 & $8.04 \%$ \\
\hline 103 & 11 & run 3 & 2 & 40 & 6 & $100 \mathrm{sq} \mathrm{m}$ & 65.638 & 2332.29 & 69.533 & 24.11 & 67.167 & 35.9 & 68.603 & 24.23 & 1.06 & $5.93 \%$ \\
\hline 104 & 11 & run 4 & 2 & 40 & 6 & $100 \mathrm{sq} \mathrm{m}$ & 65.43 & Time Limit & 67.443 & 22.79 & 64.046 & 22.71 & 67.012 & 18.44 & 1.03 & $3.08 \%$ \\
\hline 105 & 11 & run 5 & 2 & 40 & 6 & $100 \mathrm{sq} \mathrm{m}$ & 60.017 & 3415.08 & 65.087 & 31.03 & 60.016 & 19.04 & 64.123 & 21.67 & 1.08 & $8.45 \%$ \\
\hline 106 & 11 & run 6 & 2 & 40 & 6 & $100 \mathrm{sq} \mathrm{m}$ & 62.82 & 530.47 & 62.82 & 33.53 & 62.82 & 12.25 & 64.483 & 16.62 & 1.00000 & $0.00 \%$ \\
\hline 107 & 11 & run 7 & 2 & 40 & 6 & $100 \mathrm{sq} \mathrm{m}$ & 61.17 & Time Limit & 59.273 & 19.68 & 58.778 & 45.19 & 58.778 & 32.24 & 0.97 & $3.10 \%$ \\
\hline 108 & 11 & run 8 & 2 & 40 & 6 & $100 \mathrm{sq} \mathrm{m}$ & 65.936 & Time Limit & 64.841 & 34.43 & 68.841 & 41.81 & 64.841 & 21 & 0.98 & $1.66 \%$ \\
\hline 109 & 11 & run 9 & 2 & 40 & 6 & $100 \mathrm{sq} \mathrm{m}$ & 68.112 & Time Limit & 66.046 & 44.11 & 64.361 & 38.39 & 68.294 & 62.29 & 0.97 & $3.03 \%$ \\
\hline 110 & 11 & run 10 & 2 & 40 & 6 & $100 \mathrm{sq} \mathrm{m}$ & 68.988 & Time Limit & 67.282 & 22.72 & 69.342 & 20.04 & 70.966 & 42.97 & 0.98 & $2.47 \%$ \\
\hline 111 & 12 & run 1 & 2 & 40 & 6 & $400 \mathrm{sq} \mathrm{m}$ & 126.54 & Time Limit & 140.907 & 29.5 & 140.097 & 27.97 & 130.353 & 20.77 & 1.11 & $11.35 \%$ \\
\hline 112 & 12 & run 2 & 2 & 40 & 6 & $400 \mathrm{sq} \mathrm{m}$ & 128.04 & Time Limit & 148.724 & 19.49 & 153.201 & 24.26 & 144.303 & 19.27 & 1.16 & $16.15 \%$ \\
\hline 113 & 12 & run 3 & 2 & 40 & 6 & $400 \mathrm{sq} \mathrm{m}$ & 116.86 & Time Limit & 128.527 & 19.77 & 128.625 & 25.1 & 127.961 & 31.97 & 1.10 & $9.98 \%$ \\
\hline
\end{tabular}




\begin{tabular}{|c|c|c|c|c|c|c|c|c|c|c|c|c|c|c|c|c|}
\hline 114 & 12 & run 4 & 2 & 40 & 6 & $400 \mathrm{sq} \mathrm{m}$ & 133.55 & 1785 & 164.312 & 25.84 & 159.558 & 24.39 & 161.441 & 32.56 & 1.23 & $23.03 \%$ \\
\hline 115 & 12 & run 5 & 2 & 40 & 6 & $400 \mathrm{sq} \mathrm{m}$ & 127.89 & Time Limit & 158.789 & 35.6 & 160.102 & 31.6 & 160.478 & 42.85 & 1.24 & $24.16 \%$ \\
\hline 116 & 12 & run 6 & 2 & 40 & 6 & $400 \mathrm{sq} \mathrm{m}$ & 126.802 & Time Limit & 126.65 & 17.03 & 132.447 & 63.71 & 126.65 & 34.47 & 0.99880 & $0.12 \%$ \\
\hline 117 & 12 & run 7 & 2 & 40 & 6 & $400 \mathrm{sq} \mathrm{m}$ & 139.74 & Time Limit & 138.062 & 295.43 & 135.42 & 1387.29 & 136.191 & 316.68 & 0.99 & $1.20 \%$ \\
\hline 118 & 12 & run 8 & 2 & 40 & 6 & $400 \mathrm{sq} \mathrm{m}$ & 122.76 & Time Limit & 123.111 & 36.23 & 123.111 & 28.44 & 133.165 & 39.05 & 1.00286 & $0.29 \%$ \\
\hline 119 & 12 & run 9 & 2 & 40 & 6 & $400 \mathrm{sq} \mathrm{m}$ & 146.952 & Time Limit & 141.485 & 2746.51 & 145.98 & 29.07 & 144.839 & 33.83 & 0.96 & $3.72 \%$ \\
\hline 120 & 12 & run 10 & 2 & 40 & 6 & $400 \mathrm{sq} \mathrm{m}$ & 131.108 & Time Limit & 136.556 & 34.8 & 136.82 & 45.2 & 144.16 & 26.19 & 1.04 & $4.16 \%$ \\
\hline 121 & 13 & run 1 & 3 & 20 & 2 & $100 \mathrm{sq} \mathrm{m}$ & 46.368 & Time Limit & 54.167 & 1.94 & 53.806 & 1.88 & 54.508 & 15.75 & 1.17 & $16.82 \%$ \\
\hline 122 & 13 & run 2 & 3 & 20 & 2 & $100 \mathrm{sq} \mathrm{m}$ & 56.843 & 75.12 & 66.534 & 1 & 68.082 & 1.68 & 62.982 & 1.71 & 1.17 & $17.05 \%$ \\
\hline 123 & 13 & run 3 & 3 & 20 & 2 & $100 \mathrm{sq} \mathrm{m}$ & 59.866 & 9.83 & 72.117 & 1.68 & 84.646 & 1.18 & 81.609 & 1.32 & 1.20 & $20.46 \%$ \\
\hline 124 & 13 & run 4 & 3 & 20 & 2 & $100 \mathrm{sq} \mathrm{m}$ & 41.212 & 50.11 & 52.996 & 2.2 & 54.108 & 2.45 & 51.269 & 2.88 & 1.29 & $28.59 \%$ \\
\hline 125 & 13 & run 5 & 3 & 20 & 2 & $100 \mathrm{sq} \mathrm{m}$ & 55.158 & 2.51 & 62.569 & 1.46 & 63.801 & 1.62 & 57.72 & 1.46 & 1.13 & $13.44 \%$ \\
\hline 126 & 13 & run 6 & 3 & 20 & 2 & $100 \mathrm{sq} \mathrm{m}$ & 61.043 & 28.98 & 68.546 & 1.79 & 66.885 & 1.3 & 68.787 & 1.75 & 1.12 & $12.29 \%$ \\
\hline 127 & 13 & run 7 & 3 & 20 & 2 & $100 \mathrm{sq} \mathrm{m}$ & 60.286 & 4.79 & 75.357 & 1.22 & 76.335 & 1.28 & 71.359 & 1.88 & 1.25 & $25.00 \%$ \\
\hline 128 & 13 & run 8 & 3 & 20 & 2 & $100 \mathrm{sq} \mathrm{m}$ & 53.75 & 1.95 & 66.579 & 1.84 & 67.959 & 0.98 & 66.098 & 1.2 & 1.24 & $23.87 \%$ \\
\hline 129 & 13 & run 9 & 3 & 20 & 2 & $100 \mathrm{sq} \mathrm{m}$ & 53.035 & 22.57 & 65.093 & 1.16 & 63.748 & 2.37 & 63.994 & 1.59 & 1.23 & $22.74 \%$ \\
\hline 130 & 13 & run 10 & 3 & 20 & 2 & $100 \mathrm{sq} \mathrm{m}$ & 45.837 & 62.59 & 51.432 & 1.69 & 52.286 & 1.73 & 52.135 & 2.21 & 1.12 & $12.21 \%$ \\
\hline 131 & 14 & run 1 & 3 & 20 & 2 & $400 \mathrm{sq} \mathrm{m}$ & 109.872 & 3.3 & 122.649 & 1.75 & 123.035 & 1.13 & 121.683 & 1.15 & 1.12 & $11.63 \%$ \\
\hline 132 & 14 & run 2 & 3 & 20 & 2 & $400 \mathrm{sq} \mathrm{m}$ & 91.175 & 34.93 & 110.281 & 2.26 & 92.797 & 1.46 & 113.024 & 2.27 & 1.21 & $20.96 \%$ \\
\hline 133 & 14 & run 3 & 3 & 20 & 2 & $400 \mathrm{sq} \mathrm{m}$ & 122.875 & 6.32 & 145.613 & 0.81 & 140.92 & 1.29 & 140.92 & 0.95 & 1.19 & $18.50 \%$ \\
\hline 134 & 14 & run 4 & 3 & 20 & 2 & $400 \mathrm{sq} \mathrm{m}$ & 104.836 & 29.23 & 119.046 & 1.83 & 113.256 & 1.35 & 112.478 & 0.97 & 1.14 & $13.55 \%$ \\
\hline 135 & 14 & run 5 & 3 & 20 & 2 & $400 \mathrm{sq} \mathrm{m}$ & 113.991 & 3.41 & 123.625 & 1.12 & 120.546 & 1.3 & 120.463 & 1.13 & 1.08 & $8.45 \%$ \\
\hline 136 & 14 & run 6 & 3 & 20 & 2 & $400 \mathrm{sq} \mathrm{m}$ & 100.64 & 25.25 & 119.604 & 1.42 & 120.677 & 1.39 & 121.458 & 1.12 & 1.19 & $18.84 \%$ \\
\hline 137 & 14 & run 7 & 3 & 20 & 2 & $400 \mathrm{sq} \mathrm{m}$ & 104.363 & 4.22 & 112.09 & 1.66 & 111.48 & 1.86 & 115.511 & 2.53 & 1.07 & $7.40 \%$ \\
\hline 138 & 14 & run 8 & 3 & 20 & 2 & $400 \mathrm{sq} \mathrm{m}$ & 89.211 & 0.91 & 112.172 & 1.83 & 115.382 & 1.39 & 113.411 & 1.16 & 1.26 & $25.74 \%$ \\
\hline 139 & 14 & run 9 & 3 & 20 & 2 & $400 \mathrm{sq} \mathrm{m}$ & 115.925 & 14.49 & 129.041 & 1.37 & 141.146 & 1.33 & 130.529 & 1.09 & 1.11 & $11.31 \%$ \\
\hline 140 & 14 & run 10 & 3 & 20 & 2 & $400 \mathrm{sq} \mathrm{m}$ & 107.219 & 12.2 & 131.328 & 1.18 & 142.357 & 1.66 & 134.721 & 0.87 & 1.22 & $22.49 \%$ \\
\hline 141 & 15 & run 1 & 3 & 20 & 4 & $100 \mathrm{sq} \mathrm{m}$ & 56.778 & 28.85 & 73.245 & 2.09 & 72.47 & 2.35 & 67.373 & 1.98 & 1.29 & $29.00 \%$ \\
\hline 142 & 15 & run 2 & 3 & 20 & 4 & 100 sq m & 56.141 & 346.27 & 57.619 & 2.52 & 62.721 & 3.74 & 60.386 & 2.72 & 1.03 & $2.63 \%$ \\
\hline
\end{tabular}




\begin{tabular}{|c|c|c|c|c|c|c|c|c|c|c|c|c|c|c|c|c|}
\hline 143 & 15 & run 3 & 3 & 20 & 4 & $100 \mathrm{sq} \mathrm{m}$ & 59.813 & 131.07 & 69.68 & 2.67 & 70.651 & 4.13 & 68.73 & 1.79 & 1.16 & $16.50 \%$ \\
\hline 144 & 15 & run 4 & 3 & 20 & 4 & $100 \mathrm{sq} \mathrm{m}$ & 52.071 & 104.47 & 60.849 & 3.55 & 60.69 & 4.34 & 59.739 & 3.7 & 1.17 & $16.86 \%$ \\
\hline 145 & 15 & run 5 & 3 & 20 & 4 & $100 \mathrm{sq} \mathrm{m}$ & 49.826 & 66.27 & 59.624 & 3.29 & 55.516 & 3.11 & 55.17 & 3 & 1.20 & $19.66 \%$ \\
\hline 146 & 15 & run 6 & 3 & 20 & 4 & $100 \mathrm{sq} \mathrm{m}$ & 59.808 & 80.77 & 63.457 & 2.63 & 66.743 & 2.52 & 59.808 & 2.09 & 1.06 & $6.10 \%$ \\
\hline 147 & 15 & run 7 & 3 & 20 & 4 & $100 \mathrm{sq} \mathrm{m}$ & 51.102 & 84.65 & 54.745 & 3.14 & 57.521 & 2.87 & 57.511 & 2.76 & 1.07 & $7.13 \%$ \\
\hline 148 & 15 & run 8 & 3 & 20 & 4 & $100 \mathrm{sq} \mathrm{m}$ & 49.353 & 37.53 & 54.43 & 2.1 & 57.488 & 2.17 & 61.636 & 2.36 & 1.10 & $10.29 \%$ \\
\hline 149 & 15 & run 9 & 3 & 20 & 4 & $100 \mathrm{sq} \mathrm{m}$ & 54.266 & 48.14 & 59.664 & 2.19 & 62.136 & 2.19 & 71.157 & 2.24 & 1.10 & $9.95 \%$ \\
\hline 150 & 15 & run 10 & 3 & 20 & 4 & $100 \mathrm{sq} \mathrm{m}$ & 48.64 & 276.47 & 51.076 & 1.79 & 54.132 & 2.57 & 56.202 & 1.91 & 1.05 & $5.01 \%$ \\
\hline 151 & 16 & run 1 & 3 & 20 & 4 & $400 \mathrm{sq} \mathrm{m}$ & 100.374 & 43.97 & 120.389 & 2.58 & 123.783 & 1.87 & 121.015 & 3.76 & 1.20 & $19.94 \%$ \\
\hline 152 & 16 & run 2 & 3 & 20 & 4 & $400 \mathrm{sq} \mathrm{m}$ & 110.136 & 40.85 & 123.002 & 2.52 & 124.809 & 2.49 & 126.134 & 3.51 & 1.12 & $11.68 \%$ \\
\hline 153 & 16 & run 3 & 3 & 20 & 4 & $400 \mathrm{sq} \mathrm{m}$ & 96.854 & 38.69 & 130.123 & 2.55 & 108.242 & 2.71 & 114.102 & 2.23 & 1.34 & $34.35 \%$ \\
\hline 154 & 16 & run 4 & 3 & 20 & 4 & $400 \mathrm{sq} \mathrm{m}$ & 115.005 & 57.56 & 129.265 & 2.67 & 129.654 & 2.81 & 131.825 & 2.33 & 1.12 & $12.40 \%$ \\
\hline 155 & 16 & run 5 & 3 & 20 & 4 & $400 \mathrm{sq} \mathrm{m}$ & 110.873 & 76.87 & 132.839 & 2.41 & 124.685 & 3.28 & 129.252 & 2.26 & 1.20 & $19.81 \%$ \\
\hline 156 & 16 & run 6 & 3 & 20 & 4 & $400 \mathrm{sq} \mathrm{m}$ & 106.613 & 121.5 & 125.451 & 2.42 & 134.875 & 3.57 & 113.765 & 2.56 & 1.18 & $17.67 \%$ \\
\hline 157 & 16 & run 7 & 3 & 20 & 4 & $400 \mathrm{sq} \mathrm{m}$ & 108.847 & 63.23 & 124.017 & 4.21 & 126.744 & 2.65 & 126.744 & 2.82 & 1.14 & $13.94 \%$ \\
\hline 158 & 16 & run 8 & 3 & 20 & 4 & $400 \mathrm{sq} \mathrm{m}$ & 125.698 & 26.73 & 140.791 & 2.26 & 140.418 & 3.37 & 137.135 & 2.14 & 1.12 & $12.01 \%$ \\
\hline 159 & 16 & run 9 & 3 & 20 & 4 & $400 \mathrm{sq} \mathrm{m}$ & 114.778 & 123.4 & 124.331 & 2.75 & 123.229 & 2.62 & 118.888 & 2.31 & 1.08 & $8.32 \%$ \\
\hline 160 & 16 & run 10 & 3 & 20 & 4 & $400 \mathrm{sq} \mathrm{m}$ & 104.142 & 153.18 & 109.841 & 3.04 & 125.35 & 4.05 & 107.779 & 3.44 & 1.05 & $5.47 \%$ \\
\hline 161 & 17 & run 1 & 3 & 20 & 6 & $100 \mathrm{sq} \mathrm{m}$ & 55.551 & 57.82 & 61.979 & 2.71 & 63.537 & 2.91 & 63.502 & 2.42 & 1.12 & $11.57 \%$ \\
\hline 162 & 17 & run 2 & 3 & 20 & 6 & $100 \mathrm{sq} \mathrm{m}$ & 47.283 & 23.65 & 60.691 & 3.95 & 60.404 & 3.42 & 56.647 & 4.35 & 1.28 & $28.36 \%$ \\
\hline 163 & 17 & run 3 & 3 & 20 & 6 & $100 \mathrm{sq} \mathrm{m}$ & 56.922 & Time Limit & 57.839 & 9.07 & 60.522 & 6.36 & 61.026 & 6.96 & 1.02 & $1.61 \%$ \\
\hline 164 & 17 & run 4 & 3 & 20 & 6 & $100 \mathrm{sq} \mathrm{m}$ & 53.592 & 91.65 & 62.983 & 3.29 & 62.044 & 3.42 & 59.271 & 3.13 & 1.18 & $17.52 \%$ \\
\hline 165 & 17 & run 5 & 3 & 20 & 6 & $100 \mathrm{sq} \mathrm{m}$ & 47.167 & 175.28 & 51.165 & 4.18 & 53.265 & 4.63 & 54.049 & 4.01 & 1.08 & $8.48 \%$ \\
\hline 166 & 17 & run 6 & 3 & 20 & 6 & $100 \mathrm{sq} \mathrm{m}$ & 55.893 & 112.92 & 56.178 & 3.32 & 61.902 & 5.28 & 59.268 & 3.64 & 1.01 & $0.51 \%$ \\
\hline 167 & 17 & $\operatorname{run} 7$ & 3 & 20 & 6 & $100 \mathrm{sq} \mathrm{m}$ & 55.121 & 56.93 & 58.512 & 3.77 & 58.129 & 4.07 & 58.087 & 4.87 & 1.06 & $6.15 \%$ \\
\hline 168 & 17 & run 8 & 3 & 20 & 6 & $100 \mathrm{sq} \mathrm{m}$ & 53.96 & 57.48 & 57.485 & 3.24 & 57.113 & 3.67 & 57.369 & 3.05 & 1.07 & $6.53 \%$ \\
\hline 169 & 17 & run 9 & 3 & 20 & 6 & $100 \mathrm{sq} \mathrm{m}$ & 54.874 & 250.32 & 58.15 & 4.35 & 62.619 & 5.83 & 60.017 & 3.82 & 1.06 & $5.97 \%$ \\
\hline 170 & 17 & run 10 & 3 & 20 & 6 & $100 \mathrm{sq} \mathrm{m}$ & 50.443 & 116.58 & 52.847 & 3.32 & 57.301 & 8.24 & 60.173 & 4.3 & 1.05 & $4.77 \%$ \\
\hline 171 & 18 & run 1 & 3 & 20 & 6 & $400 \mathrm{sq} \mathrm{m}$ & 116.95 & 553.83 & 130.562 & 3.25 & 134.687 & 4.76 & 137.208 & 5.36 & 1.12 & $11.64 \%$ \\
\hline
\end{tabular}




\begin{tabular}{|c|c|c|c|c|c|c|c|c|c|c|c|c|c|c|c|c|}
\hline 172 & 18 & run 2 & 3 & 20 & 6 & $400 \mathrm{sq} \mathrm{m}$ & 102.318 & 97.96 & 113.097 & 5.58 & 112.812 & 2.92 & 111.766 & 4.73 & 1.11 & $10.53 \%$ \\
\hline 173 & 18 & run 3 & 3 & 20 & 6 & $400 \mathrm{sq} \mathrm{m}$ & 111.413 & 39.24 & 119.233 & 2.43 & 127.174 & 3.68 & 121.526 & 2.66 & 1.07 & $7.02 \%$ \\
\hline 174 & 18 & run 4 & 3 & 20 & 6 & $400 \mathrm{sq} \mathrm{m}$ & 106.77 & 120.23 & 118.541 & 3.08 & 127.067 & 3.92 & 131.001 & 3.26 & 1.11 & $11.02 \%$ \\
\hline 175 & 18 & $\operatorname{run} 5$ & 3 & 20 & 6 & $400 \mathrm{sq} \mathrm{m}$ & 102.273 & 485.36 & 115.288 & 6.18 & 113.484 & 5.9 & 110.719 & 3.69 & 1.13 & $12.73 \%$ \\
\hline 176 & 18 & run 6 & 3 & 20 & 6 & $400 \mathrm{sq} \mathrm{m}$ & 89.998 & 60.17 & 100.87 & 4.97 & 105.862 & 5.53 & 105.076 & 4.45 & 1.12 & $12.08 \%$ \\
\hline 177 & 18 & $\operatorname{run} 7$ & 3 & 20 & 6 & $400 \mathrm{sq} \mathrm{m}$ & 105.202 & 89.45 & 119.938 & 3.17 & 124.641 & 3.49 & 113.939 & 3.86 & 1.14 & $14.01 \%$ \\
\hline 178 & 18 & run 8 & 3 & 20 & 6 & $400 \mathrm{sq} \mathrm{m}$ & 114.206 & Time Limit & 126.733 & 7.4 & 119.539 & 9.83 & 119.539 & 6.89 & 1.11 & $10.97 \%$ \\
\hline 179 & 18 & run 9 & 3 & 20 & 6 & $400 \mathrm{sq} \mathrm{m}$ & 98.134 & 153.66 & 113.281 & 6.74 & 112.02 & 6.31 & 122.817 & 5.88 & 1.15 & $15.44 \%$ \\
\hline 180 & 18 & run 10 & 3 & 20 & 6 & $400 \mathrm{sq} \mathrm{m}$ & 94.41 & 68.83 & 102.388 & 3.31 & 103.739 & 4.05 & 101.157 & 3.78 & 1.08 & $8.45 \%$ \\
\hline 181 & 19 & run 1 & 3 & 40 & 2 & $100 \mathrm{sq} \mathrm{m}$ & 64.045 & 1066.43 & 72.488 & 20.23 & 68.974 & 14.44 & 69.272 & 16.1 & 1.13 & $13.18 \%$ \\
\hline 182 & 19 & run 2 & 3 & 40 & 2 & $100 \mathrm{sq} \mathrm{m}$ & 63.382 & Time Limit & 66.477 & 7.27 & 66.728 & 8.23 & 71.56 & 6.57 & 1.05 & $4.88 \%$ \\
\hline 183 & 19 & run 3 & 3 & 40 & 2 & $100 \mathrm{sq} \mathrm{m}$ & 68.437 & 134.57 & 79.515 & 9.27 & 79.18 & 8.56 & 76.805 & 6.68 & 1.16 & $16.19 \%$ \\
\hline 184 & 19 & run 4 & 3 & 40 & 2 & $100 \mathrm{sq} \mathrm{m}$ & 62.624 & 151.11 & 70.004 & 9.59 & 67.31 & 8.06 & 69.232 & 7.63 & 1.12 & $11.78 \%$ \\
\hline 185 & 19 & run 5 & 3 & 40 & 2 & $100 \mathrm{sq} \mathrm{m}$ & 66.496 & 55.96 & 73.522 & 5.94 & 72.475 & 5.38 & 73.62 & 4.93 & 1.11 & $10.57 \%$ \\
\hline 186 & 19 & run 6 & 3 & 40 & 2 & $100 \mathrm{sq} \mathrm{m}$ & 61.851 & Time Limit & 67.053 & 23.9 & 65.349 & 14.9 & 65.695 & 20.99 & 1.08 & $8.41 \%$ \\
\hline 187 & 19 & run 7 & 3 & 40 & 2 & $100 \mathrm{sq} \mathrm{m}$ & 69.192 & 839.56 & 81.33 & 14.67 & 77.957 & 8.6 & 76.944 & 9.85 & 1.18 & $17.54 \%$ \\
\hline 188 & 19 & run 8 & 3 & 40 & 2 & $100 \mathrm{sq} \mathrm{m}$ & 65.84 & 26.3 & 74.936 & 6.82 & 76.983 & 7.41 & 74.325 & 4.82 & 1.14 & $13.82 \%$ \\
\hline 189 & 19 & run 9 & 3 & 40 & 2 & $100 \mathrm{sq} \mathrm{m}$ & 67.593 & 434.94 & 74.755 & 7.35 & 75.691 & 8.71 & 73.967 & 17.33 & 1.11 & $10.60 \%$ \\
\hline 190 & 19 & run 10 & 3 & 40 & 2 & $100 \mathrm{sq} \mathrm{m}$ & 64.304 & Time Limit & 66.376 & 11.73 & 68.235 & 9.88 & 65.262 & 7.22 & 1.03 & $3.22 \%$ \\
\hline 191 & 20 & run 1 & 3 & 40 & 2 & $400 \mathrm{sq} \mathrm{m}$ & 149.38 & 75.19 & 157.553 & 7.98 & 164.345 & 8.63 & 169.691 & 9.28 & 1.05 & $5.47 \%$ \\
\hline 192 & 20 & run 2 & 3 & 40 & 2 & $400 \mathrm{sq} \mathrm{m}$ & 126.218 & 111.94 & 137.66 & 7.02 & 145.316 & 11.69 & 136.873 & 6.09 & 1.09 & $9.07 \%$ \\
\hline 193 & 20 & run 3 & 3 & 40 & 2 & $400 \mathrm{sq} \mathrm{m}$ & 146.023 & 178.3 & 164.938 & 5.65 & 161.234 & 9.08 & 163.583 & 4.8 & 1.13 & $12.95 \%$ \\
\hline 194 & 20 & run 4 & 3 & 40 & 2 & $400 \mathrm{sq} \mathrm{m}$ & 131.43 & 64.42 & 169.769 & 8.18 & 152.132 & 9.74 & 152.459 & 7.74 & 1.29 & $29.17 \%$ \\
\hline 195 & 20 & run 5 & 3 & 40 & 2 & $400 \mathrm{sq} \mathrm{m}$ & 133.062 & 759.69 & 147.476 & 8.39 & 152.386 & 8.7 & 149.589 & 6.96 & 1.11 & $10.83 \%$ \\
\hline 196 & 20 & run 6 & 3 & 40 & 2 & $400 \mathrm{sq} \mathrm{m}$ & 118.443 & Time Limit & 138.665 & 15.75 & 132.772 & 10.15 & 126.684 & 4.51 & 1.17 & $17.07 \%$ \\
\hline 197 & 20 & run 7 & 3 & 40 & 2 & $400 \mathrm{sq} \mathrm{m}$ & 128.723 & 1996.78 & 141.532 & 8.18 & 133.599 & 8.55 & 135.19 & 6 & 1.10 & $9.95 \%$ \\
\hline 198 & 20 & run 8 & 3 & 40 & 2 & $400 \mathrm{sq} \mathrm{m}$ & 135.39 & 423.72 & 151.767 & 12.99 & 143.648 & 15.2 & 148.729 & 5.28 & 1.12 & $12.10 \%$ \\
\hline 199 & 20 & run 9 & 3 & 40 & 2 & $400 \mathrm{sq} \mathrm{m}$ & 135.441 & 155.07 & 147.685 & 7.87 & 143.585 & 7.58 & 147.754 & 8.06 & 1.09 & $9.04 \%$ \\
\hline 200 & 20 & run 10 & 3 & 40 & 2 & $400 \mathrm{sq} \mathrm{m}$ & 129.617 & 834.53 & 139.797 & 7.77 & 144.945 & 7.71 & 142.426 & 8.79 & 1.08 & $7.85 \%$ \\
\hline
\end{tabular}




\begin{tabular}{|c|c|c|c|c|c|c|c|c|c|c|c|c|c|c|c|c|}
\hline 201 & 21 & run 1 & 3 & 40 & 4 & $100 \mathrm{sq} \mathrm{m}$ & 66.66 & Time Limit & 72.39 & 20.58 & 71.09 & 17.64 & 70.07 & 12.2 & 1.09 & $8.60 \%$ \\
\hline 202 & 21 & run 2 & 3 & 40 & 4 & $100 \mathrm{sq} \mathrm{m}$ & 62.38 & 908.72 & 67.95 & 24.05 & 69.59 & 15.45 & 69.35 & 7.2 & 1.09 & $8.93 \%$ \\
\hline 203 & 21 & run 3 & 3 & 40 & 4 & $100 \mathrm{sq} \mathrm{m}$ & 72.62 & Time Limit & 75.73 & 25.31 & 72.71 & 26.03 & 75.65 & 17.17 & 1.04 & $4.28 \%$ \\
\hline 204 & 21 & run 4 & 3 & 40 & 4 & $100 \mathrm{sq} \mathrm{m}$ & 68.66 & 3396.59 & 74.22 & 7.58 & 74.3 & 15.91 & 73.19 & 6.16 & 1.08 & $8.10 \%$ \\
\hline 205 & 21 & run 5 & 3 & 40 & 4 & $100 \mathrm{sq} \mathrm{m}$ & 67.36 & Time Limit & 76.06 & 22.67 & 76.46 & 12.57 & 72.25 & 13.45 & 1.13 & $12.92 \%$ \\
\hline 206 & 21 & run 6 & 3 & 40 & 4 & $100 \mathrm{sq} \mathrm{m}$ & 70.27 & Time Limit & 68.749 & 12.32 & 67.197 & 15.58 & 65.564 & 11.6 & 0.98 & $2.16 \%$ \\
\hline 207 & 21 & $\operatorname{run} 7$ & 3 & 40 & 4 & $100 \mathrm{sq} \mathrm{m}$ & 57.768 & Time Limit & 68.07 & 24.88 & 64.237 & 20.34 & 68.59 & 12.27 & 1.18 & $17.83 \%$ \\
\hline 208 & 21 & run 8 & 3 & 40 & 4 & $100 \mathrm{sq} \mathrm{m}$ & 62.372 & Time Limit & 65.562 & 25.25 & 66.443 & 24.32 & 66.263 & 11.37 & 1.05 & $5.11 \%$ \\
\hline 209 & 21 & run 9 & 3 & 40 & 4 & $100 \mathrm{sq} \mathrm{m}$ & 68.863 & Time Limit & 76.58 & 19.75 & 76.593 & 11.65 & 72.065 & 13.14 & 1.11 & $11.21 \%$ \\
\hline 210 & 21 & run 10 & 3 & 40 & 4 & $100 \mathrm{sq} \mathrm{m}$ & 61.951 & Time Limit & 68.534 & 14.55 & 71.66 & 22.18 & 68.592 & 13.15 & 1.11 & $10.63 \%$ \\
\hline 211 & 22 & run 1 & 3 & 40 & 4 & $400 \mathrm{sq} \mathrm{m}$ & 134.157 & 2601.42 & 158.946 & 13.91 & 149.877 & 16.41 & 147.851 & 9.55 & 1.18 & $18.48 \%$ \\
\hline 212 & 22 & run 2 & 3 & 40 & 4 & $400 \mathrm{sq} \mathrm{m}$ & 123.022 & 249.25 & 145.473 & 24.13 & 137.937 & 13.47 & 134.295 & 10.36 & 1.18 & $18.25 \%$ \\
\hline 213 & 22 & run 3 & 3 & 40 & 4 & $400 \mathrm{sq} \mathrm{m}$ & 126.849 & Time Limit & 136.124 & 13.92 & 145.965 & 16.06 & 143.594 & 16.64 & 1.07 & $7.31 \%$ \\
\hline 214 & 22 & run 4 & 3 & 40 & 4 & $400 \mathrm{sq} \mathrm{m}$ & 129.662 & 3302.55 & 142.413 & 20.87 & 149.316 & 10.12 & 151.908 & 17.71 & 1.10 & $9.83 \%$ \\
\hline 215 & 22 & run 5 & 3 & 40 & 4 & $400 \mathrm{sq} \mathrm{m}$ & 126.053 & Time Limit & 133.811 & 10.31 & 143.918 & 14.05 & 137.533 & 8.12 & 1.06 & $6.15 \%$ \\
\hline 216 & 22 & run 6 & 3 & 40 & 4 & $400 \mathrm{sq} \mathrm{m}$ & 130.811 & 1334.07 & 144.371 & 9.71 & 146.12 & 9.05 & 153.132 & 22.12 & 1.10 & $10.37 \%$ \\
\hline 217 & 22 & run 7 & 3 & 40 & 4 & $400 \mathrm{sq} \mathrm{m}$ & 143.851 & Time Limit & 148.035 & 14.32 & 148.939 & 19.56 & 160.529 & 13.72 & 1.03 & $2.91 \%$ \\
\hline 218 & 22 & run 8 & 3 & 40 & 4 & $400 \mathrm{sq} \mathrm{m}$ & 133.228 & Time Limit & 149.631 & 20.96 & 134.459 & 11.8 & 135.563 & 13.04 & 1.12 & $12.31 \%$ \\
\hline 219 & 22 & run 9 & 3 & 40 & 4 & $400 \mathrm{sq} \mathrm{m}$ & 118.972 & 487 & 144.201 & 12.26 & 133.771 & 12.29 & 144.27 & 15.34 & 1.21 & $21.21 \%$ \\
\hline 220 & 22 & run 10 & 3 & 40 & 4 & $400 \mathrm{sq} \mathrm{m}$ & 134.35 & 1069.93 & 161.975 & 10.44 & 152.594 & 11.96 & 152.813 & 16.38 & 1.21 & $20.56 \%$ \\
\hline 221 & 23 & run 1 & 3 & 40 & 6 & $100 \mathrm{sq} \mathrm{m}$ & 63.12 & Time Limit & 75.868 & 44.77 & 71.872 & 39.48 & 70.472 & 25.66 & 1.20 & $20.20 \%$ \\
\hline 222 & 23 & run 2 & 3 & 40 & 6 & $100 \mathrm{sq} \mathrm{m}$ & 71.18 & Time Limit & 69.594 & 43.67 & 73.143 & 30.45 & 70.758 & 37.8 & 0.98 & $2.23 \%$ \\
\hline 223 & 23 & run 3 & 3 & 40 & 6 & $100 \mathrm{sq} \mathrm{m}$ & 67.53 & Time Limit & 69.972 & 27.37 & 68.158 & 22.71 & 69.733 & 23.81 & 1.04 & $3.62 \%$ \\
\hline 224 & 23 & run 4 & 3 & 40 & 6 & $100 \mathrm{sq} \mathrm{m}$ & 61.55 & Time Limit & 64.891 & 75.64 & 65.883 & 94.06 & 65.073 & 55.91 & 1.05 & $5.43 \%$ \\
\hline 225 & 23 & run 5 & 3 & 40 & 6 & $100 \mathrm{sq} \mathrm{m}$ & 63.4 & Time Limit & 70.447 & 24.78 & 69.251 & 20.33 & 72.111 & 26.57 & 1.11 & $11.12 \%$ \\
\hline 226 & 23 & run 6 & 3 & 40 & 6 & $100 \mathrm{sq} \mathrm{m}$ & 70.065 & Time Limit & 67.078 & 23.72 & 67.012 & 22.35 & 67.604 & 21.28 & 0.96 & $4.26 \%$ \\
\hline 227 & 23 & run 7 & 3 & 40 & 6 & $100 \mathrm{sq} \mathrm{m}$ & 70.549 & Time Limit & 72.035 & 18.26 & 75.595 & 20.88 & 79.407 & 19.72 & 1.02 & $2.11 \%$ \\
\hline 228 & 23 & run 8 & 3 & 40 & 6 & $100 \mathrm{sq} \mathrm{m}$ & 67.668 & Time Limit & 75.649 & 11.77 & 74.122 & 11.41 & 75.178 & 26.22 & 1.12 & $11.79 \%$ \\
\hline 229 & 23 & run 9 & 3 & 40 & 6 & $100 \mathrm{sq} \mathrm{m}$ & 76.233 & Time Limit & 75.197 & 27.22 & 75.932 & 17.27 & 76.245 & 25.47 & 0.99 & $1.36 \%$ \\
\hline
\end{tabular}




\begin{tabular}{|c|c|c|c|c|c|c|c|c|c|c|c|c|c|c|c|c|}
\hline 230 & 23 & run 10 & 3 & 40 & 6 & $100 \mathrm{sq} \mathrm{m}$ & 73.815 & Time Limit & 73.333 & 23.91 & 71.729 & 16.23 & 73.687 & 22.31 & 0.99 & $0.65 \%$ \\
\hline 231 & 24 & run 1 & 3 & 40 & 6 & $400 \mathrm{sq} \mathrm{m}$ & 139.03 & Time Limit & 154.484 & 66.26 & 145.485 & 37.25 & 153.094 & 135.34 & 1.11 & $11.12 \%$ \\
\hline 232 & 24 & run 2 & 3 & 40 & 6 & $400 \mathrm{sq} \mathrm{m}$ & 143.26 & Time Limit & 145.982 & 26.09 & 148.527 & 32.59 & 145.701 & 26.59 & 1.02 & $1.90 \%$ \\
\hline 233 & 24 & run 3 & 3 & 40 & 6 & $400 \mathrm{sq} \mathrm{m}$ & 121.17 & Time Limit & 130.273 & 28.8 & 125.976 & 31.71 & 132.698 & 35.28 & 1.08 & $7.51 \%$ \\
\hline 234 & 24 & run 4 & 3 & 40 & 6 & $400 \mathrm{sq} \mathrm{m}$ & 140.75 & Time Limit & 147.679 & 51.57 & 152.035 & 58.6 & 153.298 & 53.07 & 1.05 & $4.92 \%$ \\
\hline 235 & 24 & run 5 & 3 & 40 & 6 & $400 \mathrm{sq} \mathrm{m}$ & 137.63 & Time Limit & 148.507 & 32.78 & 142.546 & 40.39 & 147.04 & 21.82 & 1.08 & $7.90 \%$ \\
\hline 236 & 24 & run 6 & 3 & 40 & 6 & $400 \mathrm{sq} \mathrm{m}$ & 124.976 & Time Limit & 147.313 & 24.84 & 140.873 & 30.59 & 145.424 & 22.25 & 1.18 & $17.87 \%$ \\
\hline 237 & 24 & run 7 & 3 & 40 & 6 & $400 \mathrm{sq} \mathrm{m}$ & 131.161 & Time Limit & 127.808 & 23.53 & 133.292 & 18.35 & 132.173 & 29.5 & 0.97 & $2.56 \%$ \\
\hline 238 & 24 & run 8 & 3 & 40 & 6 & $400 \mathrm{sq} \mathrm{m}$ & 129.556 & Time Limit & 146.215 & 20.66 & 138.95 & 11.57 & 140.143 & 12.84 & 1.13 & $12.86 \%$ \\
\hline 239 & 24 & run 9 & 3 & 40 & 6 & $400 \mathrm{sq} \mathrm{m}$ & 131.092 & Time Limit & 137.33 & 15.59 & 148.928 & 23.85 & 137.636 & 20.92 & 1.05 & $4.76 \%$ \\
\hline 240 & 24 & run 10 & 3 & 40 & 6 & $400 \mathrm{sq} \mathrm{m}$ & 145.952 & Time Limit & 163.924 & 15.46 & 152.59 & 17.16 & 148.908 & 14.1 & 1.12 & $12.31 \%$ \\
\hline 241 & 25 & run 1 & 3 & 60 & 2 & $100 \mathrm{sq} \mathrm{m}$ & 104.76 & Time Limit & 83.263 & 40.04 & 79.331 & 120.7 & 80.567 & 23.66 & 0.79 & $20.52 \%$ \\
\hline 242 & 25 & run 2 & 3 & 60 & 2 & $100 \mathrm{sq} \mathrm{m}$ & 91.52 & Time Limit & 85.507 & 97.99 & 84.06 & 38.09 & 82.528 & 20.14 & 0.93 & $6.57 \%$ \\
\hline 243 & 25 & run 3 & 3 & 60 & 2 & $100 \mathrm{sq} \mathrm{m}$ & 96.15 & Time Limit & 82.212 & 47.65 & 84.502 & 44.18 & 82.075 & 44.48 & 0.86 & $14.50 \%$ \\
\hline 244 & 25 & run 4 & 3 & 60 & 2 & $100 \mathrm{sq} \mathrm{m}$ & 101.61 & Time Limit & 84.254 & 43.26 & 81.197 & 34.24 & 83.698 & 28.78 & 0.83 & $17.08 \%$ \\
\hline 245 & 25 & run 5 & 3 & 60 & 2 & $100 \mathrm{sq} \mathrm{m}$ & 80.28 & Time Limit & 83.263 & 40.04 & 79.331 & 120.7 & 80.567 & 23.66 & 1.04 & $3.72 \%$ \\
\hline 246 & 25 & run 6 & 3 & 60 & 2 & $100 \mathrm{sq} \mathrm{m}$ & 82.967 & Time Limit & 84.786 & 15.75 & 81.918 & 17.06 & 85.978 & 17.89 & 1.02 & $2.19 \%$ \\
\hline 247 & 25 & run 7 & 3 & 60 & 2 & $100 \mathrm{sq} \mathrm{m}$ & 80.422 & Time Limit & 88.47 & 30.3 & 87.472 & 31.28 & 85.407 & 23.16 & 1.10 & $10.01 \%$ \\
\hline 248 & 25 & run 8 & 3 & 60 & 2 & $100 \mathrm{sq} \mathrm{m}$ & 84.883 & Time Limit & 82.747 & 38.2 & 85.154 & 27.42 & 84.065 & 19.19 & 0.97 & $2.52 \%$ \\
\hline 249 & 25 & run 9 & 3 & 60 & 2 & $100 \mathrm{sq} \mathrm{m}$ & 87.253 & Time Limit & 87.512 & 22.26 & 86.226 & 117.35 & 89.747 & 22.08 & 1.00297 & $0.30 \%$ \\
\hline 250 & 25 & run 10 & 3 & 60 & 2 & $100 \mathrm{sq} \mathrm{m}$ & 101.723 & Time Limit & 86.637 & 28.67 & 88.535 & 20.98 & 90.33 & 20.74 & 0.85 & $14.83 \%$ \\
\hline 251 & 26 & run 1 & 3 & 60 & 2 & $400 \mathrm{sq} \mathrm{m}$ & 204.75 & Time Limit & 155.592 & 45.33 & 144.601 & 22.51 & 160.344 & 354.28 & 0.76 & $24.01 \%$ \\
\hline 252 & 26 & run 2 & 3 & 60 & 2 & $400 \mathrm{sq} \mathrm{m}$ & 169.58 & Time Limit & 169.846 & 35.02 & 169.724 & 32.47 & 157.18 & 20.1 & 1.00157 & $0.16 \%$ \\
\hline 253 & 26 & run 3 & 3 & 60 & 2 & $400 \mathrm{sq} \mathrm{m}$ & 212.31 & Time Limit & 192.27 & 30.34 & 187.177 & 26.06 & 182.664 & 26.78 & 0.91 & $9.44 \%$ \\
\hline 254 & 26 & run 4 & 3 & 60 & 2 & $400 \mathrm{sq} \mathrm{m}$ & 188.63 & Time Limit & 168.053 & 39.89 & 167.207 & 33.03 & 172.059 & 16.76 & 0.89 & $10.91 \%$ \\
\hline 255 & 26 & run 5 & 3 & 60 & 2 & $400 \mathrm{sq} \mathrm{m}$ & 167.66 & Time Limit & 168.754 & 23.92 & 177.204 & 18.92 & 176.08 & 25.1 & 1.01 & $0.65 \%$ \\
\hline 256 & 26 & run 6 & 3 & 60 & 2 & $400 \mathrm{sq} \mathrm{m}$ & 154.12 & Time Limit & 158.6 & 45.77 & 155.22 & 36.1 & 153.17 & 18.29 & 1.03 & $2.91 \%$ \\
\hline 257 & 26 & run 7 & 3 & 60 & 2 & $400 \mathrm{sq} \mathrm{m}$ & 162.93 & Time Limit & 169.94 & 26.21 & 167.94 & 31.25 & 171.41 & 21.54 & 1.04 & $4.30 \%$ \\
\hline 258 & 26 & run 8 & 3 & 60 & 2 & $400 \mathrm{sq} \mathrm{m}$ & 182.76 & Time Limit & 180.84 & 29.65 & 192.11 & 19.52 & 177.76 & 25.81 & 0.99 & $1.05 \%$ \\
\hline
\end{tabular}




\begin{tabular}{|c|c|c|c|c|c|c|c|c|c|c|c|c|c|c|c|c|}
\hline 259 & 26 & run 9 & 3 & 60 & 2 & $400 \mathrm{sq} \mathrm{m}$ & 185.51 & Time Limit & 168.66 & 77.98 & 171.36 & 35.76 & 171.98 & 509.3 & 0.91 & $9.08 \%$ \\
\hline 260 & 26 & run 10 & 3 & 60 & 2 & $400 \mathrm{sq} \mathrm{m}$ & 187.856 & Time Limit & 162.393 & 41.6 & 163.775 & 54.13 & 168.654 & 21.4 & 0.86 & $13.55 \%$ \\
\hline 261 & 27 & run 1 & 3 & 60 & 4 & 100 sq m & 95.52 & Time Limit & 91.675 & 100.45 & 86.282 & 29.95 & 90.769 & 31.96 & 0.96 & $4.03 \%$ \\
\hline 262 & 27 & run 2 & 3 & 60 & 4 & $100 \mathrm{sq} \mathrm{m}$ & 105.4 & Time Limit & 79.204 & 42.16 & 79.694 & 32.23 & 78.124 & 26.97 & 0.75 & $24.85 \%$ \\
\hline 263 & 27 & run 3 & 3 & 60 & 4 & $100 \mathrm{sq} \mathrm{m}$ & 102.37 & Time Limit & 90.244 & 51.22 & 91.145 & 47.04 & 88.001 & 50.61 & 0.88 & $11.85 \%$ \\
\hline 264 & 27 & run 4 & 3 & 60 & 4 & $100 \mathrm{sq} \mathrm{m}$ & 115.01 & Time Limit & 91.62 & 47.37 & 85.028 & 44.61 & 82.981 & 40.33 & 0.80 & $20.34 \%$ \\
\hline 265 & 27 & run 5 & 3 & 60 & 4 & $100 \mathrm{sq} \mathrm{m}$ & 113.98 & Time Limit & 89.686 & 108.33 & 91.098 & 26.93 & 89.674 & 27.89 & 0.79 & $21.31 \%$ \\
\hline 266 & 27 & run 6 & 3 & 60 & 4 & $100 \mathrm{sq} \mathrm{m}$ & 92.271 & Time Limit & 85.185 & 25.48 & 86.38 & 27.4 & 79.747 & 14.52 & 0.92 & $7.68 \%$ \\
\hline 267 & 27 & run 7 & 3 & 60 & 4 & $100 \mathrm{sq} \mathrm{m}$ & 121.872 & Time Limit & 95.606 & 53.67 & 92.184 & 88.81 & 93.483 & 56.37 & 0.78 & $21.55 \%$ \\
\hline 268 & 27 & run 8 & 3 & 60 & 4 & $100 \mathrm{sq} \mathrm{m}$ & 108.527 & Time Limit & 86.346 & 183.23 & 88.829 & 76.09 & 86.248 & 24.45 & 0.80 & $20.44 \%$ \\
\hline 269 & 27 & run 9 & 3 & 60 & 4 & 100 sq m & 97.047 & Time Limit & 82.493 & 34.75 & 79.69 & 32.37 & 84.032 & 39.75 & 0.85 & $15.00 \%$ \\
\hline 270 & 27 & run 10 & 3 & 60 & 4 & $100 \mathrm{sq} \mathrm{m}$ & 110.827 & Time Limit & 86.673 & 36.93 & 91.163 & 55.41 & 86.379 & 127.23 & 0.78 & $21.79 \%$ \\
\hline 271 & 28 & run 1 & 3 & 60 & 4 & $400 \mathrm{sq} \mathrm{m}$ & 203.06 & Time Limit & 169.827 & 35.82 & 178.941 & 61.33 & 168.601 & 25.12 & 0.84 & $16.37 \%$ \\
\hline 272 & 28 & run 2 & 3 & 60 & 4 & $400 \mathrm{sq} \mathrm{m}$ & 173.63 & Time Limit & 174.026 & 59.28 & 157.894 & 42.06 & 174.607 & 34.9 & 1.00228 & $0.23 \%$ \\
\hline 273 & 28 & run 3 & 3 & 60 & 4 & $400 \mathrm{sq} \mathrm{m}$ & 182.97 & Time Limit & 181.186 & 55.85 & 179.576 & 44.03 & 183.713 & 49.93 & 0.99 & $0.98 \%$ \\
\hline 274 & 28 & run 4 & 3 & 60 & 4 & $400 \mathrm{sq} \mathrm{m}$ & 220.62 & Time Limit & 174.684 & 68.65 & 168.912 & 60.21 & 175.372 & 20.04 & 0.79 & $20.82 \%$ \\
\hline 275 & 28 & run 5 & 3 & 60 & 4 & $400 \mathrm{sq} \mathrm{m}$ & 212.99 & Time Limit & 173.373 & 39.44 & 168.423 & 46.64 & 192.31 & 45.62 & 0.81 & $18.60 \%$ \\
\hline 276 & 28 & run 6 & 3 & 60 & 4 & $400 \mathrm{sq} \mathrm{m}$ & 210.827 & Time Limit & 164.24 & 77.32 & 172.087 & 112.92 & 163.984 & 173.79 & 0.78 & $22.10 \%$ \\
\hline 277 & 28 & run 7 & 3 & 60 & 4 & $400 \mathrm{sq} \mathrm{m}$ & 228.279 & Time Limit & 165.074 & 52.06 & 175.567 & 78.42 & 164.167 & 48.47 & 0.72 & $27.69 \%$ \\
\hline 278 & 28 & run 8 & 3 & 60 & 4 & $400 \mathrm{sq} \mathrm{m}$ & 214.667 & Time Limit & 175.535 & 50.99 & 179.16 & 32.37 & 175.581 & 29.65 & 0.82 & $18.23 \%$ \\
\hline 279 & 28 & run 9 & 3 & 60 & 4 & $400 \mathrm{sq} \mathrm{m}$ & 188.051 & Time Limit & 184.717 & 63.62 & 170.125 & 71.36 & 181.906 & 57.26 & 0.98 & $1.77 \%$ \\
\hline 280 & 28 & run 10 & 3 & 60 & 4 & $400 \mathrm{sq} \mathrm{m}$ & 195.353 & Time Limit & 169.562 & 12.94 & 188.641 & 19.89 & 173.218 & 60.83 & 0.87 & $13.20 \%$ \\
\hline 281 & 29 & run 1 & 3 & 60 & 6 & $100 \mathrm{sq} \mathrm{m}$ & 118.75 & Time Limit & 88.871 & 40.55 & 84.764 & 35.45 & 85.238 & 47.79 & 0.75 & $25.16 \%$ \\
\hline 282 & 29 & run 2 & 3 & 60 & 6 & $100 \mathrm{sq} \mathrm{m}$ & 89.85 & Time Limit & 81.804 & 89.47 & 84.842 & 45.11 & 83.623 & 66.47 & 0.91 & $8.95 \%$ \\
\hline 283 & 29 & run 3 & 3 & 60 & 6 & $100 \mathrm{sq} \mathrm{m}$ & 130.17 & Time Limit & 89.546 & 100.38 & 87.454 & 92.98 & 90.426 & 64.53 & 0.69 & $31.21 \%$ \\
\hline 284 & 29 & run 4 & 3 & 60 & 6 & $100 \mathrm{sq} \mathrm{m}$ & 123.65 & Time Limit & 89.611 & 76.91 & 90.847 & 45.63 & 81.961 & 52.71 & 0.72 & $27.53 \%$ \\
\hline 285 & 29 & run 5 & 3 & 60 & 6 & $100 \mathrm{sq} \mathrm{m}$ & 111.92 & Time Limit & 79.324 & 88.79 & 80.422 & 77.29 & 73.668 & 51.07 & 0.71 & $29.12 \%$ \\
\hline 286 & 29 & run 6 & 3 & 60 & 6 & $100 \mathrm{sq} \mathrm{m}$ & 125.657 & Time Limit & 92.34 & 43.7 & 90.971 & 79.25 & 84.976 & 44.02 & 0.73 & $26.51 \%$ \\
\hline 287 & 29 & run 7 & 3 & 60 & 6 & $100 \mathrm{sq} \mathrm{m}$ & 138.959 & Time Limit & 89.829 & 149.47 & 89.625 & 64.48 & 91.42 & 77.72 & 0.65 & $35.36 \%$ \\
\hline
\end{tabular}




\begin{tabular}{|c|c|c|c|c|c|c|c|c|c|c|c|c|c|c|c|c|}
\hline 288 & 29 & run 8 & 3 & 60 & 6 & $100 \mathrm{sq} \mathrm{m}$ & 119.87 & Time Limit & 85.311 & 161.47 & 88.51 & 108.12 & 85.311 & 19.51 & 0.71 & $28.83 \%$ \\
\hline 289 & 29 & run 9 & 3 & 60 & 6 & $100 \mathrm{sq} \mathrm{m}$ & 136.466 & Time Limit & 88.936 & 89.01 & 86.043 & 52.73 & 87.258 & 32.14 & 0.65 & $34.83 \%$ \\
\hline 290 & 29 & run 10 & 3 & 60 & 6 & $100 \mathrm{sq} \mathrm{m}$ & 120.852 & Time Limit & 87.986 & 81.6 & 84.576 & 164.61 & 86.798 & 59.52 & 0.73 & $27.20 \%$ \\
\hline 291 & 30 & run 1 & 3 & 60 & 6 & $400 \mathrm{sq} \mathrm{m}$ & 212.66 & Time Limit & 160.55 & 50.38 & 170.482 & 131.12 & 163.621 & 61.22 & 0.75 & $24.50 \%$ \\
\hline 292 & 30 & run 2 & 3 & 60 & 6 & $400 \mathrm{sq} \mathrm{m}$ & 231.4 & Time Limit & 162.756 & 138.26 & 166.592 & 201.88 & 167.466 & 94.04 & 0.70 & $29.66 \%$ \\
\hline 293 & 30 & run 3 & 3 & 60 & 6 & $400 \mathrm{sq} \mathrm{m}$ & 240.9 & Time Limit & 167.644 & 100.77 & 175.304 & 117.61 & 163.568 & 106.93 & 0.70 & $30.41 \%$ \\
\hline 294 & 30 & run 4 & 3 & 60 & 6 & $400 \mathrm{sq} \mathrm{m}$ & 259.61 & Time Limit & 184.361 & 51.06 & 178.24 & 57.05 & 187 & 46.81 & 0.71 & $28.99 \%$ \\
\hline 295 & 30 & run 5 & 3 & 60 & 6 & $400 \mathrm{sq} \mathrm{m}$ & 210.76 & Time Limit & 155.601 & 82.68 & 171.828 & 68.79 & 161.574 & 47.34 & 0.74 & $26.17 \%$ \\
\hline 296 & 30 & run 6 & 3 & 60 & 6 & $400 \mathrm{sq} \mathrm{m}$ & 220.666 & Time Limit & 177.427 & 349.48 & 171.249 & 114.13 & 183.642 & 98.23 & 0.80 & $19.59 \%$ \\
\hline 297 & 30 & run 7 & 3 & 60 & 6 & $400 \mathrm{sq} \mathrm{m}$ & 244.31 & Time Limit & 180.147 & 47.49 & 175.197 & 79.54 & 175.158 & 29.58 & 0.74 & $26.26 \%$ \\
\hline 298 & 30 & run 8 & 3 & 60 & 6 & $400 \mathrm{sq} \mathrm{m}$ & 178.957 & Time Limit & 167.099 & 40.88 & 164.081 & 43.47 & 158.723 & 17.32 & 0.93 & $6.63 \%$ \\
\hline 299 & 30 & run 9 & 3 & 60 & 6 & $400 \mathrm{sq} \mathrm{m}$ & 239.955 & Time Limit & 174.555 & 245.95 & 191.68 & 750.75 & 174.627 & 115.55 & 0.73 & $27.26 \%$ \\
\hline 300 & 30 & run 10 & 3 & 60 & 6 & $400 \mathrm{sq} \mathrm{m}$ & 241.694 & Time Limit & 177.918 & 35.02 & 179.629 & 31 & 173.502 & 37.04 & 0.74 & $26.39 \%$ \\
\hline 301 & 31 & run 1 & 4 & 20 & 2 & $100 \mathrm{sq} \mathrm{m}$ & 59.903 & 12.52 & 69.611 & 0.34 & 64.783 & 0.41 & 65.483 & 0.44 & 1.16 & $16.21 \%$ \\
\hline 302 & 31 & run 2 & 4 & 20 & 2 & $100 \mathrm{sq} \mathrm{m}$ & 62.521 & 2.7 & 73.115 & 0.59 & 66.325 & 0.36 & 68.958 & 0.29 & 1.17 & $16.94 \%$ \\
\hline 303 & 31 & run 3 & 4 & 20 & 2 & $100 \mathrm{sq} \mathrm{m}$ & 60.441 & 7.33 & 63.548 & 0.47 & 63.976 & 0.53 & 66.706 & 0.49 & 1.05 & $5.14 \%$ \\
\hline 304 & 31 & run 4 & 4 & 20 & 2 & $100 \mathrm{sq} \mathrm{m}$ & 61.909 & 2.84 & 68.896 & 0.37 & 70.408 & 0.41 & 66.054 & 0.26 & 1.11 & $11.29 \%$ \\
\hline 305 & 31 & run 5 & 4 & 20 & 2 & $100 \mathrm{sq} \mathrm{m}$ & 64.579 & 1.85 & 72.485 & 0.32 & 75.235 & 0.44 & 73.261 & 0.29 & 1.12 & $12.24 \%$ \\
\hline 306 & 31 & run 6 & 4 & 20 & 2 & $100 \mathrm{sq} \mathrm{m}$ & 53.832 & 2.56 & 68.817 & 0.46 & 65.319 & 0.38 & 62.335 & 0.4 & 1.28 & $27.84 \%$ \\
\hline 307 & 31 & run 7 & 4 & 20 & 2 & $100 \mathrm{sq} \mathrm{m}$ & 55.381 & 8.68 & 61.693 & 0.42 & 65.673 & 0.46 & 64.396 & 0.44 & 1.11 & $11.40 \%$ \\
\hline 308 & 31 & run 8 & 4 & 20 & 2 & $100 \mathrm{sq} \mathrm{m}$ & 60.924 & 6.63 & 68.456 & 0.44 & 70.85 & 0.53 & 66.032 & 0.33 & 1.12 & $12.36 \%$ \\
\hline 309 & 31 & run 9 & 4 & 20 & 2 & $100 \mathrm{sq} \mathrm{m}$ & 54.888 & 10.24 & 64.08 & 0.55 & 62.291 & 0.68 & 60.755 & 0.49 & 1.17 & $16.75 \%$ \\
\hline 310 & 31 & run 10 & 4 & 20 & 2 & $100 \mathrm{sq} \mathrm{m}$ & 46.734 & 2.96 & 53.09 & 0.53 & 53.483 & 0.32 & 54.581 & 0.31 & 1.14 & $13.60 \%$ \\
\hline 311 & 32 & run 1 & 4 & 20 & 2 & $400 \mathrm{sq} \mathrm{m}$ & 119.192 & 0.54 & 138.259 & 0.41 & 145.706 & 0.41 & 143.909 & 0.61 & 1.16 & $16.00 \%$ \\
\hline 312 & 32 & run 2 & 4 & 20 & 2 & $400 \mathrm{sq} \mathrm{m}$ & 123.084 & 10.36 & 133.197 & 0.52 & 133.86 & 0.37 & 132.232 & 0.35 & 1.08 & $8.22 \%$ \\
\hline 313 & 32 & run 3 & 4 & 20 & 2 & $400 \mathrm{sq} \mathrm{m}$ & 103.531 & 22.41 & 114.666 & 0.43 & 126.769 & 0.63 & 124.694 & 0.51 & 1.11 & $10.76 \%$ \\
\hline 314 & 32 & run 4 & 4 & 20 & 2 & $400 \mathrm{sq} \mathrm{m}$ & 113.468 & 1.22 & 125.477 & 0.57 & 123.377 & 0.44 & 127.225 & 0.47 & 1.11 & $10.58 \%$ \\
\hline 315 & 32 & run 5 & 4 & 20 & 2 & $400 \mathrm{sq} \mathrm{m}$ & 103.318 & 1.78 & 114.918 & 0.6 & 119.944 & 0.57 & 108.817 & 0.45 & 1.11 & $11.23 \%$ \\
\hline 316 & 32 & run 6 & 4 & 20 & 2 & $400 \mathrm{sq} \mathrm{m}$ & 116.733 & 10.85 & 132.97 & 0.58 & 127.253 & 0.45 & 138.099 & 0.42 & 1.14 & $13.91 \%$ \\
\hline
\end{tabular}




\begin{tabular}{|c|c|c|c|c|c|c|c|c|c|c|c|c|c|c|c|c|}
\hline 317 & 32 & run 7 & 4 & 20 & 2 & $400 \mathrm{sq} \mathrm{m}$ & 123.531 & 2.87 & 135.682 & 0.5 & 152.486 & 0.42 & 146.52 & 0.31 & 1.10 & $9.84 \%$ \\
\hline 318 & 32 & run 8 & 4 & 20 & 2 & $400 \mathrm{sq} \mathrm{m}$ & 111.616 & 11.85 & 127.831 & 0.38 & 136.061 & 0.55 & 141.459 & 0.34 & 1.15 & $14.53 \%$ \\
\hline 319 & 32 & run 9 & 4 & 20 & 2 & $400 \mathrm{sq} \mathrm{m}$ & 112.783 & 2.39 & 123.138 & 0.38 & 129.709 & 0.37 & 129.663 & 0.43 & 1.09 & $9.18 \%$ \\
\hline 320 & 32 & run 10 & 4 & 20 & 2 & $400 \mathrm{sq} \mathrm{m}$ & 93.113 & 8.44 & 117.904 & 0.47 & 121.326 & 0.4 & 115.406 & 0.42 & 1.27 & $26.62 \%$ \\
\hline 321 & 33 & run 1 & 4 & 20 & 4 & $100 \mathrm{sq} \mathrm{m}$ & 71.214 & 41.2 & 78.535 & 0.83 & 79.944 & 0.78 & 81.901 & 0.55 & 1.10 & $10.28 \%$ \\
\hline 322 & 33 & run 2 & 4 & 20 & 4 & $100 \mathrm{sq} \mathrm{m}$ & 59.462 & 93.54 & 69.434 & 0.78 & 71 & 0.9 & 68.04 & 0.83 & 1.17 & $16.77 \%$ \\
\hline 323 & 33 & run 3 & 4 & 20 & 4 & $100 \mathrm{sq} \mathrm{m}$ & 61.03 & 319.01 & 65.913 & 0.67 & 70.879 & 0.9 & 67.485 & 0.65 & 1.08 & $8.00 \%$ \\
\hline 324 & 33 & run 4 & 4 & 20 & 4 & $100 \mathrm{sq} \mathrm{m}$ & 69.346 & 42.02 & 76.208 & 0.8 & 80.153 & 1.03 & 69.346 & 0.52 & 1.10 & $9.90 \%$ \\
\hline 325 & 33 & run 5 & 4 & 20 & 4 & $100 \mathrm{sq} \mathrm{m}$ & 65.701 & 317.66 & 76.9 & 0.6 & 75.473 & 0.81 & 75.363 & 0.7 & 1.17 & $17.05 \%$ \\
\hline 326 & 33 & run 6 & 4 & 20 & 4 & $100 \mathrm{sq} \mathrm{m}$ & 51.965 & 49.87 & 63.852 & 1.06 & 61.891 & 0.79 & 56.414 & 0.92 & 1.23 & $22.88 \%$ \\
\hline 327 & 33 & run 7 & 4 & 20 & 4 & $100 \mathrm{sq} \mathrm{m}$ & 65.499 & 67.56 & 79.848 & 0.76 & 73.046 & 0.72 & 70.671 & 0.75 & 1.22 & $21.91 \%$ \\
\hline 328 & 33 & run 8 & 4 & 20 & 4 & $100 \mathrm{sq} \mathrm{m}$ & 61.301 & 373.63 & 68.271 & 1.03 & 69.41 & 1.04 & 66.242 & 0.88 & 1.11 & $11.37 \%$ \\
\hline 329 & 33 & run 9 & 4 & 20 & 4 & $100 \mathrm{sq} \mathrm{m}$ & 55.694 & 31.08 & 63.225 & 0.67 & 62.652 & 0.62 & 66.161 & 0.81 & 1.14 & $13.52 \%$ \\
\hline 330 & 33 & run 10 & 4 & 20 & 4 & $100 \mathrm{sq} \mathrm{m}$ & 54.045 & 52.07 & 60.584 & 0.67 & 61.516 & 0.6 & 59.636 & 0.67 & 1.12 & $12.10 \%$ \\
\hline 331 & 34 & run 1 & 4 & 20 & 4 & $400 \mathrm{sq} \mathrm{m}$ & 117.915 & 92.53 & 143.831 & 0.78 & 129.528 & 0.8 & 151.446 & 0.6 & 1.22 & $21.98 \%$ \\
\hline 332 & 34 & run 2 & 4 & 20 & 4 & $400 \mathrm{sq} \mathrm{m}$ & 128.359 & 28.78 & 154.927 & 0.93 & 140.465 & 0.5 & 152.198 & 0.47 & 1.21 & $20.70 \%$ \\
\hline 333 & 34 & run 3 & 4 & 20 & 4 & $400 \mathrm{sq} \mathrm{m}$ & 113.091 & 9.25 & 132.632 & 0.51 & 131.233 & 0.47 & 124.306 & 0.44 & 1.17 & $17.28 \%$ \\
\hline 334 & 34 & run 4 & 4 & 20 & 4 & $400 \mathrm{sq} \mathrm{m}$ & 131.672 & 52.69 & 150.791 & 1.02 & 153.78 & 0.76 & 146.456 & 0.53 & 1.15 & $14.52 \%$ \\
\hline 335 & 34 & run 5 & 4 & 20 & 4 & $400 \mathrm{sq} \mathrm{m}$ & 109.584 & 461.3 & 131.056 & 0.89 & 133.935 & 0.86 & 138.345 & 0.92 & 1.20 & $19.59 \%$ \\
\hline 336 & 34 & run 6 & 4 & 20 & 4 & $400 \mathrm{sq} \mathrm{m}$ & 112.01 & 77.06 & 130.566 & 0.83 & 121.242 & 0.56 & 121.242 & 0.81 & 1.17 & $16.57 \%$ \\
\hline 337 & 34 & run 7 & 4 & 20 & 4 & $400 \mathrm{sq} \mathrm{m}$ & 141.198 & 222.52 & 159.252 & 0.65 & 157.589 & 0.81 & 156.951 & 0.6 & 1.13 & $12.79 \%$ \\
\hline 338 & 34 & run 8 & 4 & 20 & 4 & $400 \mathrm{sq} \mathrm{m}$ & 115.012 & 47.54 & 134.93 & 0.72 & 129.988 & 0.58 & 150.522 & 0.77 & 1.17 & $17.32 \%$ \\
\hline 339 & 34 & run 9 & 4 & 20 & 4 & $400 \mathrm{sq} \mathrm{m}$ & 126.541 & 7.83 & 137.507 & 0.86 & 143.765 & 0.87 & 134.762 & 0.86 & 1.09 & $8.67 \%$ \\
\hline 340 & 34 & run 10 & 4 & 20 & 4 & $400 \mathrm{sq} \mathrm{m}$ & 113.618 & 37.07 & 125.443 & 0.74 & 123.783 & 0.65 & 123.686 & 0.55 & 1.10 & $10.41 \%$ \\
\hline 341 & 35 & run 1 & 4 & 20 & 6 & $100 \mathrm{sq} \mathrm{m}$ & 48.894 & 16.16 & 57.559 & 1.11 & 53.287 & 1.2 & 55.303 & 0.95 & 1.18 & $17.72 \%$ \\
\hline 342 & 35 & run 2 & 4 & 20 & 6 & $100 \mathrm{sq} \mathrm{m}$ & 54.748 & 13.44 & 62.738 & 1.45 & 66.082 & 1.26 & 64.248 & 0.81 & 1.15 & $14.59 \%$ \\
\hline 343 & 35 & run 3 & 4 & 20 & 6 & $100 \mathrm{sq} \mathrm{m}$ & 49.505 & 294.35 & 58.668 & 1.46 & 58.291 & 1.56 & 63.305 & 2.05 & 1.19 & $18.51 \%$ \\
\hline 344 & 35 & run 4 & 4 & 20 & 6 & $100 \mathrm{sq} \mathrm{m}$ & 53.235 & 119.39 & $\begin{array}{l}58.8 \\
\end{array}$ & 1.4 & 59.811 & 1.13 & 58.821 & 1.28 & 1.10 & $10.45 \%$ \\
\hline 345 & 35 & run 5 & 4 & 20 & 6 & $100 \mathrm{sq} \mathrm{m}$ & 65.864 & 162.34 & 71.683 & 0.93 & 73.501 & 1.08 & 74.329 & 1.37 & 1.09 & $8.83 \%$ \\
\hline
\end{tabular}




\begin{tabular}{|c|c|c|c|c|c|c|c|c|c|c|c|c|c|c|c|c|}
\hline 346 & 35 & run 6 & 4 & 20 & 6 & $100 \mathrm{sq} \mathrm{m}$ & 55.779 & 149.15 & 57.991 & 1.43 & 60.387 & 1.44 & 62.895 & 1.87 & 1.04 & $3.97 \%$ \\
\hline 347 & 35 & run 7 & 4 & 20 & 6 & $100 \mathrm{sq} \mathrm{m}$ & 53.133 & 429.93 & 59.088 & 1.62 & 57.165 & 1.28 & 58.746 & 1.64 & 1.11 & $11.21 \%$ \\
\hline 348 & 35 & run 8 & 4 & 20 & 6 & 100 sq m & 64.944 & 48.7 & 72.332 & 1.43 & 75.268 & 1.16 & 71.039 & 1.43 & 1.11 & $11.38 \%$ \\
\hline 349 & 35 & run 9 & 4 & 20 & 6 & $100 \mathrm{sq} \mathrm{m}$ & 52.038 & 130.32 & 64.511 & 1.4 & 58.559 & 1.22 & 61.857 & 1.42 & 1.24 & $23.97 \%$ \\
\hline 350 & 35 & run 10 & 4 & 20 & 6 & $100 \mathrm{sq} \mathrm{m}$ & 55.007 & 57.66 & 65.522 & 1.28 & 63.257 & 1.56 & 66.002 & 1.12 & 1.19 & $19.12 \%$ \\
\hline 351 & 36 & run 1 & 4 & 20 & 6 & $400 \mathrm{sq} \mathrm{m}$ & 113.151 & 232.16 & 127.126 & 1.06 & 121.4 & 0.94 & 121.972 & 0.91 & 1.12 & $12.35 \%$ \\
\hline 352 & 36 & run 2 & 4 & 20 & 6 & $400 \mathrm{sq} \mathrm{m}$ & 121.431 & 557.77 & 140.461 & 1.56 & 140.488 & 1.27 & 141.101 & 1.22 & 1.16 & $15.67 \%$ \\
\hline 353 & 36 & run 3 & 4 & 20 & 6 & $400 \mathrm{sq} \mathrm{m}$ & 115.795 & 111.36 & 124.695 & 1.27 & 116.69 & 1.1 & 125.731 & 1.73 & 1.08 & $7.69 \%$ \\
\hline 354 & 36 & run 4 & 4 & 20 & 6 & $400 \mathrm{sq} \mathrm{m}$ & 118.819 & 184.79 & 136.781 & 1.46 & 134.99 & 1.49 & 134.779 & 2.15 & 1.15 & $15.12 \%$ \\
\hline 355 & 36 & run 5 & 4 & 20 & 6 & $400 \mathrm{sq} \mathrm{m}$ & 108.438 & 149 & 111.274 & 1.19 & 122.842 & 1.14 & 112.749 & 0.82 & 1.03 & $2.62 \%$ \\
\hline 356 & 36 & run 6 & 4 & 20 & 6 & $400 \mathrm{sq} \mathrm{m}$ & 122.496 & 26.43 & 140.528 & 1.36 & 150.995 & 1.32 & 139.038 & 0.9 & 1.15 & $14.72 \%$ \\
\hline 357 & 36 & run 7 & 4 & 20 & 6 & $400 \mathrm{sq} \mathrm{m}$ & 100.781 & 27.73 & 121.831 & 1.6 & 127.388 & 1.89 & 126.718 & 1.48 & 1.21 & $20.89 \%$ \\
\hline 358 & 36 & run 8 & 4 & 20 & 6 & $400 \mathrm{sq} \mathrm{m}$ & 106.832 & 442.61 & 122.552 & 1.17 & 115.413 & 1.11 & 127.392 & 0.9 & 1.15 & $14.71 \%$ \\
\hline 359 & 36 & run 9 & 4 & 20 & 6 & $400 \mathrm{sq} \mathrm{m}$ & 102.197 & 44.15 & 140.833 & 1.57 & 134.549 & 1.42 & 132.388 & 0.93 & 1.38 & $37.81 \%$ \\
\hline 360 & 36 & run 10 & 4 & 20 & 6 & $400 \mathrm{sq} \mathrm{m}$ & 125.308 & 932.23 & 139.166 & 1.56 & 133.567 & 1.4 & 140.777 & 1.32 & 1.11 & $11.06 \%$ \\
\hline 361 & 37 & run 1 & 4 & 40 & 2 & $100 \mathrm{sq} \mathrm{m}$ & 70.704 & 34.32 & 78.922 & 2.15 & 86.82 & 2.48 & 85.557 & 2.06 & 1.12 & $11.62 \%$ \\
\hline 362 & 37 & run 2 & 4 & 40 & 2 & $100 \mathrm{sq} \mathrm{m}$ & 74.362 & 582.4 & 85.445 & 2.46 & 84.716 & 2.4 & 84.812 & 1.69 & 1.15 & $14.90 \%$ \\
\hline 363 & 37 & run 3 & 4 & 40 & 2 & $100 \mathrm{sq} \mathrm{m}$ & 67.657 & 1256.82 & 79.319 & 5.77 & 73.356 & 72.39 & 75.593 & 1.19 & 1.17 & $17.24 \%$ \\
\hline 364 & 37 & run 4 & 4 & 40 & 2 & $100 \mathrm{sq} \mathrm{m}$ & 76.601 & 1039.28 & 82.439 & 2.62 & 82.469 & 2.73 & 78.866 & 1.83 & 1.08 & $7.62 \%$ \\
\hline 365 & 37 & run 5 & 4 & 40 & 2 & $100 \mathrm{sq} \mathrm{m}$ & 76.349 & 807.84 & 85.426 & 2.07 & 86.444 & 1.36 & 88.514 & 1.29 & 1.12 & $11.89 \%$ \\
\hline 366 & 37 & run 6 & 4 & 40 & 2 & $100 \mathrm{sq} \mathrm{m}$ & 66.62 & 900.09 & 75.415 & 1.66 & 73.512 & 1.95 & 78.745 & 1.85 & 1.13 & $13.20 \%$ \\
\hline 367 & 37 & run 7 & 4 & 40 & 2 & $100 \mathrm{sq} \mathrm{m}$ & 72.439 & 227.85 & 83.128 & 2.08 & 81.103 & 2.12 & 83.335 & 1.31 & 1.15 & $14.76 \%$ \\
\hline 368 & 37 & run 8 & 4 & 40 & 2 & $100 \mathrm{sq} \mathrm{m}$ & 64.367 & 1232.19 & 74.896 & 2.47 & 72.36 & 3.06 & 74.614 & 1.75 & 1.16 & $16.36 \%$ \\
\hline 369 & 37 & run 9 & 4 & 40 & 2 & $100 \mathrm{sq} \mathrm{m}$ & 75.027 & 946.68 & 81.289 & 2.7 & 82.39 & 2.27 & 78.538 & 3.05 & 1.08 & $8.35 \%$ \\
\hline 370 & 37 & run 10 & 4 & 40 & 2 & $100 \mathrm{sq} \mathrm{m}$ & 69.394 & 1850.46 & 84.835 & 4.85 & 80.233 & 2.35 & 73.52 & 1.88 & 1.22 & $22.25 \%$ \\
\hline 371 & 38 & run 1 & 4 & 40 & 2 & $400 \mathrm{sq} \mathrm{m}$ & 157.833 & 10.95 & 177.256 & 1.53 & 177.064 & 1.65 & 177.25 & 1.73 & 1.12 & $12.31 \%$ \\
\hline 372 & 38 & run 2 & 4 & 40 & 2 & $400 \mathrm{sq} \mathrm{m}$ & 164.892 & 122.3 & 190.494 & 1.74 & 185.868 & 1.96 & 172.598 & 1.14 & 1.16 & $15.53 \%$ \\
\hline 373 & 38 & run 3 & 4 & 40 & 2 & $400 \mathrm{sq} \mathrm{m}$ & 146.395 & 277.51 & 165.449 & 1.84 & 166.08 & 3.3 & 165.176 & 1.07 & 1.13 & $13.02 \%$ \\
\hline 374 & 38 & run 4 & 4 & 40 & 2 & $400 \mathrm{sq} \mathrm{m}$ & 137.973 & 297.34 & 156.078 & 2.28 & 161.529 & 2.91 & 160.708 & 1.98 & 1.13 & $13.12 \%$ \\
\hline
\end{tabular}




\begin{tabular}{|c|c|c|c|c|c|c|c|c|c|c|c|c|c|c|c|c|}
\hline 375 & 38 & run 5 & 4 & 40 & 2 & $400 \mathrm{sq} \mathrm{m}$ & 159.98 & 676.95 & 171.919 & 2.06 & 176.975 & 2.3 & 168.594 & 1.99 & 1.07 & $7.46 \%$ \\
\hline 376 & 38 & run 6 & 4 & 40 & 2 & $400 \mathrm{sq} \mathrm{m}$ & 133.969 & Time Limit & 158.442 & 2.73 & 149.659 & 2.7 & 148.344 & 2.01 & 1.18 & $18.27 \%$ \\
\hline 377 & 38 & run 7 & 4 & 40 & 2 & $400 \mathrm{sq} \mathrm{m}$ & 142.557 & 64.32 & 162.234 & 1.42 & 151.929 & 1.42 & 157.08 & 1.61 & 1.14 & $13.80 \%$ \\
\hline 378 & 38 & $\operatorname{run} 8$ & 4 & 40 & 2 & $400 \mathrm{sq} \mathrm{m}$ & 135.086 & Time Limit & 157.615 & 2.92 & 150.654 & 3.78 & 157.055 & 3.86 & 1.17 & $16.68 \%$ \\
\hline 379 & 38 & run 9 & 4 & 40 & 2 & $400 \mathrm{sq} \mathrm{m}$ & 143.153 & 1858.59 & 175.143 & 2.19 & 182.728 & 1.57 & 173.408 & 22.09 & 1.22 & $22.35 \%$ \\
\hline 380 & 38 & run 10 & 4 & 40 & 2 & $400 \mathrm{sq} \mathrm{m}$ & 131.64 & 3452.34 & 148.021 & 2.98 & 155.277 & 4.51 & 149.096 & 1.4 & 1.12 & $12.44 \%$ \\
\hline 381 & 39 & run 1 & 4 & 40 & 4 & $100 \mathrm{sq} \mathrm{m}$ & 64.622 & Time Limit & 69.975 & 4.09 & 76.539 & 3.49 & 69.986 & 2.44 & 1.08 & $8.28 \%$ \\
\hline 382 & 39 & run 2 & 4 & 40 & 4 & $100 \mathrm{sq} \mathrm{m}$ & 75.542 & 758.46 & 86.154 & 2.54 & 87.128 & 2.84 & 83.57 & 4.6 & 1.14 & $14.05 \%$ \\
\hline 383 & 39 & run 3 & 4 & 40 & 4 & $100 \mathrm{sq} \mathrm{m}$ & 67.281 & 1224.42 & 75.807 & 2.72 & 76.142 & 2.53 & 71.575 & 2.04 & 1.13 & $12.67 \%$ \\
\hline 384 & 39 & run 4 & 4 & 40 & 4 & $100 \mathrm{sq} \mathrm{m}$ & 72.618 & Time Limit & 78.178 & 3.43 & 79.378 & 7.79 & 73.506 & 2.55 & 1.08 & $7.66 \%$ \\
\hline 385 & 39 & run 5 & 4 & 40 & 4 & $100 \mathrm{sq} \mathrm{m}$ & 63.673 & 634.95 & 76.507 & 2.86 & 73.114 & 3.55 & 77.286 & 2.91 & 1.20 & $20.16 \%$ \\
\hline 386 & 39 & run 6 & 4 & 40 & 4 & $100 \mathrm{sq} \mathrm{m}$ & 69.201 & 543.13 & 83.469 & 2.86 & 77.037 & 3.29 & 79.609 & 3.21 & 1.21 & $20.62 \%$ \\
\hline 387 & 39 & $\operatorname{run} 7$ & 4 & 40 & 4 & $100 \mathrm{sq} \mathrm{m}$ & 65.725 & 206.64 & 77.75 & 4.38 & 76.603 & 2.58 & 71.512 & 2.77 & 1.18 & $18.30 \%$ \\
\hline 388 & 39 & run 8 & 4 & 40 & 4 & $100 \mathrm{sq} \mathrm{m}$ & 66.747 & 2644.51 & 80.098 & 2.84 & 80.094 & 2.68 & 72.98 & 2.08 & 1.20 & $20.00 \%$ \\
\hline 389 & 39 & run 9 & 4 & 40 & 4 & $100 \mathrm{sq} \mathrm{m}$ & 69.265 & Time Limit & 77.645 & 3.38 & 71.91 & 3.1 & 72.409 & 2.6 & 1.12 & $12.10 \%$ \\
\hline 390 & 39 & run 10 & 4 & 40 & 4 & $100 \mathrm{sq} \mathrm{m}$ & 62.403 & Time Limit & 78.871 & 6.31 & 71.834 & 8.89 & 73.606 & 3.96 & 1.26 & $26.39 \%$ \\
\hline 391 & 40 & run 1 & 4 & 40 & 4 & $400 \mathrm{sq} \mathrm{m}$ & 149.509 & 450.04 & 165.504 & 2.1 & 167.359 & 2.43 & 176.173 & 4.57 & 1.11 & $10.70 \%$ \\
\hline 392 & 40 & run 2 & 4 & 40 & 4 & $400 \mathrm{sq} \mathrm{m}$ & 142.039 & 28.68 & 156.652 & 2.89 & 159.474 & 2.2 & 151.446 & 2.04 & 1.10 & $10.29 \%$ \\
\hline 393 & 40 & run 3 & 4 & 40 & 4 & $400 \mathrm{sq} \mathrm{m}$ & 137.744 & 593.22 & 160.729 & 4.55 & 156.495 & 2.65 & 163.424 & 3.74 & 1.17 & $16.69 \%$ \\
\hline 394 & 40 & run 4 & 4 & 40 & 4 & $400 \mathrm{sq} \mathrm{m}$ & 142.907 & Time Limit & 164.237 & 3.08 & 164.41 & 3.96 & 158.843 & 2.6 & 1.15 & $14.93 \%$ \\
\hline 395 & 40 & run 5 & 4 & 40 & 4 & $400 \mathrm{sq} \mathrm{m}$ & 125.751 & 745.09 & 151.496 & 3.29 & 148.386 & 3.46 & 146.888 & 2.81 & 1.20 & $20.47 \%$ \\
\hline 396 & 40 & run 6 & 4 & 40 & 4 & $400 \mathrm{sq} \mathrm{m}$ & 146.695 & Time Limit & 162.499 & 3.76 & 160.612 & 4.38 & 161.001 & 4.57 & 1.11 & $10.77 \%$ \\
\hline 397 & 40 & run 7 & 4 & 40 & 4 & $400 \mathrm{sq} \mathrm{m}$ & 153.343 & Time Limit & 172.616 & 11.74 & 164.245 & 3.43 & 157.096 & 2.2 & 1.13 & $12.57 \%$ \\
\hline 398 & 40 & run 8 & 4 & 40 & 4 & $400 \mathrm{sq} \mathrm{m}$ & 138.664 & Time Limit & 151.79 & 9.55 & 148.526 & 5.31 & 150.952 & 2.44 & 1.09 & $9.47 \%$ \\
\hline 399 & 40 & run 9 & 4 & 40 & 4 & $400 \mathrm{sq} \mathrm{m}$ & 143.732 & Time Limit & 158.103 & 2.94 & 155.497 & 3.23 & 160.445 & 2.22 & 1.10 & $10.00 \%$ \\
\hline 400 & 40 & run 10 & 4 & 40 & 4 & $400 \mathrm{sq} \mathrm{m}$ & 142.098 & 1081.01 & 155.801 & 4.27 & 156.346 & 5.37 & 158.234 & 4.02 & 1.10 & $9.64 \%$ \\
\hline 401 & 41 & run 1 & 4 & 40 & 6 & $100 \mathrm{sq} \mathrm{m}$ & 75.592 & Time Limit & 80.752 & 5.78 & 79.611 & 6.33 & 72.301 & 3.47 & 1.07 & $6.83 \%$ \\
\hline 402 & 41 & run 2 & 4 & 40 & 6 & $100 \mathrm{sq} \mathrm{m}$ & 75.971 & Time Limit & 79.258 & 4.84 & 83.891 & 4.2 & 80.122 & 4.15 & 1.04 & $4.33 \%$ \\
\hline 403 & 41 & run 3 & 4 & 40 & 6 & $100 \mathrm{sq} \mathrm{m}$ & 65.476 & Time Limit & 77.878 & 9.52 & 77.468 & 12.66 & 74.728 & 6.06 & 1.19 & $18.94 \%$ \\
\hline
\end{tabular}




\begin{tabular}{|c|c|c|c|c|c|c|c|c|c|c|c|c|c|c|c|c|}
\hline 404 & 41 & run 4 & 4 & 40 & 6 & $100 \mathrm{sq} \mathrm{m}$ & 70.016 & Time Limit & 76.633 & 6.65 & 79.218 & 4.77 & 80.325 & 4.29 & 1.09 & $9.45 \%$ \\
\hline 405 & 41 & run 5 & 4 & 40 & 6 & $100 \mathrm{sq} \mathrm{m}$ & 62.908 & Time Limit & 74.247 & 7.34 & 74.235 & 7.46 & 70.247 & 5.33 & 1.18 & $18.02 \%$ \\
\hline 406 & 41 & run 6 & 4 & 40 & 6 & $100 \mathrm{sq} \mathrm{m}$ & 66.168 & Time Limit & 82.697 & 3.88 & 80.445 & 8.03 & 81.376 & 3.33 & 1.25 & $24.98 \%$ \\
\hline 407 & 41 & run 7 & 4 & 40 & 6 & $100 \mathrm{sq} \mathrm{m}$ & 69.906 & Time Limit & 82.435 & 7.33 & 78.11 & 20.08 & 76.475 & 5.23 & 1.18 & $17.92 \%$ \\
\hline 408 & 41 & run 8 & 4 & 40 & 6 & $100 \mathrm{sq} \mathrm{m}$ & 70.92 & Time Limit & 76.218 & 5.81 & 76.304 & 3.93 & 80.783 & 7.56 & 1.07 & $7.47 \%$ \\
\hline 409 & 41 & run 9 & 4 & 40 & 6 & $100 \mathrm{sq} \mathrm{m}$ & 66.038 & Time Limit & 65.708 & 5.06 & 70.276 & 4.9 & 71.285 & 3.95 & 0.99500 & $0.50 \%$ \\
\hline 410 & 41 & run 10 & 4 & 40 & 6 & $100 \mathrm{sq} \mathrm{m}$ & 67.76 & Time Limit & 74.097 & 4.2 & 78.362 & 4.75 & 71.414 & 1.86 & 1.09 & $9.35 \%$ \\
\hline 411 & 42 & run 1 & 4 & 40 & 6 & $400 \mathrm{sq} \mathrm{m}$ & 143.826 & Time Limit & 157.098 & 6.02 & 151.585 & 4.45 & 157.055 & 4.29 & 1.09 & $9.23 \%$ \\
\hline 412 & 42 & run 2 & 4 & 40 & 6 & $400 \mathrm{sq} \mathrm{m}$ & 139.938 & Time Limit & 162.189 & 6.37 & 160.723 & 3.81 & 158.167 & 3.84 & 1.16 & $15.90 \%$ \\
\hline 413 & 42 & run 3 & 4 & 40 & 6 & $400 \mathrm{sq} \mathrm{m}$ & 131.909 & Time Limit & 147.358 & 8.04 & 146.817 & 11.77 & 150.209 & 9.81 & 1.12 & $11.71 \%$ \\
\hline 414 & 42 & run 4 & 4 & 40 & 6 & $400 \mathrm{sq} \mathrm{m}$ & 140.574 & Time Limit & 160.625 & 7.69 & 155.467 & 4.87 & 153.027 & 9.66 & 1.14 & $14.26 \%$ \\
\hline 415 & 42 & run 5 & 4 & 40 & 6 & $400 \mathrm{sq} \mathrm{m}$ & 143.012 & Time Limit & 159.128 & 6.27 & 153.93 & 6.12 & 158.491 & 5.13 & 1.11 & $11.27 \%$ \\
\hline 416 & 42 & run 6 & 4 & 40 & 6 & $400 \mathrm{sq} \mathrm{m}$ & 141.894 & Time Limit & 170.306 & 13.49 & 160.029 & 4.79 & 150.855 & 6.4 & 1.20 & $20.02 \%$ \\
\hline 417 & 42 & run 7 & 4 & 40 & 6 & $400 \mathrm{sq} \mathrm{m}$ & 149.187 & Time Limit & 158.149 & 6.81 & 166.697 & 5.25 & 171.496 & 4.23 & 1.06 & $6.01 \%$ \\
\hline 418 & 42 & run 8 & 4 & 40 & 6 & $400 \mathrm{sq} \mathrm{m}$ & 138.779 & Time Limit & 173.547 & 8.15 & 157.852 & 7.15 & 152.599 & 3.9 & 1.25 & $25.05 \%$ \\
\hline 419 & 42 & run 9 & 4 & 40 & 6 & $400 \mathrm{sq} \mathrm{m}$ & 137.247 & Time Limit & 162.731 & 4.43 & 154.18 & 4.57 & 148.839 & 3.79 & 1.19 & $18.57 \%$ \\
\hline 420 & 42 & run 10 & 4 & 40 & 6 & $400 \mathrm{sq} \mathrm{m}$ & 153.65 & Time Limit & 167.309 & 5.22 & 162.348 & 4.41 & 174.423 & 4.22 & 1.09 & $8.89 \%$ \\
\hline 421 & 43 & run 1 & 4 & 60 & 2 & $100 \mathrm{sq} \mathrm{m}$ & 90.473 & Time Limit & 99.228 & 528.69 & 96.602 & 17.31 & 94.079 & 14.28 & 1.10 & $9.68 \%$ \\
\hline 422 & 43 & run 2 & 4 & 60 & 2 & $100 \mathrm{sq} \mathrm{m}$ & 90.248 & Time Limit & 99.849 & 4.95 & 103.151 & 3.4 & 97.625 & 15.79 & 1.11 & $10.64 \%$ \\
\hline 423 & 43 & run 3 & 4 & 60 & 2 & $100 \mathrm{sq} \mathrm{m}$ & 76.384 & Time Limit & 84.711 & 6.54 & 86.653 & 115.5 & 89.66 & 11 & 1.11 & $10.90 \%$ \\
\hline 424 & 43 & run 4 & 4 & 60 & 2 & $100 \mathrm{sq} \mathrm{m}$ & 84.054 & Time Limit & 92.852 & 4.87 & 93.381 & 14.52 & 96.111 & 4.93 & 1.10 & $10.47 \%$ \\
\hline 425 & 43 & run 5 & 4 & 60 & 2 & $100 \mathrm{sq} \mathrm{m}$ & 89.415 & Time Limit & 92.987 & 11.94 & 96.226 & 18.66 & 99.43 & 8.81 & 1.04 & $3.99 \%$ \\
\hline 426 & 43 & run 6 & 4 & 60 & 2 & $100 \mathrm{sq} \mathrm{m}$ & 83.718 & Time Limit & 87.183 & 7.17 & 89.69 & 10.4 & 91.009 & 35.83 & 1.04 & $4.14 \%$ \\
\hline 427 & 43 & run 7 & 4 & 60 & 2 & $100 \mathrm{sq} \mathrm{m}$ & 81.892 & Time Limit & 90.936 & 5.86 & 93.031 & 4.47 & 91.638 & 4.69 & 1.11 & $11.04 \%$ \\
\hline 428 & 43 & run 8 & 4 & 60 & 2 & $100 \mathrm{sq} \mathrm{m}$ & 82.766 & Time Limit & 94.278 & 8.39 & 90.14 & 6.31 & 89.11 & 5.71 & 1.14 & $13.91 \%$ \\
\hline 429 & 43 & run 9 & 4 & 60 & 2 & $100 \mathrm{sq} \mathrm{m}$ & 77.872 & Time Limit & 87.578 & 5.78 & 86.819 & 10.47 & 82.625 & 6.58 & 1.12 & $12.46 \%$ \\
\hline 430 & 43 & run 10 & 4 & 60 & 2 & $100 \mathrm{sq} \mathrm{m}$ & 96.105 & Time Limit & 97.908 & 8.88 & 102.706 & 11.51 & 97.636 & 8.24 & 1.02 & $1.88 \%$ \\
\hline 431 & 44 & run 1 & 4 & 60 & 2 & $400 \mathrm{sq} \mathrm{m}$ & 177.045 & Time Limit & 195.808 & 11.36 & 192.958 & 23.49 & 195.201 & 15.81 & 1.11 & $10.60 \%$ \\
\hline 432 & 44 & run 2 & 4 & 60 & 2 & $400 \mathrm{sq} \mathrm{m}$ & 191.39 & Time Limit & 179.212 & 37.2 & 174.546 & 13.74 & 179.973 & 22.23 & 0.94 & $6.36 \%$ \\
\hline
\end{tabular}




\begin{tabular}{|c|c|c|c|c|c|c|c|c|c|c|c|c|c|c|c|c|}
\hline 433 & 44 & run 3 & 4 & 60 & 2 & $400 \mathrm{sq} \mathrm{m}$ & 175.099 & Time Limit & 178.729 & 41.02 & 175.868 & 81.39 & 173.899 & 25.16 & 1.02 & $2.07 \%$ \\
\hline 434 & 44 & run 4 & 4 & 60 & 2 & $400 \mathrm{sq} \mathrm{m}$ & 179.28 & Time Limit & 187.588 & 13.64 & 171.222 & 11.44 & 178.735 & 12.16 & 1.05 & $4.63 \%$ \\
\hline 435 & 44 & $\operatorname{run} 5$ & 4 & 60 & 2 & $400 \mathrm{sq} \mathrm{m}$ & 260.31 & Time Limit & 187.25 & 24.78 & 174.273 & 24.15 & 175.458 & 14.12 & 0.72 & $28.07 \%$ \\
\hline 436 & 44 & run 6 & 4 & 60 & 2 & $400 \mathrm{sq} \mathrm{m}$ & 176.44 & Time Limit & 186.035 & 25.1 & 179.993 & 23.78 & 186.311 & 26.23 & 1.05 & $5.44 \%$ \\
\hline 437 & 44 & run 7 & 4 & 60 & 2 & $400 \mathrm{sq} \mathrm{m}$ & 186.87 & Time Limit & 172.671 & 27.32 & 170.44 & 25.61 & 166.42 & 28.91 & 0.92 & $7.60 \%$ \\
\hline 438 & 44 & run 8 & 4 & 60 & 2 & $400 \mathrm{sq} \mathrm{m}$ & 172.657 & Time Limit & 177.748 & 19.45 & 184.402 & 22.73 & 181.245 & 20.56 & 1.03 & $2.95 \%$ \\
\hline 439 & 44 & run 9 & 4 & 60 & 2 & $400 \mathrm{sq} \mathrm{m}$ & 177.735 & Time Limit & 198.613 & 32.56 & 191.019 & 34.67 & 190.61 & 30.59 & 1.12 & $11.75 \%$ \\
\hline 440 & 44 & run 10 & 4 & 60 & 2 & $400 \mathrm{sq} \mathrm{m}$ & 182.458 & Time Limit & 189.163 & 29.2 & 196.638 & 31.53 & 196.83 & 30.81 & 1.04 & $3.67 \%$ \\
\hline 441 & 45 & run 1 & 4 & 60 & 4 & $100 \mathrm{sq} \mathrm{m}$ & 87.51 & Time Limit & 90.13 & 28.55 & 92.369 & 30.5 & 86.724 & 20.57 & 1.03 & $2.99 \%$ \\
\hline 442 & 45 & run 2 & 4 & 60 & 4 & $100 \mathrm{sq} \mathrm{m}$ & 132.68 & Time Limit & 93.611 & 39.35 & 88.843 & 41.84 & 86.411 & 22.63 & 0.71 & $29.45 \%$ \\
\hline 443 & 45 & run 3 & 4 & 60 & 4 & $100 \mathrm{sq} \mathrm{m}$ & 111.51 & Time Limit & 94.224 & 19.35 & 90.065 & 13.44 & 99.23 & 26.12 & 0.84 & $15.50 \%$ \\
\hline 444 & 45 & run 4 & 4 & 60 & 4 & $100 \mathrm{sq} \mathrm{m}$ & 103.42 & Time Limit & 97.37 & 29.15 & 96.222 & 14.03 & 93.557 & 17.73 & 0.94 & $5.85 \%$ \\
\hline 445 & 45 & run 5 & 4 & 60 & 4 & $100 \mathrm{sq} \mathrm{m}$ & 112.59 & Time Limit & 88.399 & 57.13 & 99.371 & 668.58 & 91.622 & 37.19 & 0.79 & $21.49 \%$ \\
\hline 446 & 45 & run 6 & 4 & 60 & 4 & $100 \mathrm{sq} \mathrm{m}$ & 93.483 & Time Limit & 88.093 & 9.51 & 97.513 & 16.93 & 90.109 & 22.16 & 0.94 & $5.77 \%$ \\
\hline 447 & 45 & run 7 & 4 & 60 & 4 & $100 \mathrm{sq} \mathrm{m}$ & 103.019 & Time Limit & 87.277 & 17.67 & 92.913 & 158.94 & 85.399 & 7.49 & 0.85 & $15.28 \%$ \\
\hline 448 & 45 & run 8 & 4 & 60 & 4 & $100 \mathrm{sq} \mathrm{m}$ & 101.422 & Time Limit & 92.977 & 14.09 & 93.609 & 8.49 & 94.698 & 8.83 & 0.92 & $8.33 \%$ \\
\hline 449 & 45 & run 9 & 4 & 60 & 4 & $100 \mathrm{sq} \mathrm{m}$ & 96.219 & Time Limit & 99.659 & 9.25 & 102.76 & 10.57 & 95.652 & 4.12 & 1.04 & $3.58 \%$ \\
\hline 450 & 45 & run 10 & 4 & 60 & 4 & $100 \mathrm{sq} \mathrm{m}$ & 100.57 & Time Limit & 90.928 & 8.46 & 91.589 & 7.85 & 88.486 & 7.34 & 0.90 & $9.59 \%$ \\
\hline 451 & 46 & run 1 & 4 & 60 & 4 & $400 \mathrm{sq} \mathrm{m}$ & 178.501 & Time Limit & 188.216 & 30.07 & 183.846 & 24.66 & 176.851 & 17.24 & 1.05 & $5.44 \%$ \\
\hline 452 & 46 & run 2 & 4 & 60 & 4 & $400 \mathrm{sq} \mathrm{m}$ & 203.42 & Time Limit & 193.088 & 23.43 & 192.587 & 23.19 & 192.947 & 22.73 & 0.95 & $5.08 \%$ \\
\hline 453 & 46 & run 3 & 4 & 60 & 4 & $400 \mathrm{sq} \mathrm{m}$ & 274.4 & Time Limit & 181.971 & 42.68 & 183.454 & 28.19 & 189.18 & 88.64 & 0.66 & $33.68 \%$ \\
\hline 454 & 46 & run 4 & 4 & 60 & 4 & $400 \mathrm{sq} \mathrm{m}$ & 206.42 & Time Limit & 192.277 & 61 & 190.773 & 22.31 & 178.384 & 34.67 & 0.93 & $6.85 \%$ \\
\hline 455 & 46 & run 5 & 4 & 60 & 4 & $400 \mathrm{sq} \mathrm{m}$ & 224.49 & Time Limit & 192.487 & 28.88 & 190.056 & 20.05 & 191.956 & 14.05 & 0.86 & $14.26 \%$ \\
\hline 456 & 46 & run 6 & 4 & 60 & 4 & $400 \mathrm{sq} \mathrm{m}$ & 242.644 & Time Limit & 193.171 & 7.9 & 178.414 & 16.3 & 181.3 & 11.27 & 0.80 & $20.39 \%$ \\
\hline 457 & 46 & run 7 & 4 & 60 & 4 & $400 \mathrm{sq} \mathrm{m}$ & 192.276 & Time Limit & 188.943 & 11.33 & 176.949 & 8.03 & 170.479 & 8.43 & 0.98 & $1.73 \%$ \\
\hline 458 & 46 & run 8 & 4 & 60 & 4 & $400 \mathrm{sq} \mathrm{m}$ & 219.505 & Time Limit & 179.157 & 10.23 & 191.96 & 10.73 & 175.933 & 20 & 0.82 & $18.38 \%$ \\
\hline 459 & 46 & run 9 & 4 & 60 & 4 & $400 \mathrm{sq} \mathrm{m}$ & 190.065 & Time Limit & 188.035 & 13.8 & 186.897 & 21.35 & 183.077 & 18.56 & 0.99 & $1.07 \%$ \\
\hline 460 & 46 & run 10 & 4 & 60 & 4 & $400 \mathrm{sq} \mathrm{m}$ & 191.293 & Time Limit & 197.549 & 12.5 & 191.223 & 35.2 & 196.386 & 54.29 & 1.03 & $3.27 \%$ \\
\hline 461 & 47 & run 1 & 4 & 60 & 6 & $100 \mathrm{sq} \mathrm{m}$ & 111.88 & Time Limit & 90.51 & 34.47 & 95.182 & 37.3 & 89.308 & 22.17 & 0.81 & $19.10 \%$ \\
\hline
\end{tabular}




\begin{tabular}{|c|c|c|c|c|c|c|c|c|c|c|c|c|c|c|c|c|}
\hline 462 & 47 & run 2 & 4 & 60 & 6 & $100 \mathrm{sq} \mathrm{m}$ & 125.47 & Time Limit & 95.244 & 80.6 & 90.981 & 57.92 & 91.532 & 43.39 & 0.76 & $24.09 \%$ \\
\hline 463 & 47 & run 3 & 4 & 60 & 6 & $100 \mathrm{sq} \mathrm{m}$ & 145.97 & Time Limit & 93.514 & 75.87 & 86.461 & 102.71 & 84.395 & 27.06 & 0.64 & $35.94 \%$ \\
\hline 464 & 47 & run 4 & 4 & 60 & 6 & $100 \mathrm{sq} \mathrm{m}$ & 130.52 & Time Limit & 96.114 & 58.29 & 92.205 & 29.75 & 91.232 & 26.14 & 0.74 & $26.36 \%$ \\
\hline 465 & 47 & run 5 & 4 & 60 & 6 & $100 \mathrm{sq} \mathrm{m}$ & 115.25 & Time Limit & 93.652 & 29.66 & 95.736 & 29.75 & 93.426 & 44.81 & 0.81 & $18.74 \%$ \\
\hline 466 & 47 & run 6 & 4 & 60 & 6 & $100 \mathrm{sq} \mathrm{m}$ & 125.319 & Time Limit & 85.744 & 20.17 & 91.675 & 14.45 & 87.655 & 13.55 & 0.68 & $31.58 \%$ \\
\hline 467 & 47 & run 7 & 4 & 60 & 6 & $100 \mathrm{sq} \mathrm{m}$ & 120.445 & Time Limit & 101.206 & 27.49 & 95.979 & 11.42 & 94.919 & 14.71 & 0.84 & $15.97 \%$ \\
\hline 468 & 47 & run 8 & 4 & 60 & 6 & $100 \mathrm{sq} \mathrm{m}$ & 105.792 & Time Limit & 90.879 & 15.84 & 99.202 & 20.19 & 90.387 & 7.66 & 0.86 & $14.10 \%$ \\
\hline 469 & 47 & run 9 & 4 & 60 & 6 & $100 \mathrm{sq} \mathrm{m}$ & 90.332 & Time Limit & 95.344 & 20.18 & 95.949 & 8.49 & 95.038 & 18.3 & 1.06 & $5.55 \%$ \\
\hline 470 & 47 & run 10 & 4 & 60 & 6 & $100 \mathrm{sq} \mathrm{m}$ & 114.94 & Time Limit & 91.898 & 21.19 & 89.677 & 20.61 & 87.311 & 6.43 & 0.80 & $20.05 \%$ \\
\hline 471 & 48 & run 1 & 4 & 60 & 6 & $400 \mathrm{sq} \mathrm{m}$ & 300.88 & Time Limit & 206.991 & 125.52 & 206.91 & 123.17 & 200.418 & 24.87 & 0.69 & $31.20 \%$ \\
\hline 472 & 48 & run 2 & 4 & 60 & 6 & $400 \mathrm{sq} \mathrm{m}$ & 224.54 & Time Limit & 195.012 & 38.04 & 183.696 & 46.26 & 181.698 & 26.79 & 0.87 & $13.15 \%$ \\
\hline 473 & 48 & run 3 & 4 & 60 & 6 & $400 \mathrm{sq} \mathrm{m}$ & 229.81 & Time Limit & 189.024 & 26.35 & 186.885 & 36.74 & 179.992 & 31.67 & 0.82 & $17.75 \%$ \\
\hline 474 & 48 & run 4 & 4 & 60 & 6 & $400 \mathrm{sq} \mathrm{m}$ & 246.97 & Time Limit & 185.266 & 64.2 & 191.603 & 293.36 & 182.89 & 46.65 & 0.75 & $24.98 \%$ \\
\hline 475 & 48 & run 5 & 4 & 60 & 6 & $400 \mathrm{sq} \mathrm{m}$ & 201.62 & Time Limit & 192.832 & 25.61 & 189.78 & 31.93 & 182.871 & 22.7 & 0.96 & $4.36 \%$ \\
\hline 476 & 48 & run 6 & 4 & 60 & 6 & $400 \mathrm{sq} \mathrm{m}$ & 239.042 & Time Limit & 200.817 & 54.1 & 201.552 & 91.77 & 189.04 & 33.5 & 0.84 & $15.99 \%$ \\
\hline 477 & 48 & run 7 & 4 & 60 & 6 & $400 \mathrm{sq} \mathrm{m}$ & 210.079 & Time Limit & 174.842 & 12.48 & 192.212 & 25.55 & 182.792 & 12.75 & 0.83 & $16.77 \%$ \\
\hline 478 & 48 & run 8 & 4 & 60 & 6 & $400 \mathrm{sq} \mathrm{m}$ & 230.192 & Time Limit & 197.514 & 16.7 & 182.652 & 26.25 & 185.828 & 20.64 & 0.86 & $14.20 \%$ \\
\hline 479 & 48 & run 9 & 4 & 60 & 6 & $400 \mathrm{sq} \mathrm{m}$ & 208.548 & Time Limit & 182.364 & 20.24 & 185.324 & 12.41 & 181.72 & 21.49 & 0.87 & $12.56 \%$ \\
\hline 480 & 48 & run 10 & 4 & 60 & 6 & $400 \mathrm{sq} \mathrm{m}$ & 223.254 & Time Limit & 182.547 & 8.5 & 187.053 & 21.35 & 173.213 & 18.31 & 0.82 & $18.23 \%$ \\
\hline
\end{tabular}

